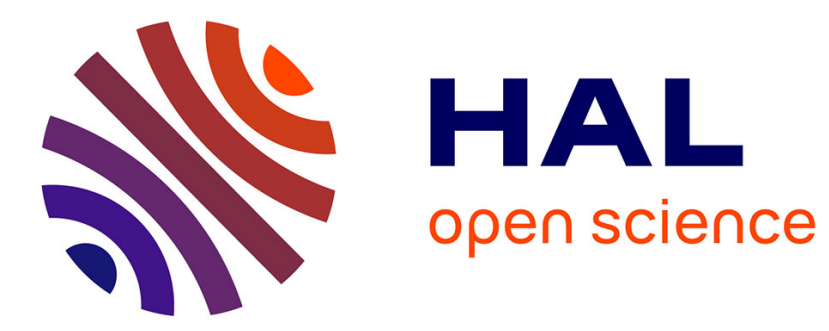

\title{
Mésusage des traitements de l'hypertrophie bénigne de la prostate chez le sujet âgé
}

Thomas Renoncourt

\section{To cite this version:}

Thomas Renoncourt. Mésusage des traitements de l'hypertrophie bénigne de la prostate chez le sujet âgé. Gériatrie et gérontologie. 2020. dumas-03164600

\section{HAL Id: dumas-03164600 https://dumas.ccsd.cnrs.fr/dumas-03164600}

Submitted on 10 Mar 2021

HAL is a multi-disciplinary open access archive for the deposit and dissemination of scientific research documents, whether they are published or not. The documents may come from teaching and research institutions in France or abroad, or from public or private research centers.
L'archive ouverte pluridisciplinaire HAL, est destinée au dépôt et à la diffusion de documents scientifiques de niveau recherche, publiés ou non, émanant des établissements d'enseignement et de recherche français ou étrangers, des laboratoires publics ou privés. 
UNIVERSITE PICARDIE JULES VERNE AMIENS

FACULTE DE MEDECINE

ANNEE 2020

UNIVERSITÉ

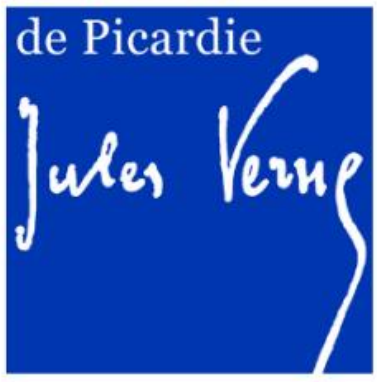

$\mathrm{N}^{\circ} \mathbf{2 0 2 0 - 1 7 1}$

\title{
MESUSAGE DES TRAITEMENTS DE L'HYPERTROPHIE BENIGNE DE LA PROSTATE CHEZ LE SUJET AGE
}

\section{THESE}

\section{POUR LE DIPLOME D'ETAT DE DOCTEUR EN MEDECINE SPECIALITE : GERIATRIE}

\begin{abstract}
Présentée et soutenue publiquement le 23/10/2020 par
\end{abstract}
M. Thomas RENONCOURT

JURY :

Président du jury : Monsieur le Professeur Fabien Saint

Membres du jury : Monsieur le Docteur Bennis Youssef Madame le Docteur Lisa Mondet

Directeur de thèse : Monsieur le Professeur Frédéric Bloch 
La vie est courte, l'art est long, l'occasion fugitive, l'expérience trompeuse, le jugement difficile.

Hippocrate 


\section{REMERCIEMENTS}

\section{A Monsieur le Professeur Fabien SAINT,}

Professeur des Universités - Praticien Hospitalier

Pôle "Médico-chirurgical digestif, rénal, infectieux, médecine interne et endocrinologie" (D.R.I.M.E) (urologie).

C'est un honneur de vous avoir comme président de ce jury. Je vous remercie sincèrement pour tous nos échanges productifs et vos conseils éclairés. J'espère que ce travail sera à la hauteur de vos attentes.

\section{A Monsieur le Professeur Frédéric BLOCH}

\section{Professeur des Universités - Praticien Hospitalier}

Chef du service de Gériatrie, Pôle Autonomie (gériatrie).

Vous me faites l'honneur de diriger cette thèse. Merci de m'avoir permis de travailler à vos côtés. Avec vous, j'ai beaucoup appris. Merci pour votre réactivité sans faille depuis 3 ans déjà. J'espère que ce travail, point de départ de ma vie de médecin, ne vous décevra pas. Soyez assuré de mon profond respect.

\section{A Monsieur le Docteur Youssef BENNIS}

Maître de Conférences des Universités - Praticien Hospitalier

\section{Pharmacologie clinique}

Vous me faites l'honneur de juger cette thèse. Merci d'avoir accepté d'être dans mon jury. Merci pour les échanges que nous avons eu lors de mon semestre en pharmacovigilance, pour votre accessibilité et votre bienveillance.

\section{A Madame le Docteur Lisa Mondet,}

\section{Pharmacologie clinique}

Vous me faites l'honneur de juger cette thèse. Merci pour l'aide apportée au début de ce travail. J'espère que de nombreux autres projets nous permettront de collaborer de nouveau ensemble. 
A Monsieur le Docteur Moyet, déjà presque 4 ans depuis mon stage avec toi en tant qu'externe, premier lien avec la gériatrie. Tu m'as ensuite permis d'obtenir mon poste de FFI qui m'a conduit ici aujourd'hui. Je te remercie pour ton accessibilité et ton soutien.

A Monsieur le Docteur Goffart, après quelques semaines de stage à tes côtés, je me souviens très bien du moment où tu m'as dit que tu me verrais bien gériatre. Ce fût là le début d'une réflexion personnelle qui m'a ensuite littéralement fait changer de projet de vie. Je suis heureux d'avoir débuté à tes côtés. Amicalement.

A Madame le Docteur Hannat, merci pour ce premier semestre en gériatrie à vos côtés, point névralgique de mon internat. Au prix de nombreuses réprimandes et de quelques moments difficiles, votre rigueur et amour des bonnes pratiques m'ont gagné et j'espère continuer sur la bonne voie. Au fur et à mesure, j'ai appris à vous connaitre et je vous sais désormais bien réceptive à mon humour...C'est avec grand plaisir que je continuerai à travailler à vos côtés.

A Monsieur le Docteur Deschasse, les 6 mois passé ensemble ont été un autre tournant dans mon internat. Vous m'avez fait approfondir mes connaissances avec rigueur, réflexion, éthique et évaluation gériatrique individualisée. Les nombreux débats médicaux et périmédicaux pendant les visites, furent éclairants...même si je ne peux toujours pas vous promettre d'avoir lu l'art de la guerre de Machiavel à l'aube de mes 35 ans...

A Madame de Docteur Dailly, merci pour ces derniers mois de stage à vos côtés. J'y ai appris la gériatrie sur une autre temporalité, où connaitre le malade dans sa globalité prend tout son sens. Avec vous, j'ai appris l'autonomie et approfondi mes connaissances. Je vous en remercie sincèrement.

A l'ensemble du service de gériatrie et des services qui m'ont accueilli pendant ces années d'internat, merci à vous, de votre accueil et de votre dévouement avec les patients. Vous m'avez notamment appris à travailler en équipe et à développer ma capacité d'adaptation.

A Papa et Maman, je ne vous remercierai jamais assez pour tout votre soutien. J'en suis là grâce à vous. Merci d'avoir été là dans les moments de réussites ou de déception. Je vous aime de tout mon cœur. 
A Charlotte, Adrien, Éloïse...... et futur bébé......, merci de toujours être là dans la bonne humeur, et moi aussi je serai toujours là pour vous aussi...mais autour d'une raclette si possible.

A l'ensemble de ma famille, vous savez à quel point je vous suis reconnaissant de m'avoir soutenu au cours ces années malgré mon absence régulière aux divers évènements familiaux. $\mathrm{J}$ 'espère que nous continuerons nos réunions familiales, remplies de bonne humeur.

A ma (future) belle-famille, Dominique, Marina, Arina et Axelle, merci de m'avoir accepté, pour le ski, les week-ends et j'en passe. Comptez sur moi pour continuer à goûter votre champagne « minéral».

A mes amis proches, (Milou, Gui, Nico, Max) merci de m'avoir soutenu, d'avoir été là pour moi au bout du téléphone, en facetime ou à l'étage du dessus. Nous avons encore plein de voyages à réaliser ensemble alors j'espère que vous êtes prêts ! Merci à vous les copains.

Et à toi...Roxane, merci d'être là à chaque instant. Vivement notre mariage. Je t'aime. 
SOMMAIRE

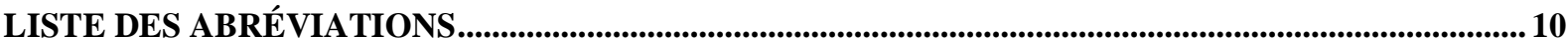

LISTE DES SCHEMAS, TABLEAUX ET FIGURES .......................................................................

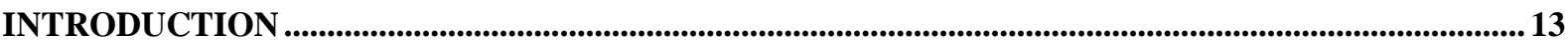

PARTIE 1 : PATIENTS AGES ET TROUBLES URINAIRES ............................................................................ 14

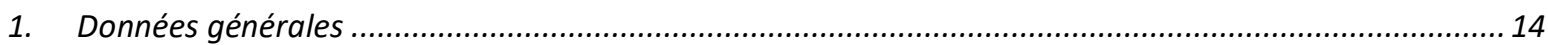

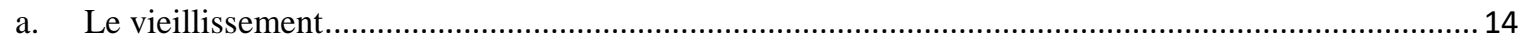

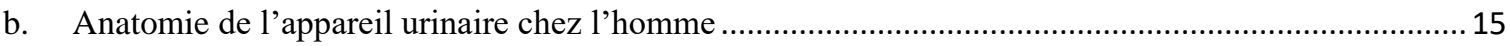

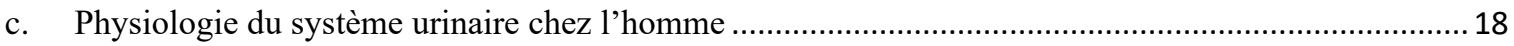

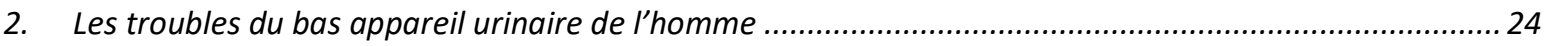

a. Etiologies des troubles du bas appareil urinaire de l'homme .............................................................24

b. Modifications induites par l'hypertrophie bénigne de la prostate .......................................................25

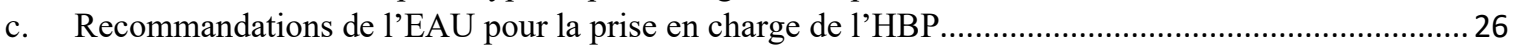

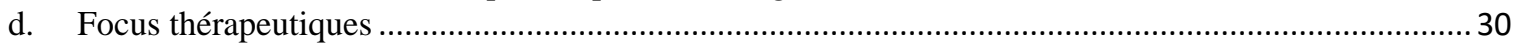

\section{PARTIE 2 : MESUSAGE DES TRAITEMENTS DE L'HYPERTROPHIE BÉNIGNE DE LA}

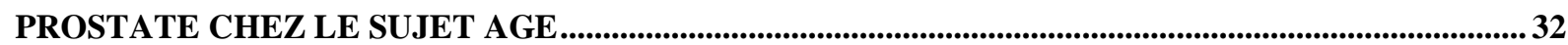

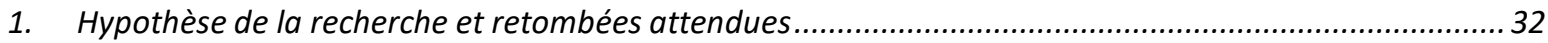

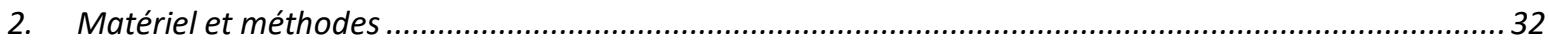

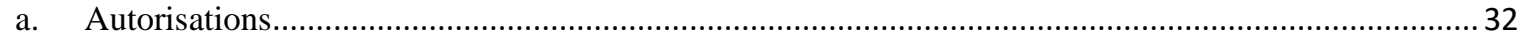

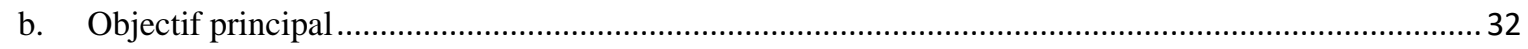

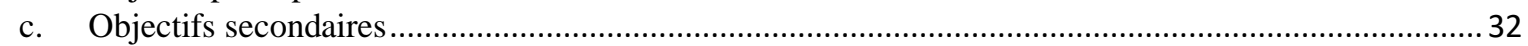

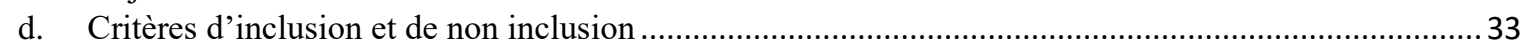

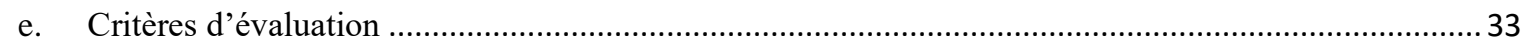

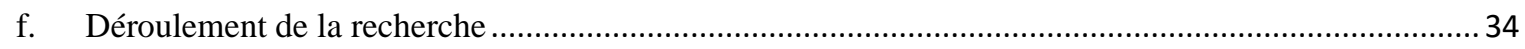

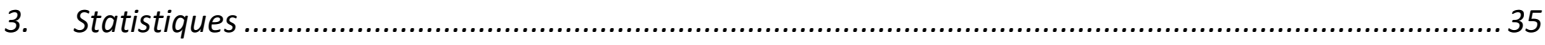

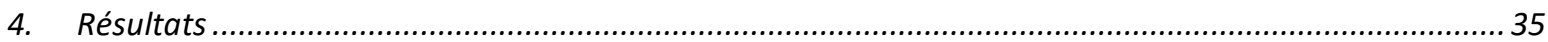

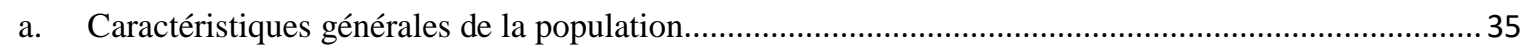

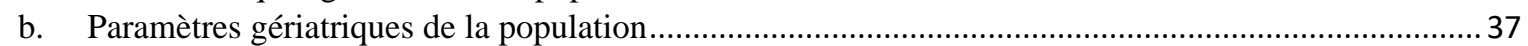

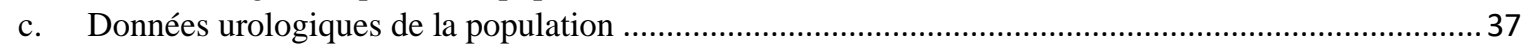

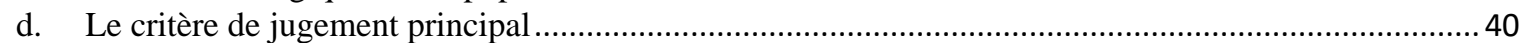

e. Analyses univariées sur le critère de jugement principal .......................................................................... 42

f. Analyses multivariées sur le critère de jugement principal.................................................................... 45

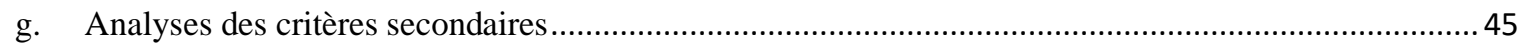

PARTIE 3 : DISCUSSION

CONCLUSION ...............................................................................................................................................56

RÉFÉRENCES BIBLIOGRAPHIQUES ...........................................................................................57

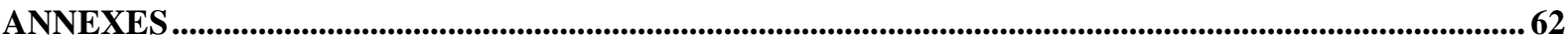

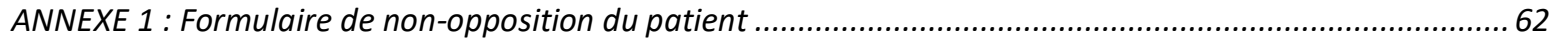

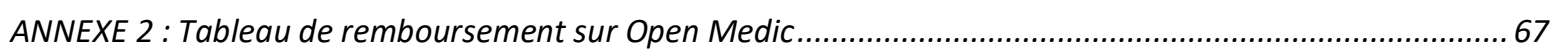


ANNEXE 3 : Score IPSS (international Prostate Symptom Score ) et d'évaluation de la qualité de vie. (ANAES,

2003)

ANNEXE 4 : Score ICIQ-MLUTS (International Consultation on Incontinence Questionnaire Male Lower Urinary Tract Symptoms Long Form Module)

ANNEXE 5 : Score ICIQ-NQoL (International Consultation on Incontinence Questionnaire Nocturia Quality of Life Module).

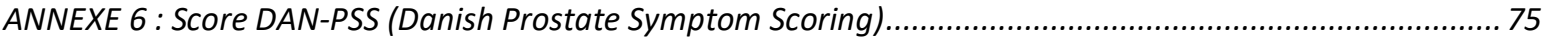

ANNEXE 7 : Score PGI-I (Patient Global Impression of Improvement) ........................................................... 76

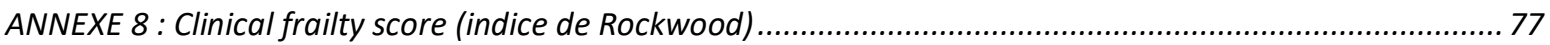

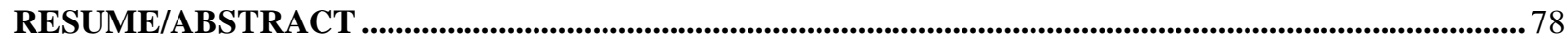




\section{LISTE DES ABRÉVIATIONS}

ADL: Activities of Daily Living

AMM : Autorisation de mise sur le marché

AVC : Accidents vasculaires cérébraux

BPCO : Bronchopneumopathie chronique obstructive

BU: Bandelette urinaire

CGRP: Calcitonin gene related peptide

DAN-PSS: Danish Prostate Symptom Scoring

DHT: Dihydrotestostérone

EAU: European Association of Urology

ECBU : Examen cytobactériologique des urines

EMG : Electromyogramme

FVC : Diagramme de volume fréquence

HBP : Hypertrophie bénigne de la prostate

HTO : Hypotension orthostatique

I5AR : Inhibiteur de l'alpha-5-testostérone réductase

ICIQ-MLUTS : International Consultation on Incontinence Questionnaire Male Lower

Urinary Tract Symptoms Long Form Module

ICIQ-NQoL: International Consultation on Incontinence Questionnaire Nocturia Quality of Life Module

IPSS: International Prostate Symptom Score

LUTS: Lower urinary tract symptoms

NANC : Neurotransmetteurs non cholinergiques et non adrénergiques

NO : Monoxyde d'azote

OR : Orthosympathique

PGI-I : Patient Global Impression of Improvement

PS : Parasympathique

PSA : Antigène spécifique de la prostate

PU : Pression urétrale

PV : Pression vésicale

QDV : Qualité de vie

RAU : Rétention aigüe d'urine

RCP : Résumé des caractéristiques du produit

RPM/PVR : Résidu post mictionnel/ post-void residual

RTUP : Résection transurétrale de prostate

SAS : Syndrome d'apnée du sommeil

SAD : Sonde à demeure

TR/DRE : Toucher rectal/digital rectal examination

US : Ultrasound

VIP : Peptide intestinal vasoactif 


\section{LISTE DES SCHEMAS, TABLEAUX ET FIGURES}

\section{SCHEMAS :}

Schéma 1 : coupe latérale de la prostate

Schéma 2 : rapports intrinsèques de la prostate

Schéma 3 : innervation du sphincter urétral

Schéma 4: les centres somatiques, sympathique et parasympathiques de la physiologie vésico-sphinctérienne

Schéma 5 : neurotransmetteurs et neurorécepteurs adrénergiques et cholinergiques

Schéma 6 : étiologies des troubles du bas appareil urinaire chez l'homme

Schéma 7 : les récepteurs et neuromédiateurs du bas appareil urinaire

\section{TABLEAUX :}

Tableau 1 : caractéristiques générales des patients

Tableau 2 : antécédents de chirurgies abdominales

Tableau 3 : paramètres gériatriques

Tableau 4 : données urologiques

Tableau 5 : détails du critère de jugement principal (composite)

Tableau 6 : traitements anti-hypertenseurs

Tableau 7 : données de pharmacodynamies

Tableau 8 : chirurgies des voies urinaires

Tableau 9 : analyse multivariée sur le risque de chutes

Tableau 10 : examens urologiques complémentaires

Tableau 11 : étiologies participantes aux troubles mictionnels

Tableau 12 : montants remboursés par la sécurité sociale en 2018

\section{FIGURES :}

Figure 1: modifications morphologiques et évolution des paramètres urodynamiques de la miction

Figure 2: assessment algorithm of LUTS in men aged 40 years or older

Figure 3: treatment algorithm of male LUTS using medical and/or conservative treatment options

Figure 4 : flowchart

Figure 5 : histogrammes analysant la chute selon le mésusage, l'indépendance et la prise d'alphabloquant

Figure 6 : évolution du remboursement des alphabloquants et des I5AR 


\section{INTRODUCTION}

L'hypertrophie bénigne de la prostate (HBP) est un processus faisant partie du vieillissement normal. En 1984, S.J Berry a montré que $80 \%$ des hommes étaient concernés à 80 ans [1] . L'HBP devient symptomatique dans plus de 62,5\% des cas [2] et serait à l'origine d'une baisse de la qualité de vie pour $30 \%$ des plus de 80 ans [3]. Ainsi, la prescription des traitements spécifiques par les alphabloquants et les inhibiteurs de l'alpha-5-testostérone réductase (I5AR), a connu un essor considérable depuis les années 2000. Tous ces traitements sont efficaces pour réduire les symptômes, améliorer le débit urinaire et la qualité de vie chez l'adulte jeune.

Chez les patients âgés répondant au «profil gériatrique » avec dépendance, comorbidités neurocognitives, respiratoires ou cardiovasculaires notamment, l'équilibre de l'appareil urogénital est modifié et la qualité de vie recherchée est différente. Nous n'avons pas encore suffisamment de preuves pour affirmer que les traitements médicamenteux de l'HBP ont la même efficacité et sécurité d'emploi dans cette population. Les questionnaires couramment utilisés ne sont pas adaptés aux particularités gériatriques. A contrario, les effets secondaires sont plus nombreux et aux conséquences plus graves. L'iatrogénie est responsable de $20 \%$ des hospitalisations dont $30 \%$ sont évitables [4]. Pour diminuer ce risque, il faut diminuer le mésusage, défini comme une utilisation intentionnelle d'un médicament, non conforme à son autorisation de mise sur le marché ainsi qu'aux recommandations de bonnes pratiques [5]. Aucune étude, à notre connaissance, ne s'est intéressée au mésusage de ces traitements en population gériatrique.

L'objectif principal de cette étude était de comptabiliser le nombre de mésusages avec les traitements par alphabloquants et I5AR en population gériatrique. 


\section{PARTIE 1: PATIENTS AGES ET TROUBLES URINAIRES}

\section{Données générales}

\section{a. Le vieillissement}

Le vieillissement est défini comme un ensemble de processus physiologiques modifiant la structure et les fonctions de l'organisme dès l'âge mûr. Il est plurifactoriel, inévitable, lent et progressif.

Au niveau urologique, le vieillissement se traduit par des fibres musculaires lisses qui se raréfient au profit des fibres graisseuses. Des fibres de collagènes prolifèrent au niveau de la paroi vésicale, entrainant une perte d'élasticité et de contractilité de la vessie. La perte de tonus musculaire retentit sur les sphincters lisses et striés, mais également sur le périnée (surtout chez la femme par carence en œstrogène). Le muscle de la vessie se dénerve, le nombre des récepteurs sympathiques diminue, d'où un déséquilibre favorable aux récepteurs parasympathiques. Les récepteurs qui contrôlent le remplissage sont également moins nombreux et moins fonctionnels. Le vieillissement affecte aussi les rythmes physiologiques nycthéméraux, comme la sécrétion de l'hormone antidiurétique (vasopressine) qui ne fait plus correctement son rôle d'espacement des mictions la nuit (à l'origine de réveils nocturnes). Enfin, la taille de la prostate augmente et peut être à l'origine de troubles obstructifs et irritatifs [6].

A ce vieillissement physiologique s'ajoutent les pathologies puis les facteurs précipitants à l'origine des complications, c'est le modèle général du 1+2+3 de J.P Bouchon [7].

\begin{tabular}{|l|}
\hline \multicolumn{1}{|c|}{ CHANGEMENTS PHYSIOLOGIQUES SUR L'APPAREIL MICTIONNEL } \\
\hline \multicolumn{1}{|c|}{ Fonction vésicale } \\
\hline Baisse de la capacité \\
\hline Baisse de la sensation de remplissage \\
\hline Baisse de la contractilité \\
\hline Hausse de l'hyperactivité du détrusor \\
\hline Hausse du résidu post mictionnel \\
\hline \multicolumn{1}{|c|}{ Urètre } \\
\hline Baisse de la pression de clôture \\
\hline \multicolumn{1}{|c|}{ Prostate } \\
\hline Hypertrophie \\
\hline \multicolumn{1}{|c|}{ Neurologique } \\
\hline Hausse de la production d'urine la nuit \\
\hline Déficit des neurotransmetteurs et des récepteurs \\
\hline Hausse des troubles vasculaires de la substance blanche \\
\hline
\end{tabular}




\section{b. Anatomie de l'appareil urinaire chez l'homme}

\section{i. Anatomie de la prostate}

La prostate est une glande génitale masculine impaire et médiane, à sécrétion endocrine et exocrine [8]. Elle est annexée à la vessie et engaine la partie initiale de l'urètre. Elle participe à la fertilité, à l'éjaculation et à la miction. Elle est ferme au toucher. La prostate physiologique fait $3 \mathrm{~cm}$ de hauteur, $2 \mathrm{~cm}$ de largeur et 20 à $30 \mathrm{~g}$. Son poids augmente avec l'âge sans consensus établi.

Elle a la forme générale d'une châtaigne, avec un cône aplati. Elle a une face ventrale plane, une face dorsale convexe, avec un sillon médian, un sommet (ou apex caudal) et une base crâniale. Elle est traversée par l'urètre et les voies spermatiques (Schéma 1).

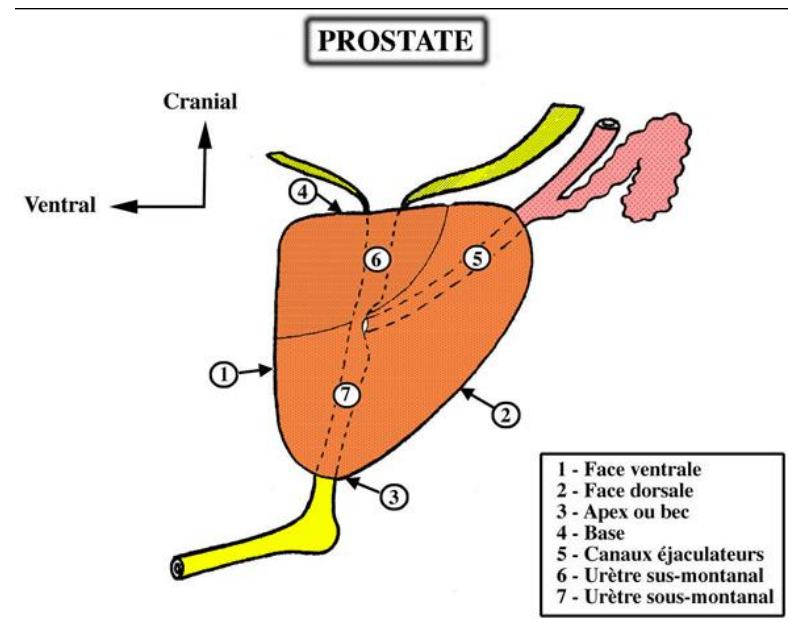

Schéma 1: coupe latérale de la prostate

La portion crâniale est davantage stimulée par les œstrogènes et la portion caudale par les androgènes. L'adénome prostatique se développe aux dépend de la portion crâniale. Le cancer de la prostate en revanche se développe à partir de la portion caudale.

\section{Rapports intrinsèques :}

La prostate contient l'urètre prostatique qui est entouré du sphincter lisse, cependant c'est le sphincter strié qui assure véritablement le rôle de sphincter. A sa partie moyenne, l'urètre présente le veru montanum (ou colliculus séminal), constitué de corps érectiles et empêchant alors la miction lors de l'érection par sa dilatation. A sa partie supérieure il existe 2 replis, les freins du colliculus dont l'hypertrophie peut entraver la miction. En son centre s'ouvre l'utricule prostatique et de chaque côté les orifices des canaux éjaculateurs qui traversent obliquement la prostate (schéma 2). 


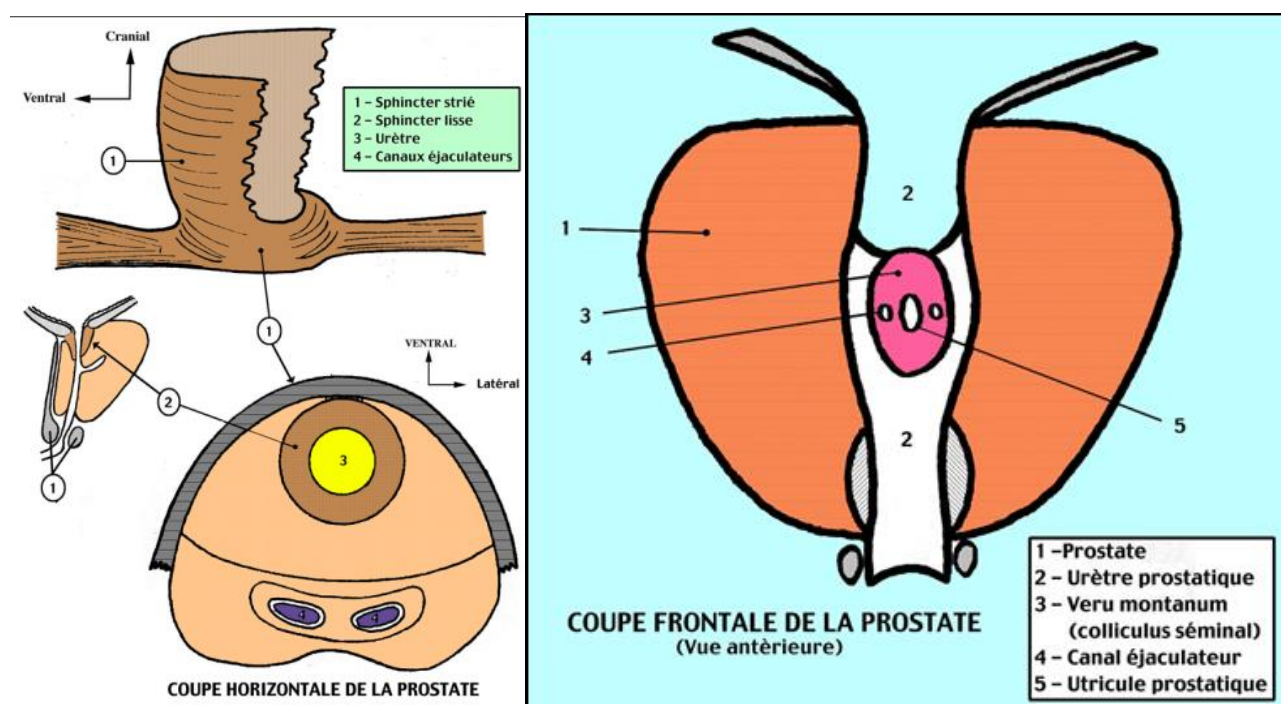

Schéma 2 : rapports intrinsèques de la prostate

\section{ii. L'innervation}

L'innervation se fait par le plexus hypogastrique inférieur pour le contingent sympathique (OS) et les nerfs du plexus sacré de S3 et S4 pour le contingent parasympathique (PS).

L'innervation sphinctérienne dépend du nerf pudendal (sphincter strié) et des nerfs pelviens (sphincter lisse) (schéma 3).

Le centre médullaire moteur est dans la corne antérieure de S2 à S4, directement relié au centre frontal (aire somato-motrice, dans le gyrus précentral). Le nerf pudendal naît de ces racines S2, S3 et S4. Il quitte le pelvis par la grande échancrure sciatique puis s'engage dans le périnée dans un dédoublement de l'aponévrose du muscle obturateur interne appelé canal d'Alcock où il donne ses branches terminales : le nerf rectal inférieur, le nerf périnéal et le nerf dorsal de la verge.

L'innervation autonome (orthosympathique et parasympathique) concerne toute la musculature lisse de la vessie et de l'urètre. Les centres corticaux sont localisés sur la face interne du lobe frontal et dans les structures sous-jacentes du cortex limbique pour la commande volontaire et instinctive du réflexe mictionnel. Les centres pontiques jouent un rôle important dans le réflexe mictionnel avec le centre $\mathrm{M}$ (médian), dont la stimulation déclenche une miction, et le centre $\mathrm{L}$ (latéral) dont la stimulation induit à l'inverse une contraction sphinctérienne et périnéale. Les centres médullaires dans la corne latérale de la moelle, se situent à l'étage dorso-lombaire (Th10 à L2) pour le système OS, et à l'étage sacré (S2 à S4) pour le système PS. Les nerfs splanchniques, en provenance de la moelle lombaire 
descendent sur la face latérale de l'aorte, forment le plexus hypogastrique supérieur, puis de chaque côté les nerfs hypogastriques, pour ensuite rejoindre le plexus hypogastrique inférieur. La réunion des $2 \mathrm{e}, 3 \mathrm{e}$ et $4 \mathrm{e}$ nerfs sacrés et de leurs branches antérieures forme le plexus pudendal d'où sont issus le nerf pudendal et les nerfs pelviens (ou érecteurs) qui gagnent le plexus hypogastrique inférieur. Dans l'ensemble, on peut assimiler les nerfs hypogastriques au système OS, les nerfs pelviens au système PS, et considérer le plexus hypogastrique inferieur comme une structure commune avec des nerfs destinés au rectum, à la vessie, au col vésical, à la prostate, aux corps érectiles et à l'urètre (sphincter lisse) (Schéma 4).

Le système nerveux autonome intrinsèque regroupe toutes les structures nerveuses qui échappent à la dénervation par section des troncs nerveux. Dans ce réseau, les neurones sont identifiés par leurs neuromédiateurs. Le dôme et la base sont richement innervés presque exclusivement de terminaisons cholinergiques, alors que le col et l'urètre le sont pauvrement.

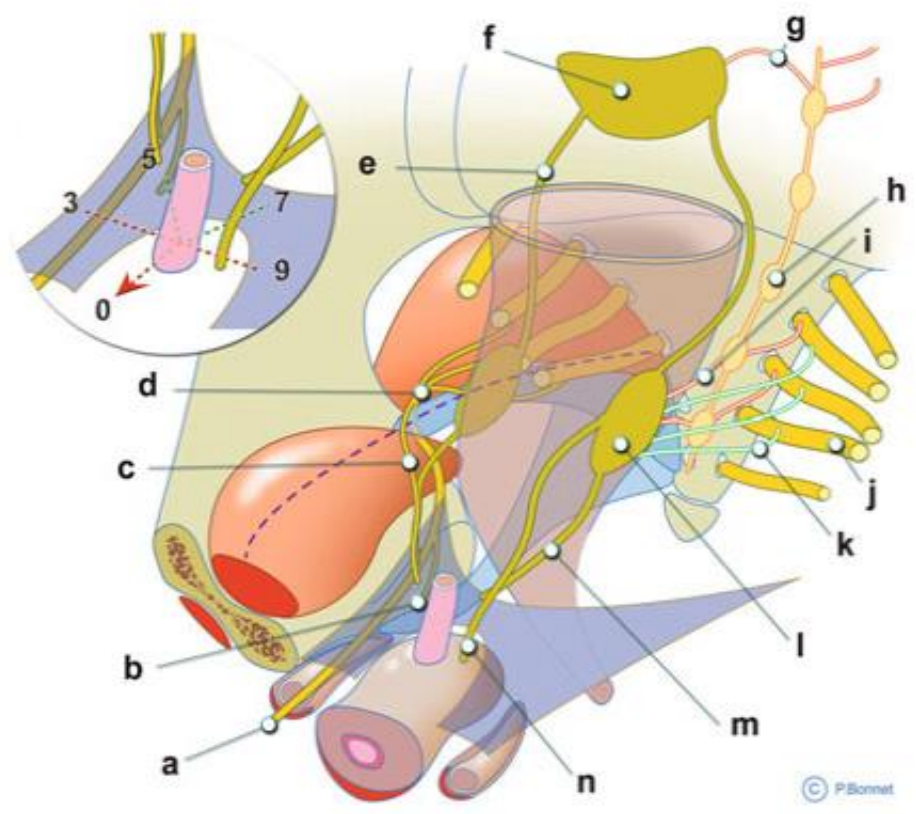

Schéma 3 : innervation du sphincter urétral

$\mathrm{a}=$ nerf dorsal de la verge $; \mathrm{b}=$ branche périnéale sphinctérienne $; \mathrm{c}=$ branche pelvienne du nerf honteux destinée au sphincter ; $\mathrm{d}=$ nerf honteux ; $\mathrm{e}=$ nerf hypogastrique droit ; $\mathrm{f}=$ plexus hypogastrique supérieur ; $\mathrm{g}=\mathrm{nerf}$ splanchnique lombaire $(\mathrm{OS}) ; \mathrm{h}=$ chaîne $\mathrm{OS} ; \mathrm{I}=$ nerf splanchnique sacré $(\mathrm{OS}) ; \mathrm{j}=$ racine sacrée $(4 \mathrm{e})$; $\mathrm{k}=$ nerf splanchnique pelvien (PS) ou nerf érecteur ; l= plexus hypogastrique inférieur gauche ; $\mathrm{m}=$ contingent autonome destiné au sphincter ; $\mathrm{n}=$ nerf caverneux gauche 


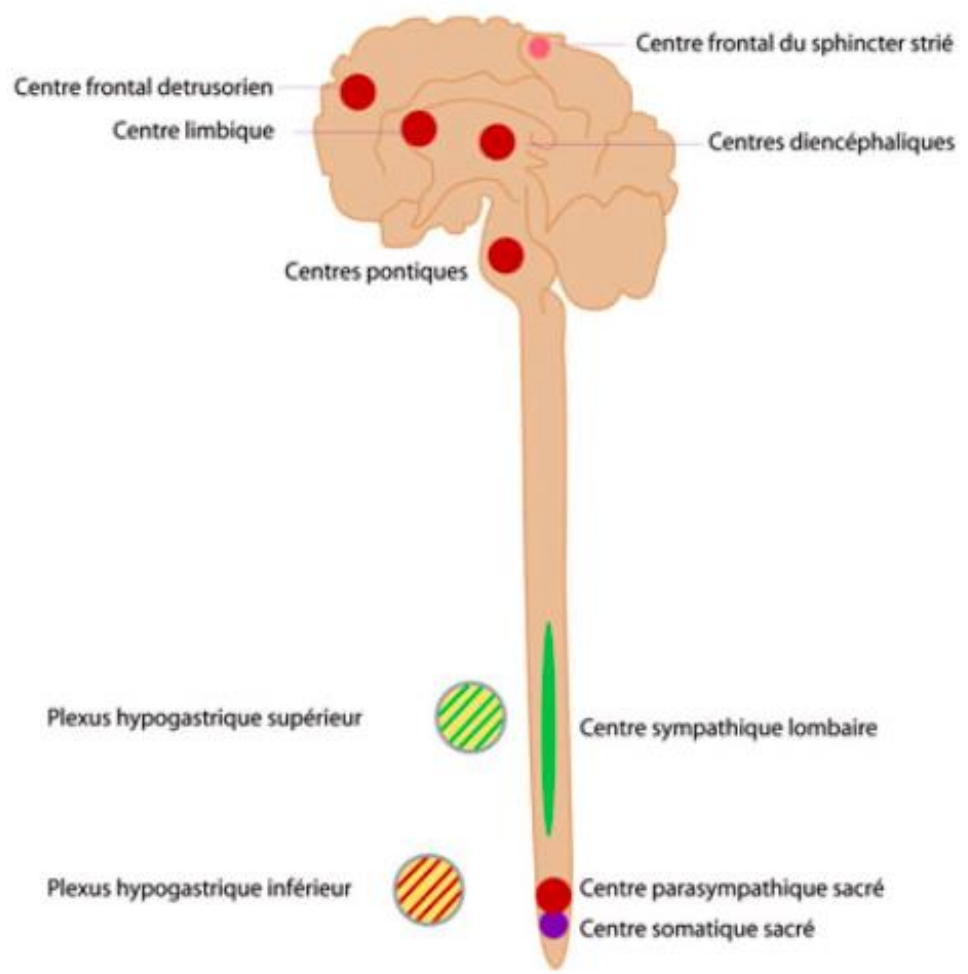

Schéma 4: Les centres somatiques en couleur violette, sympathiques en couleur verte, et parasympathiques en couleur rouge qui interviennent dans la physiologie vésico-sphinctérienne.

\section{c. Physiologie du système urinaire chez l'homme}

\section{i. L'innervation cholinergique, adrénergique et non cholinergique-non adrénergique}

L'acétylcholine a un effet excitateur sur la fibre musculaire. Elle est synthétisée par les neurones présynaptiques sympathiques et parasympathiques, puis se fixe à ses récepteurs post synaptiques nicotiniques. Il existe des récepteurs muscariniques stimulants (M1 et M3) et des récepteurs muscariniques inhibiteurs (M2 et M4). Normalement, dans la vessie, seuls les récepteurs M3 interviennent dans la contraction, alors que les récepteurs M2, pourtant majoritaires en nombre, n'interviennent qu'en cas de dénervation (Schéma 5).

La noradrénaline a une action sur la fibre musculaire lisse qui dépend de la nature du récepteur, avec un effet de contraction pour les récepteurs $\alpha$ et de relaxation pour les récepteurs $\beta$. Les récepteurs $\alpha$ (notamment $\alpha 1 \mathrm{~A}$ ) participent donc au maintien d'un tonus actif du sphincter lisse, et les récepteurs $\beta$ (notamment B2) à la relaxation de la vessie et du sphincter lisse de l'urètre. 
Les neurotransmetteurs non cholinergiques et non adrénergiques (NANC) interviennent de façon ubiquitaire, à la fois sur le système central et périphérique, sur la voie afférente et la voie efférente, directement sur la fibre musculaire lisse, ou indirectement comme cotransmetteurs ou modulateurs de l'acétylcholine ou de la noradrénaline. La résultante motrice peut alors être une contraction ou une relaxation selon la nature du transmetteur et du récepteur. Dans la physiologie vésicale, l'intervention des neurotransmetteurs NANC, bien que faible en situation normale, est importante en situations pathologiques telles que l'obstruction et l'hyperactivité. L'effet dominant est alors une contraction du détrusor. Parmi les neurotransmetteurs NANC il y a les purines, les neuropeptides (kinines, enképhalines, vasoactive intestinal peptide [VIP], le neuropeptide gamma, la calcitonine gene related peptide [CGRP]), l'histamine, la sérotonine, les prostaglandines, le monoxyde d'azote (NO).
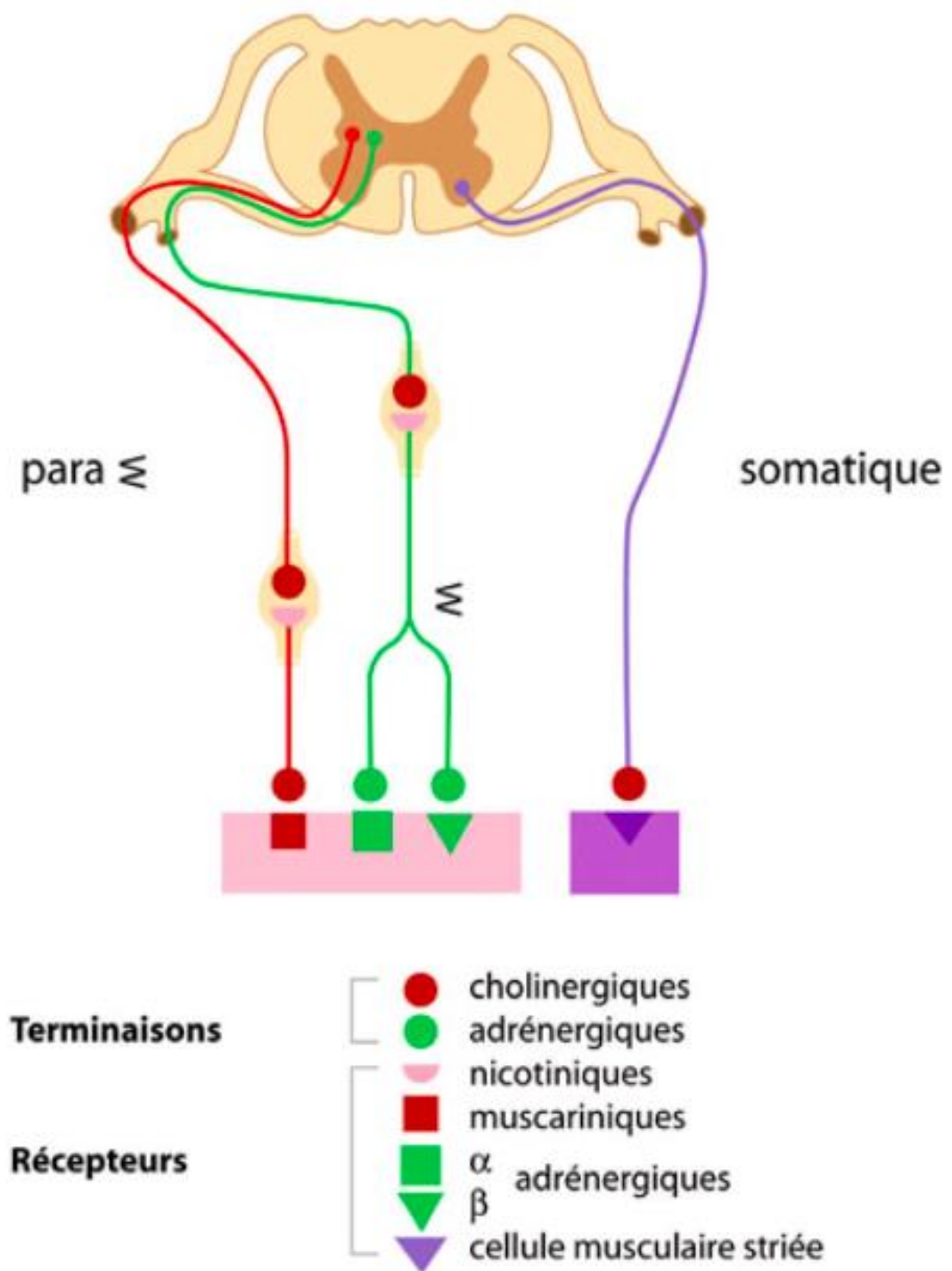


\section{ii. la phase de remplissage}

La vessie s'étale dans le petit bassin en se remplissant. Le col vésical est fermé hermétiquement même lors des efforts de toux. Le gradient de pression urétro-vésical, largement positif suffit à maintenir la continence (figure 1).

\section{La continence urinaire au repos :}

La pression vésicale de remplissage reste basse, ne dépassant pas $15 \mathrm{~cm}$ d'eau pour un volume de $300 \mathrm{ml}$. Cette capacité de stocker un grand volume à basse pression est appelée «compliance» et est indispensable pour la continence et la protection du haut appareil urinaire.

Les forces de retenue (résistance aux fuites) comprennent :

- La pression urétrale (PU), dont la valeur maximum (60 à $80 \mathrm{~cm}$ d'eau) augmente au cours du remplissage vésical puis s'effondre pour permettre la miction. Elle est déterminée par le tonus des fibres musculaires lisses et striées. Les plexus vasculaires sous-muqueux jouent un rôle de joint d'étanchéité supplémentaire.

- La résistance urétrale correspond aux forces passives dépendantes du col et de l'urètre et augmente avec l'âge et le développement de la prostate.

La phase de remplissage est sous le contrôle des systèmes sympathique et somatique qui contribuent à relâcher le détrusor et à contracter l'appareil sphinctérien. Les récepteurs adrénergiques permettent le rôle de réflexe mictionnel joué par le système sympathique pendant la phase de remplissage avec la relaxation du détrusor (récepteurs $\beta$ ) et la contraction des fibres musculaires lisses du col et de l'urètre (récepteurs $\alpha$ ). Le point de départ de ce réflexe sympathique est la stimulation des récepteurs de tension du détrusor ; les afférents gagnent la moelle dorsolombaire par les nerfs pelviens, tandis que les efférents rejoignent la vessie et l'urètre par les nerfs hypogastriques. Ce réflexe est placé sous influence inhibitrice supra-médullaire. En condition physiologique, le centre médullaire n'intervient que dans les phénomènes d'adaptation au remplissage (abaissement de la pression vésicale et augmentation de la pression urétrale). 


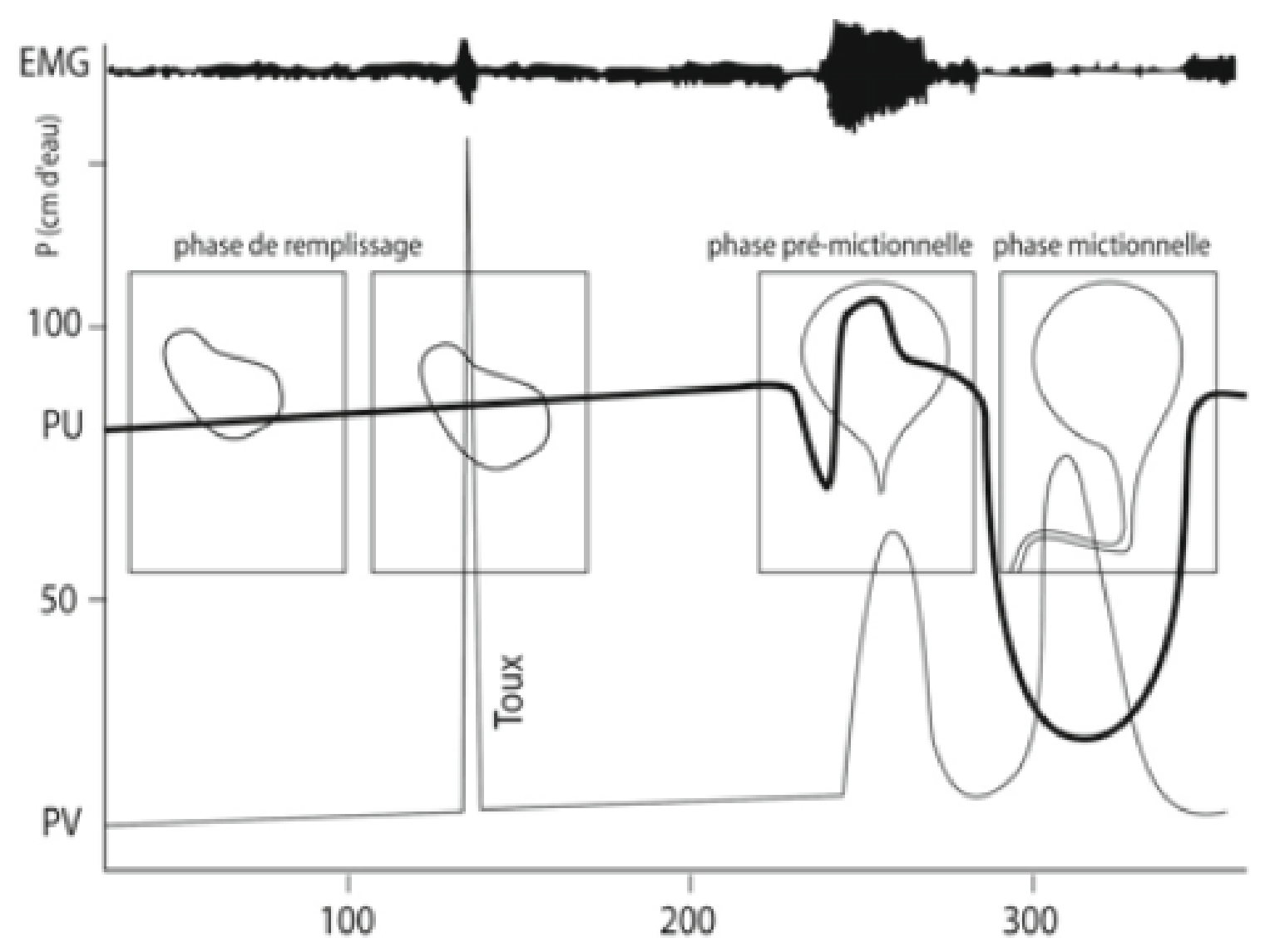

Figure 1: Modifications morphologiques et évolution des paramètres urodynamiques (électromyogramme [EMG] du sphincter strié urétral, pression urétrale maximale [PU] et pression vésicale [PV]) pendant les phases de remplissage, pré-mictionnelle et mictionnelle.

\section{La continence urinaire à l'effort :}

Certains efforts comme la toux, le rire, la marche ou le passage à l'orthostatisme élèvent brutalement la pression abdominale et la pression intra-vésicale à $100 \mathrm{~cm}$ d'eau ou plus, risquant de dépasser la pression intra-urétrale et créer une incontinence d'effort. La continence est alors maintenue par la contraction réflexe de la musculature périnéosphinctérienne en réponse à la soudaine augmentation de la pression abdominale. Ce réflexe de continence appelé « guarding reflex », est un réflexe somatique passant par le noyau d'Onuf et implique le sphincter strié de l'urètre et la musculature périnéale. 


\section{iii. La phase mictionnelle}

Le schéma 6 montre qu'en se contractant, la vessie se transforme en une sphère qui se rétracte concentriquement. Sa base se transforme alors en entonnoir et le col vésical puis l'urètre s'ouvrent au passage du flux urinaire. La pression vésicale s'élève entre 30 et $60 \mathrm{~cm}$ d'eau alors que la pression urétrale s'effondre.

\section{Le reflexe mictionnel}

Le reflexe mictionnel correspond à l'intervention du système parasympathique permettant d'une part, la contraction puissante et organisée des cellules musculaires lisses du détrusor (appelée contraction phasique) et d'autre part, l'inhibition réflexe des systèmes antagonistes, sympathique et somatique, avec pour conséquence l'effondrement du tonus sphinctérien. Ce réflexe mictionnel organisé dans le tronc cérébral a pour point de départ la stimulation des récepteurs de tension du détrusor.

Le reflexe mictionnel illustre bien le contrôle réciproque du système parasympathique (qui assure la contraction vésicale), des systèmes sympathique et somatique (qui assurent la contraction sphinctérienne). Ainsi, la contraction vésicale induit une relaxation sphinctérienne, sans laquelle il existe une dyssynergie vésico-sphinctérienne pathologique. Inversement, la contraction du sphincter strié inhibe la contraction vésicale et le besoin d'uriner, sans laquelle il existe une impériosité pathologique. Les hypertonies sphinctériennes, lisses et/ou striées peuvent être responsables d'une acontractilité vésicale réflexe. Cette coordination est organisée au niveau des centres médullaires et dans les plexus ganglionnaires périphériques pour la coordination des systèmes OS/PS et au niveau des centres du tronc cérébral pour la coordination des systèmes PS/somatique.

\section{Le contrôle cérébral du reflexe mictionnel.}

Le besoin d'uriner est la perception de l'état de réplétion de la vessie et est un préalable à toute continence volontaire. Le point de départ de ce besoin d'uriner est la stimulation des récepteurs de tension du détrusor. L'information est projetée sur le cortex pariétal, par l'intermédiaire de la voie extralemniscale, perçue comme une tension douloureuse de l'épigastre. Cette information doit ensuite être traitée et décryptée en une impression subtile «d'envie d'uriner», ce qui fait intervenir l'ensemble de la corticalité. Chez le patient neurologique, la perte du besoin d'uriner est la principale cause d'incontinence. 
Le premier aspect du contrôle volontaire est la possibilité de retenir un besoin par la contraction du sphincter strié et des muscles périnéaux. Elle permet de gagner quelques centimètres d'eau et d'éviter la fuite. Mais cette situation est précaire, car la musculature striée est fatigable. La contraction volontaire du sphincter strié induit par voie réflexe une inhibition du détrusor.

\section{Déclenchement et inhibition volontaire du reflexe mictionnel}

Le contrôle cérébral permet de déclencher ou d'inhiber globalement le réflexe mictionnel organisé dans les centres du tronc cérébral, grâce aux connexions les reliant aux centres corticaux et sous-corticaux. C'est ainsi qu'une miction réflexe peut être déclenchée :

- Par la volonté : c'est la miction par raison, permettant d'uriner sur commande, même lorsque la vessie n'est pas pleine. Cette faculté fait probablement de la vessie le viscère le plus «corticalisé » et donc le plus psychologiquement vulnérable (pollakiuries et rétentions psychogènes). Elle implique l'intervention du centre mictionnel localisé à la face interne du lobe frontal.

- Lors des paroxysmes émotionnels (fou-rire, orgasme, frayeur, colère...). Cette miction incontrôlable fait intervenir le système limbique.

- Lors des stimuli sensoriels : ce sont les besoins déclenchés par la vue, l'audition de l'eau coulante, l'exposition au froid, ou lors de rituels du couché ou du levé. Cela fait intervenir les connexions du lobe frontal avec les aires sensitives et sensorielles du lobe pariétal.

L'altération de ce contrôle cérébral du réflexe mictionnel représente l'un des principaux facteurs de l'incontinence des personnes âgées, allant de pair avec l'altération des fonctions supérieures, et des lésions vasculaires des lobes frontaux. 


\section{Les troubles du bas appareil urinaire de l'homme}

\section{a. Etiologies des troubles du bas appareil urinaire de l'homme}

Les troubles urinaires du bas appareil ou LUTS (lower urinary tract symptoms) ont de multiples étiologies souvent entremêlées. La recherche étiologique permet une prise en charge optimale et individualisée. Si plusieurs causes sont identifiées, il faut hiérarchiser la prise en charge en fonction des conséquences médicales qu'elles représentent et de leur retentissement fonctionnel, mais aussi en incluant le patient dans le processus de décision, quel que soit son statut cognitif. Si le consentement n'est pas possible, il faut essayer de rechercher son assentiment avant toute prise de décision [9].

Le schéma 6 est une synthèse des étiologies responsables des troubles du bas appareil urinaire chez l'homme $[10,11]$.

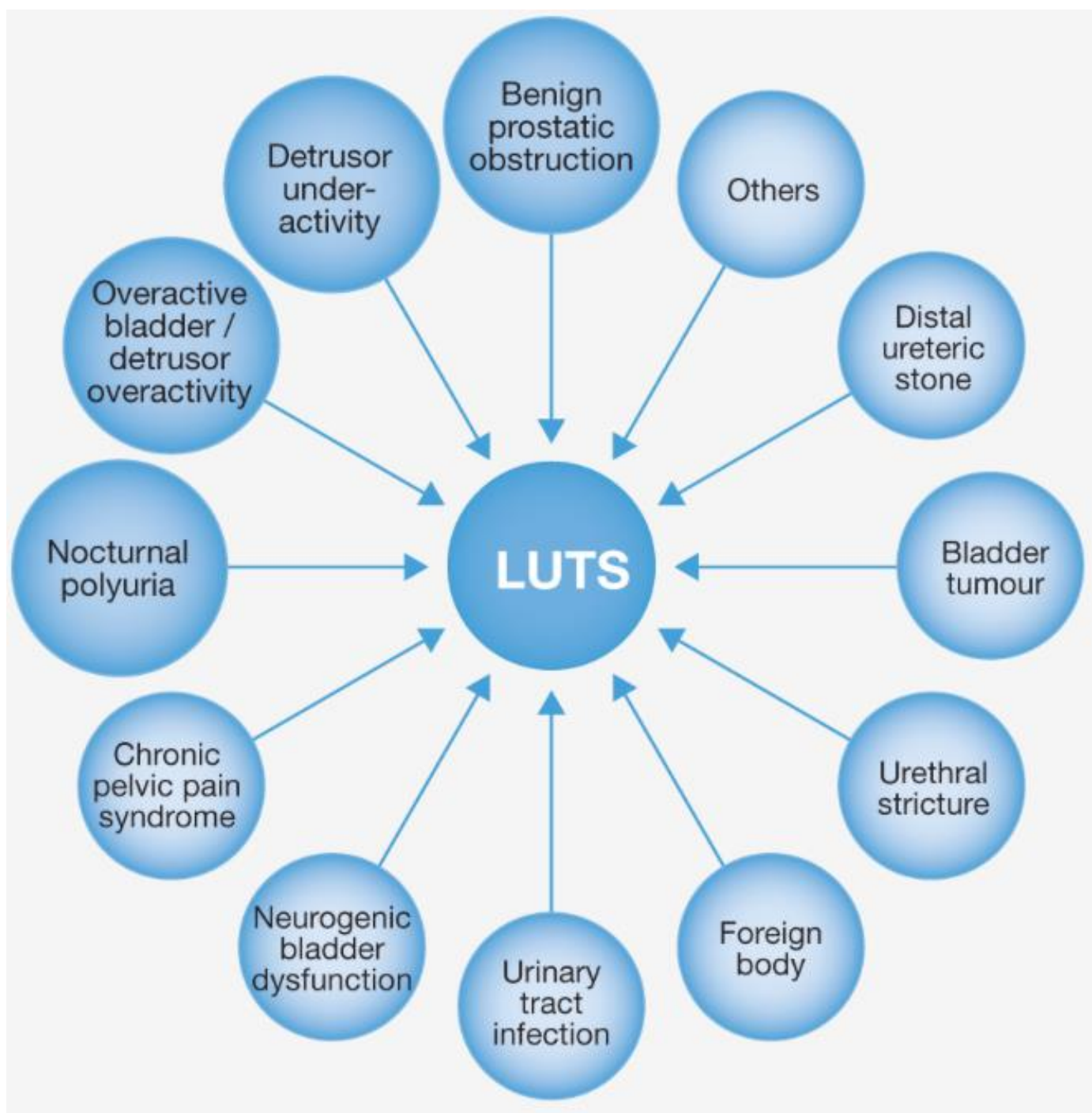

Schéma 6: étiologies des troubles du bas appareil urinaire chez l'homme ; LUTS= lower urinary tract symptoms 


\section{b. Modifications induites par l'hypertrophie bénigne de la prostate}

L'HBP histologique a une prévalence pouvant atteindre 80-90\% chez les plus de 80 ans [12]. Elle se caractérise par une augmentation de l'épaisseur du détrusor et une modification de son innervation. Cliniquement cela se traduit par une obstruction chronique pouvant aboutir à une hyperactivité vésicale ou à l'inverse à une hypocontractilité vésicale [13]. La rétention chronique est définie comme une vessie non douloureuse, qui reste palpable ou percutable après que le patient a uriné. Le terme implique une mesure du résidu post mictionnel (RPM), avec un chiffre minimum de $300 \mathrm{ml}$ mentionné [1;2]. Néanmoins, les définitions exactes restent controversées [3].

L'hyperactivité vésicale est le symptôme le plus fréquemment rapporté et est à l'origine du handicap de cette pathologie. Elle toucherait 50/100 des hommes avec un syndrome obstructif. D'un point de vue physiopathologique, c'est l'augmentation de la pression vésicale qui conduit à une dénervation partielle du détrusor, avec hyper sensibilité post-jonctionnelle. Cette dénervation est partiellement réversible après une adémomectomie. Des stimuli sensoriels anormaux dus à l'obstacle peuvent induire une suractivité du détrusor [14]. L'ablation par la chirurgie de ces stimuli sur l'urètre prostatique est donc bénéfique et explique en partie la réduction des signes d'hyperactivité vésicale après le geste chirurgical. La fibrose du détrusor par accumulation excessive de collagène est associée à la sévérité des symptômes bien que non pathognomonique car également retrouvée dans le vieillissement normal.

L'hypoactivité vésicale [15] est induite par une distension chronique des fibres musculaires lisses sans aucune pathologie neurologique sous-jacente. Elle est définie comme une faible contraction du trésor avec une vidange incomplète et prolongée. Il n'y a pas de consensus franc sur ces critères diagnostiques, mais l'hypoactivité du détrusor est à l'origine d'une rétention urinaire chronique avec augmentation du RPM. Après désobstruction par Holep, il y a une amélioration sur les scores cliniques, le résidu post mictionnel et la débimétrie.

Les résultats de traitements chirurgical et médical sont d'autant plus défavorables que l'adénome est petit et que les symptômes sont associés [13].

En dehors du tableau chronique peuvent subvenir des phénomènes aigus. La rétention urinaire aigue (RAU) est définie comme une vessie douloureuse, palpable ou percussible. Le patient est incapable de faire passer l'urine. Cette complication est un motif fréquent de passage aux urgences et la pose de sonde vésicale est indispensable. 


\section{c. Recommandations de l'EAU pour la prise en charge de l'HBP \\ i. Diagnostic}

\section{Interrogatoire et examen clinique}

L'interrogatoire permet de définir les symptômes de la phase de stockage (incontinence, pollakiurie, nycturie, urgenturie), de la phase mictionnelle (retard au démarrage de la miction, nécessité de pousser pour initier la miction, jet faible, jet en arrosoir ou haché, jet interrompu, miction en plusieurs temps, brûlures mictionnelles), ou de la phase post-mictionnelle (gouttes retardataires et sensation de vidange incomplète). Ces symptômes peuvent être mixtes. Cette description permet une première orientation étiologique, même si elle n'est pas spécifique [16].

L'examen clinique permet de rechercher une sténose du méat urinaire, un écoulement urétral, un phimosis, une matité hypogastrique. Le toucher rectal doit être réalisé pour estimer la consistance et le volume prostatique (permet de distinguer une prostate supérieure ou inférieure à 50g) [17].

La passation d'un questionnaire (IPSS, ICIQ-MLUTS, ICIQ-NQoL, DAN-PSS, PGI-I) (annexes 3 à 7) a pour but d'évaluer la sévérité des symptômes et leurs retentissements sur la vie quotidienne du patient.

Si possible, la réalisation d'un diagramme de volume de fréquence (FVC) sur 3 à 7 jours, avec la durée et les heures mictionnelles, l'information des apports hydriques associés et l'utilisation du nombre de protections, permet de connaitre plus précisément le profil vésical, utile en cas de nycturie pour l'adaptation des apports et avec un effet d'entrainement vésical pour le patient (figure 2).

L'HBP donne classiquement un tableau irritatif (troubles de la phase de stockage) ou de la phase de vidange quand il y a obstruction. 


\section{Examens paracliniques}

Après l'interrogatoire une analyse d'urine doit être faite pour rechercher une infection urinaire masculine (si signes cliniques compatibles) et/ou des sédiments.

Le RPM, mesuré par échographie sus-pubienne (bladder scann), permet de rechercher rapidement une RAU ou une rétention d'urine chronique, mais est peu spécifique de l'étiologie obstructive (ne distingue pas la conséquence d'un obstacle prostatique ou urétral, d'une hypoactivité du détrusor).

Le dosage de l'antigène spécifique de la prostate (PSA) ne doit pas être systématique mais peut être une aide dans certaines situations complexes si cela modifie la prise en charge du patient.

Si ces premiers examens sont sans particularité et les symptômes sans retentissement significatif, il n'y a pas d'autres explorations à envisager et une simple surveillance suffit. En cas d'examens normaux mais avec atteinte de la qualité de vie, le bilan sera complété par une débimétrie pour orienter d'avantage le diagnostic, même si elle ne permet pas d'avoir le mécanisme précis des LUTS, et par une échographie prostatique (transrectale si possible pour mieux recherche un lobe médian).

Ces examens seront complétés d'un bilan biologique rénal et d'une échographie de l'arbre urinaire en cas d'hématurie, de RPM important ou d'antécédent de lithiase. La réalisation d'une urétrocystoscopie sera discutée en cas d'hématurie, de sténose urétérale ou d'antécédent de cancer prostatique. Ces résultats et l'impact sur la qualité de vie orienteront une prise en charge médicale ou chirurgicale (dans ce cas complétée d'un bilan urodynamique) (figure 2).

\section{ii. Traitement médical}

En cas de nycturie, une baisse des apports hydriques, des stimulants comme la caféine ou la théine et l'adaptation des traitements diurétiques sont d'abord conseillés En cas de majoration des symptômes, du RPM, ou de l'atteinte de la qualité de vie, un traitement sera alors proposé.

Les symptômes prédominants en phase de stockage et altérant la qualité de vie peuvent amener à prescrire des anticholinergiques ou des Beta-3 agonistes avec précautions d'usages à respecter. 
En dehors des symptômes de la phase de stockage, si la prostate est hypertrophiée $>30-40 \mathrm{ml}$, un traitement à long terme est envisagé avec en premier lieu un I5AR pouvant être associé à un alpha bloquant les 6 premiers mois.

Pour les prostates de faible volume, les I5AR ont moins d'efficacité. Seront alors privilégiés les alphas bloquants à visée purement symptomatique (figure 3).

Quand le traitement médical n'améliore pas les symptômes, qu'il y a un retentissement sur le haut appareil urinaire ou d'autres complications, alors un traitement chirurgical doit être envisagé avec l'urologue.

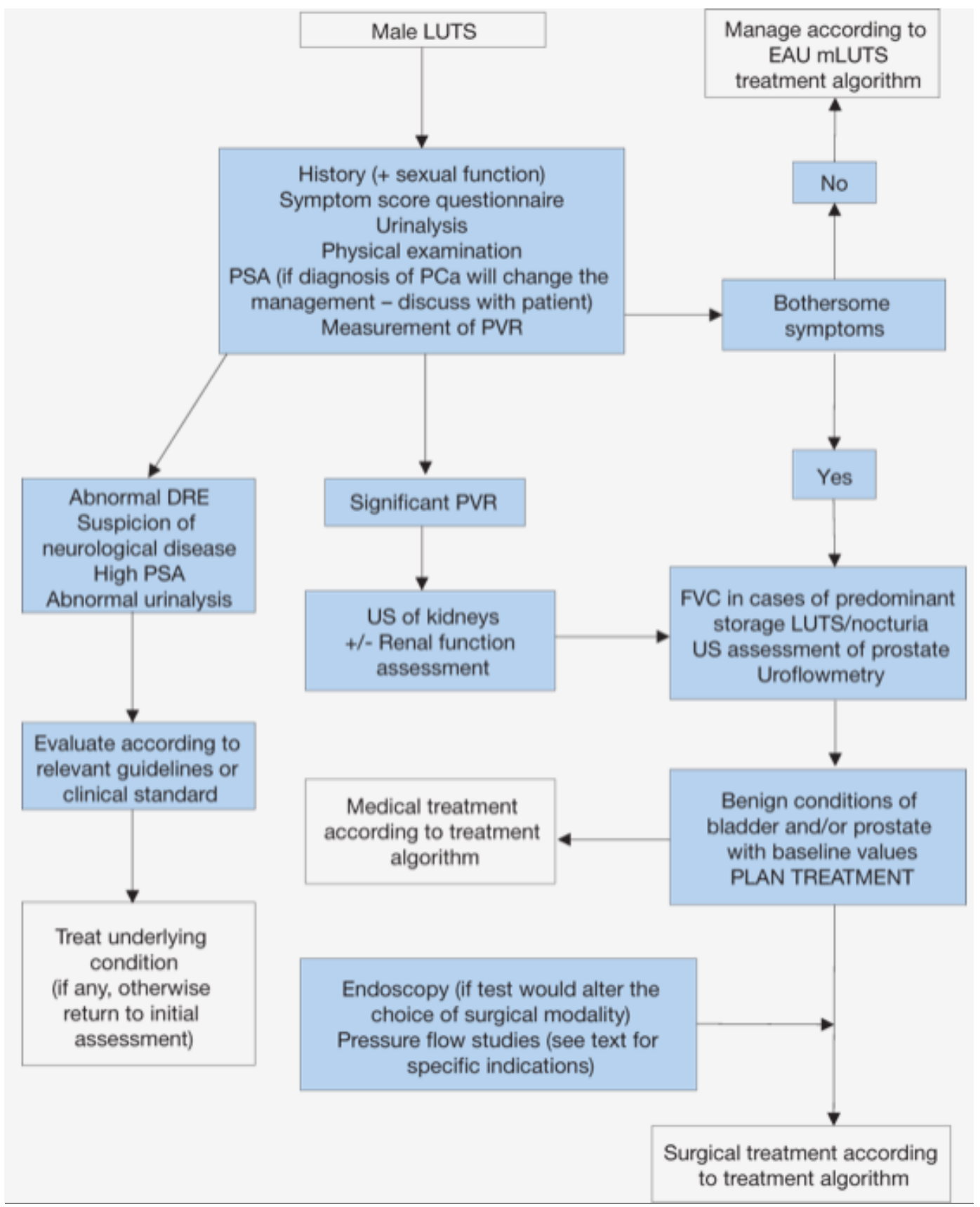

Figure 2: Assessment algorithm of LUTS in men aged 40 years or older

Readers are strongly recommended to read the full text that highlights the current position of each test in detail.DRE = digital-rectal examination; FVC = frequency volume chart; LUTS = lower urinary tract symptoms; $\mathrm{PCa}=$ prostate cancer; PSA = prostate specific antigen; PVR = post-void residual; US = ultrasound. 


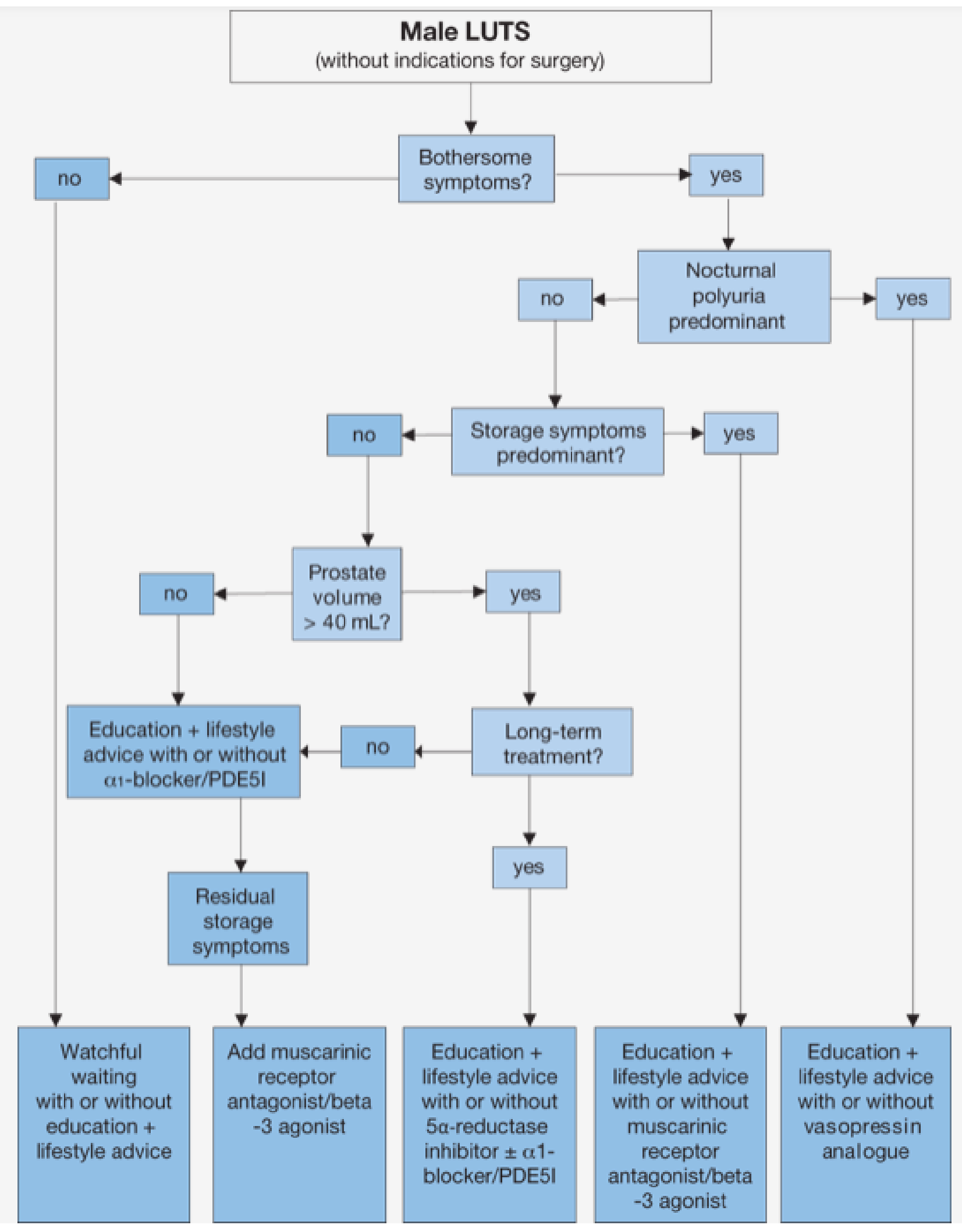

Figure 3: Treatment algorithm of male LUTS using medical and/or conservative treatment options. Treatment decisions depend on results assessed during initial evaluation. Note that patients' preferences may result in different treatment decisions.

PDE5I = phosphodiesterase type 5 inhibitors. 


\section{d. Focus thérapeutiques}

\section{i. Alphabloquants}

Les récepteurs alpha-adrénergiques 1 sont couplés à une protéine $\mathrm{G}$ activatrice. En étant activés, ils vont faire pénétrer le calcium en intracellulaire et permettre une contraction des cellules musculaires lisses. Au niveau de l'œil ils provoquent une mydriase, au niveau urologique et digestif ils provoquent la contraction des sphincters et au niveau vasculaire ils permettent une contraction des vaisseaux (sauf pour les artères coronaires où ils ne sont pas prédominants).

Les récepteurs alpha-adrénergiques 1 sont divisés en récepteurs alpha 1A, B ou D. Les récepteurs alpha 1A permettent d'entretenir le tonus musculaire de la prostate et du col vésical, les récepteurs alpha $1 \mathrm{~B}$ permettent le tonus des cellules musculaires lisses des vaisseaux périphérique et donc de maintenir une certaine pression artérielle, et les récepteurs alpha 1D entretiennent la contraction vésicale (schéma 7).

Le blocage de ces récepteurs alpha-adrénergiques relaxe les vaisseaux, ce qui abaisse la pression artérielle et induit une tachycardie par mise en jeu du baro-réflexe, s'il est préservé.

L'alfuzosine, la silodosine et la tamsulosine sont les principaux alphabloquants validés en France dans la prise en charge urologique. L'alfuzosine est peu spécifique et a donc d'importants effets secondaires vasculaires. La tamsulosine est plus spécifique des sous types alpha 1A et 1D et a donc moins d'effets vasculaires [18]. La silodosine est encore plus spécifique des récepteurs alpha $1 \mathrm{~A}$ et a donc là aussi moins d'effets vasculaires secondaires, et pourrait même apporter une amélioration des patients non soulagés par la tamsulosine sur le score IPSS et particulièrement sur les symptômes de la phase de remplissage [19;20] et l'énurésie [21].

En traitement adjuvant au désondage, seule l'alfuzosine a l'AMM pour être utilisée pendant au moins $48 \mathrm{~h}$ avant tentative d'ablation de sonde puis stopper $24 \mathrm{~h}$ après. Quatre alphabloquants différents ont été testés dans cette indication (alfuzosine, tamsulosine, doxazosine et silodosine). Une revue de littérature Cochrane a estimé que seule la doxazosine n'a pas semblé être efficace. Cependant, la durée idéale du traitement par alphabloquant après sevrage de la sonde vésicale reste inconnue, car elle n'a été rapportée par aucun essai [22]. 


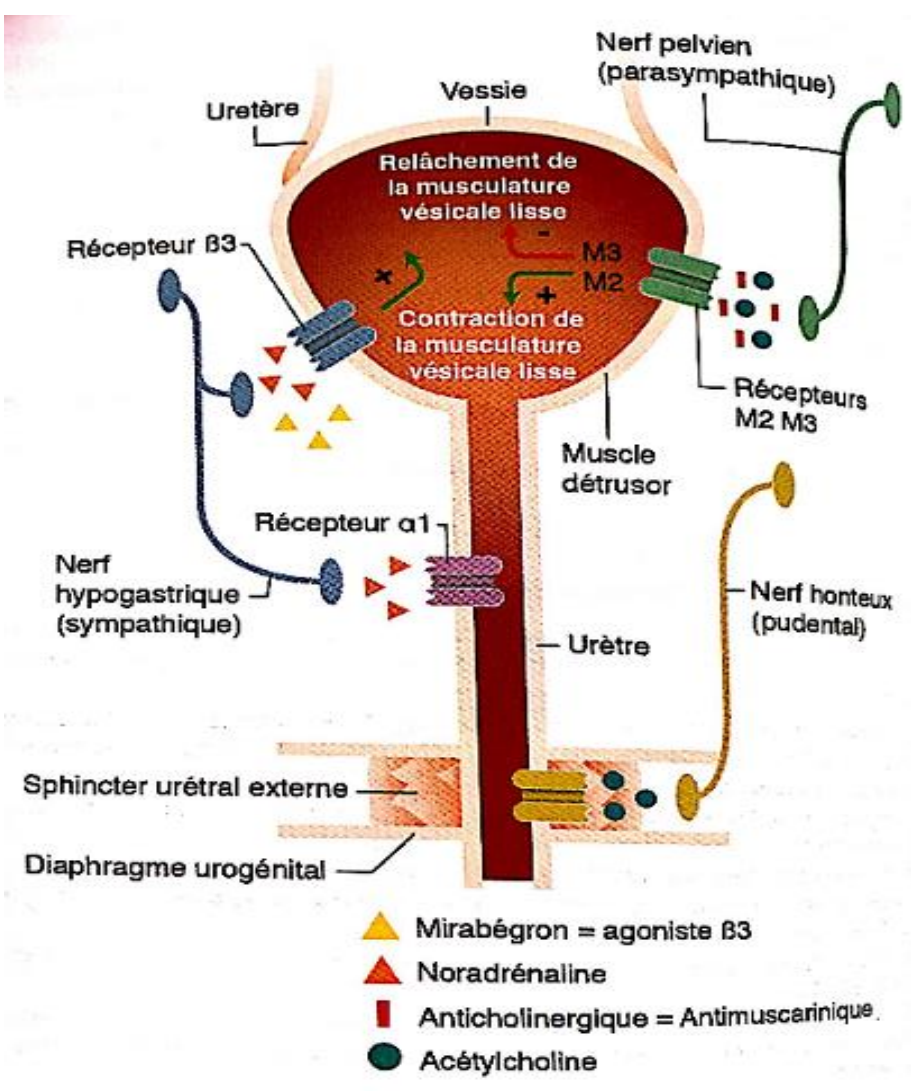

Schéma 7 : les récepteurs et neuromédiateurs du bas appareil urinaire

\section{ii. Inhibiteurs de l'alpha-5-testostérone réductase (I5AR)}

Les androgènes sont synthétisés par le testicule et la surrénale. La testostérone, par le biais de la 5-alpha réductase, est convertie en dihydrotestostérone (DHT) qui règle ensuite l'activité sexuelle. Les deux molécules Dutastéride et Finastéride permettent une réduction du volume de la prostate après plusieurs mois d'utilisation. Ces I5AR permettent une baisse des taux de DHT dans la prostate à l'origine des processus d'hypertrophie [23].

Théoriquement, le Dutastéride est plus puissant que le Finastéride car il bloque les deux types d'iso-enzymes de la 5-alpha réductase, alors que le Finastéride n'en bloque qu'une seule. Mais cette différence n'est pas retrouvée en clinique [24]. Leur efficacité a été démontrée dans plusieurs études [25]

Leur utilisation diminue la taille de la prostate, les symptômes urinaires liés à l'HBP et prévient les complications de RAU, notamment par actions sur la prostate et le col de la vessie [26;27]

Les principaux effets secondaires sont l'éjaculation rétrograde et la perte de libido confirmés dans plusieurs études cliniques mais réversibles à l'arrêt du traitement [28]. 


\section{PARTIE 2 : MESUSAGE DES TRAITEMENTS DE}

L'HYPERTROPHIE BÉNIGNE DE LA PROSTATE CHEZ LE SUJET AGE

\section{Hypothèse de la recherche et retombées attendues}

Face à l'absence de prise en charge spécifique des troubles mictionnels du sujet âgé gériatrique, nous avons cherché à donner une nouvelle définition de mésusage des traitements par alphabloquants et I5AR chez les patients de plus de 75 ans au sein de notre établissement. Cela permettra de mieux comprendre comment sont prescrits et réévalués les traitements à tropisme prostatique dans cette population, puis de créer un algorithme décisionnel nouveau de prise en charge médicale de l'HBP adaptée à la population gériatrique.

\section{Matériel et méthodes}

\section{a. Autorisations}

Version $\mathrm{n}^{\circ} 4 \mathrm{du} 24 / 06 / 2020$

Ayant reçu l'avis favorable de la DRCI et de la CNIL le 26/06/2020 sous le numéro PI2020_843_0083 sous couvert du respect de conformité à la Méthodologie de Référence 004 (MR004).

\section{b. Objectif principal}

Comptabiliser le nombre de mésusages des traitements de la classe ATC G04CA (alphabloquants) et ATC G04CB (inhibiteur de l'alpha-5-testostérone réductase).

\section{c. Objectifs secondaires}

1. Comptabiliser le nombre de patients traités chirurgicalement pour une hypertrophie bénigne de la prostate et encore sous traitement urologique

2. Comptabiliser le nombre de patients qui ont eu des explorations étiologiques et une évaluation sur la qualité de vie

3. Rechercher les causes non prostatiques participant aux troubles mictionnels

4. Rechercher les interactions pharmacodynamiques entre les traitements urologiques et les autres médicaments

5. Estimer le coût médico économique dû au mésusage

6. Proposer un nouvel algorithme de prise en charge adaptée à la population âgée 


\section{d. Critères d'inclusion et de non inclusion}

Tous les patients avec une prescription de la classe ATC G04C (hors phytothérapie) sur la période du 25 février au 3 mars 2019 et du 25 mars au 31 mars 2019 à partir de la base de données de DXCARE du CHU d'AMIENS ont été inclus. Les critères de non inclusion ont été les femmes devant l'absence d'autorisation de mise sur le marché (AMM) et de preuves scientifiques en faveur de leur utilisation, ainsi que la phytothérapie en monothérapie devant l'absence d'évènement iatrogène imputable à cette classe et des effets bénéfiques peu établis.

\section{e. Critères d'évaluation}

\section{iii. Evaluation principale}

Le mésusage a été défini comme un critère composite. Les 8 composants ont été définis en se basant sur l'AMM des produits, leur RCP, la recherche bibliographique, les données gériatriques et les recommandations de l'EAU. Ces critères nommés de R1 à R8 sont les suivants :

- R1 : Patient avec sonde à demeure (SAD) sous alpha bloquant

- R2: Absence d'arrêt du traitement après chirurgie prostatique ou antécédent de chirurgie prostatique, avec reprise d'un traitement sans réévaluation par un examen complémentaire prouvant une composante prostatique à la symptomatologie

- R3 : Introduction au long cours d'un alpha bloquant après une RAU, définie comme la présence du traitement sur l'ordonnance de sortie et/ou utilisation d'un alpha bloquant plus d'un an pour prévenir le risque de survenue d'une RAU et/ou utilisation à visée symptomatique avec HBP > 40ml confirmée sans I5AR associée

- R4 : Utilisation d'un alpha bloquant dans les situations de contre-indication selon l'AMM de chaque produit

- R5 : Utilisation d'un I5AR sans HBP, définie par une prostate de moins de 30g, sans lobe médian, ni d'autre argument clinique ou paraclinique en faveur d'une gêne prostatique

- R6 : Utilisation d'un I5AR chez un patient avec espérance de vie limitée $<6$ mois

- R7 : Absence de bénéfice sur la qualité de vie (QDV)

- R8 : Données insuffisantes pour réévaluer la prescription de l'alpha bloquant 


\section{iv. Evaluation secondaire}

1. Recueil des antécédents de chirurgie urologique et de la chronologie des traitements urologiques

2. Recherche des explorations réalisées dans le cadre du bilan étiologique et du bilan de retentissement : bandelette urinaire (BU), examen cytobactériologique des urines (ECBU), échographie des voies urinaires, échographie prostatique par voie sus pubienne ou endorectale, débimétrie, créatinine plasmatique, cystoscopie, examen urodynamique. Le retentissement sur la qualité de vie sera évalué par la présence d'un score validé en urologie (ex:IPSS) ou par la mention dans une observation de gêne dans la vie quotidienne du patient du fait des symptômes urinaires.

3. Les pathologies définies comme potentiellement responsables de la symptomatologie urinaire seront séparées en trois sous-groupes : Le groupe cortico-sous-corticale, le groupe sous vésicale et le groupe autre. Le premier groupe comprendra les troubles neurocognitifs, la maladie de parkinson idiopathique, les accidents vasculaires cérébraux (AVC) ischémiques ou hémorragiques, l'épilepsie, le syndrome d'apnée du sommeil (SAS). Le second groupe comprendra l'HBP, la constipation, la sténose urétrale et également la maladie de parkinson idiopathique. Le troisième regroupera l'insuffisance cardiaque congestive et à fraction d'éjection altérée, l'insuffisance respiratoire chronique, l'obésité, l'insuffisance rénale chronique à partir du stade modéré et la cirrhose.

4. Une analyse d'ordonnance sera réalisée et la recherche d'interactions pharmacologiques avec les traitements urologiques sera réalisée à l'aide du logiciel GRP Diane®.

5. Vérification du prix de chaque molécule et de leur taux de remboursement sur le site Thériaque ${ }^{\circledR}$ pour estimer le coût du mésusage sur l'échantillon, ainsi que du remboursement annuel réalisé par la sécurité sociale à l'aide du site Open médic, pour estimer le coût du mésusage en France à partir des résultats de l'échantillon.

6. Réalisation d'un algorithme de prise en charge adapté au profil de fragilité du patient, avec un dépistage simple et rapide pouvant être réalisé en consultation, et en se basant sur la littérature, les recomandations actuelles et l'évaluation gériatrique

\section{f. Déroulement de la recherche}

C'était une étude transversale sur deux semaines de recueil de données du 25 février au 3 mars 2019 et du 25 mars au 31 mars 2019 à partir de la base de données de prescriptions de la classe ATC G04C retenant 186 patients. Non inclusion des patients sous phytothérapies $(n=22)$, des patients de sexe féminin $(n=5)$ et retrait des 26 doublons, soit un échantillon final de 117 patients à analyser (figure 4). 


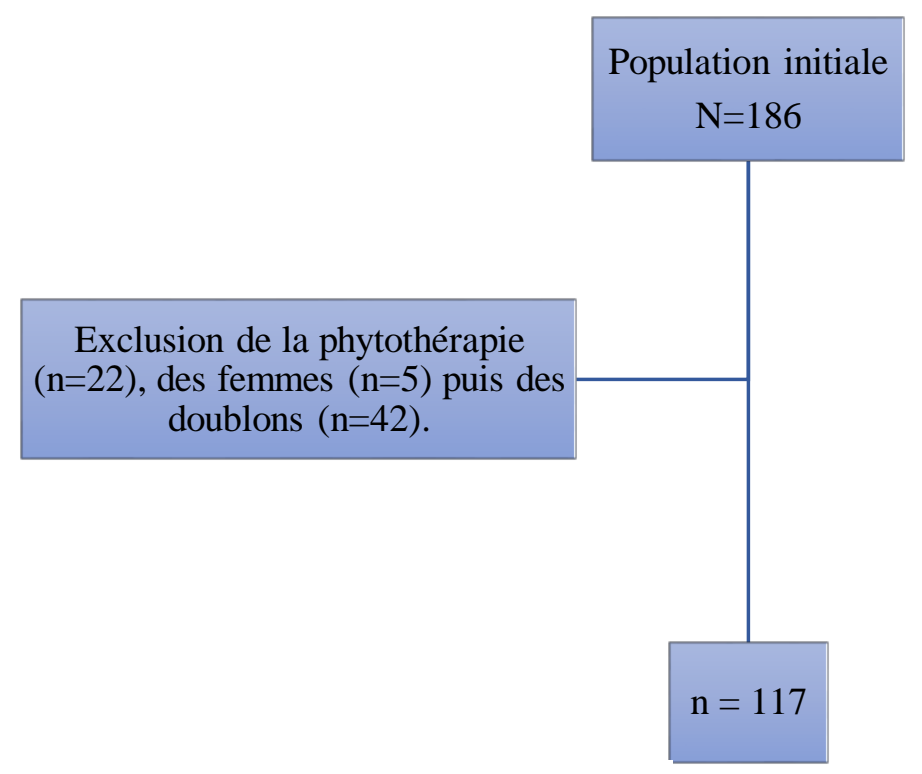

Figure 4 : flowchart

\section{Statistiques}

Un test $\mathrm{T}$ de Student a été réalisé pour les variables continues. Le test non paramétrique de Mann-Whitney a été utilisé pour les variables non continues. Les variables qualitatives ont été comparées par un test du Chi2 ou par le test non paramétrique $\mathrm{F}$ de Fisher lorsque les conditions de validité n'étaient pas respectées. L'analyse multivariée par régression logistique a été réalisée en ajustant sur quatre variables du fait d'un faible nombre de patients dans le groupe non-mésusage. Les variables ayant un lien de colinéarité n'ont pas été incluses.

\section{Résultats}

\section{a. Caractéristiques générales de la population}

La médiane d'âge était de 84,5 ans allant de 75 à 97 ans. Notre échantillon était représentatif d'une population gériatrique avec un score de Charlson moyen de 7,3 (allant de 3 à 15), la présence de troubles neurocognitifs chez $57,3 \%$ des patients représentant, après l'hypertension artérielle, la principale comorbidité. On retrouvait la fibrillation atriale à $44,4 \%$, l'AVC à 30,8\%, le diabète à 26,5\%, l'insuffisance cardiaque à 29,1\% (majoritairement à fraction d'éjection systolique altérée), et 24,8\% étaient coronariens. Un syndrome d'apnée du sommeil était identifié à $9,5 \%$, et $14,5 \%$ avaient une bronchopneumopathie chronique obstructive (BPCO) (tableau 1). Il y avait 45 patients $(38,5 \%)$ avec antécédent de chirurgie abdominale dont les détails sont résumés dans le tableau 2. 


\begin{tabular}{|c|c|c|c|c|}
\hline Caractéristiques & Total & $\begin{array}{l}\text { Groupe } \\
\text { mésusage }\end{array}$ & Groupe non-mésusage & $\mathrm{p}$ \\
\hline Patients & $117(100 \%)$ & $84(71.8 \%)$ & $33(28.2 \%)$ & - \\
\hline Age & $84.5 \pm 6.3$ & $84.5 \pm 5.9$ & $84.3 \pm 7.2$ & 0.906 \\
\hline Taille & $170.8 \pm 7$ & $171.1 \pm 7.1$ & $170.3 \pm 6.8$ & 0.472 \\
\hline Poids & $74 \pm 16.7$ & $73.7 \pm 13.4$ & $74.8 \pm 22.8$ & 0.797 \\
\hline IMC & $25.6 \pm 5.0$ & $25.5 \pm 4.5$ & $25.8 \pm 6.1$ & 0.721 \\
\hline \multicolumn{5}{|l|}{ Comorbidités } \\
\hline Troubles neurocognitifs & $67(57.3 \%)$ & $49(58.3 \%)$ & $18(54.5 \%)$ & 0.913 \\
\hline Mineurs & $25(21.4 \%)$ & $18(21.4 \%)$ & $7(21.2 \%)$ & 0.945 \\
\hline Majeurs & $41(35.0 \%)$ & $30(35.7 \%)$ & $11(33.3 \%)$ & 0.929 \\
\hline HTA & $84(71.8 \%)$ & $60(71.4 \%)$ & $24(72.7 \%)$ & 0.888 \\
\hline Diabète & $31(26.5 \%)$ & $22(26.2 \%)$ & $9(27.3 \%)$ & 0.905 \\
\hline Fibrillation atriale & $52(44.4 \%)$ & $37(44 \%)$ & $15(45.5 \%)$ & 0.890 \\
\hline AVC & $36(30.8 \%)$ & $27(32.1 \%)$ & $9(27.3 \%)$ & 0.608 \\
\hline Coronarien & $29(24.8 \%)$ & $19(22.6 \%)$ & $10(30.3 \%)$ & 0.386 \\
\hline Insuffisance cardiaque 1 & $34(29.1 \%)$ & $24(28.6 \%)$ & $10(30.3 \%)$ & 0.853 \\
\hline FE altérée & $19(16.2 \%)$ & $16(19.0 \%)$ & $3(9.1 \%)$ & 0.189 \\
\hline FE conservée & $15(12.8 \%)$ & $8(9.5 \%)$ & $7(21.2 \%)$ & 0.123 \\
\hline AOMI & $30(25.6 \%)$ & $20(23.8 \%)$ & $10(30.3 \%)$ & 0.469 \\
\hline Insuffisance rénale chronique 2 & $52(44.4 \%)$ & $32(38.1 \%)$ & $20(60.6 \%)$ & 0.027 \\
\hline Stade $3 \mathrm{~A}$ & $23(19.7 \%)$ & $14(16.7 \%)$ & $9(27.3 \%)$ & 0.194 \\
\hline Stade 3B & $20(17.1 \%)$ & $12(4.3 \%)$ & $8(24.2 \%)$ & 0.198 \\
\hline Stade 4 & $3(2.6 \%)$ & $2(2.4 \%)$ & $1(3.0 \%)$ & 1.000 \\
\hline Stade 5 & $6(5.1 \%)$ & $4(4.8 \%)$ & $2(6.1 \%)$ & 1.000 \\
\hline Syndrome d'apnée du sommeil & $11(9.4 \%)$ & $9(10.7 \%)$ & $2(6.1 \%)$ & 0.726 \\
\hline $\mathrm{BPCO}$ & $17(14.5 \%)$ & $12(14.3 \%)$ & $5(15.2 \%)$ & 1.000 \\
\hline Maladie de Parkinson & $5(4.3 \%)$ & $3(3.6 \%)$ & $2(6.1 \%)$ & 0.620 \\
\hline Épilepsie & $5(4.3 \%)$ & $3(3.6 \%)$ & $2(6.1 \%)$ & 0.620 \\
\hline Lésion médullaire & 0 & 0 & 0 & \\
\hline Cancer actif & $29(24.8 \%)$ & $20(23.8 \%)$ & $9(27.3 \%)$ & 0.696 \\
\hline Cirrhose & $5(4.3 \%)$ & $4(4.8 \%)$ & $1(3.0 \%)$ & 1.000 \\
\hline Hypothyroïdie & $11(9.4 \%)$ & $8(9.5 \%)$ & $3(9.1 \%)$ & 1.000 \\
\hline Hyperthyroïdie & $2(1.7 \%)$ & $1(1.2 \%)$ & $1(3.0 \%)$ & 0.486 \\
\hline Dépression & $28(23.9 \%)$ & $17(20.2 \%)$ & $11(33.3 \%)$ & 1.000 \\
\hline
\end{tabular}

Abréviations: IMC, indice de masse corporelle; HTA, hypertension artérielle; AVC, accident vasculaire cérébrale; $\mathrm{FE}$, fraction d'éjection ventriculaire gauche; AOMI, artériopathie oblitérante des membres inférieurs ; BPCO, bronchite chronique obstructive.

1, Insuffisance cardiaque à FE altérée définie par une FE inférieure ou égale à $45 \%$

2, Estimation faite par la formule « Modification of Diet in Renal Disease » (MDRD) en ml/min/1.73 m2. Les patients avec un débit de filtration glomérulaire supérieur à $60 \mathrm{ml} / \mathrm{min} / 1.73 \mathrm{~m} 2 \mathrm{n}$ 'ont pas étaient considérés insuffisants rénaux 


\section{b. Paramètres gériatriques de la population}

L'analyse des dossiers a permis de recueillir 11 paramètres gériatriques : la polymédication, la présence de chutes, les activités de la vie quotidienne estimées par l'échelle Activities of Daily Living (ADL), l'incontinence urinaire, la constipation, la présence d'une hypotension orthostatique (HTO), de troubles visuels, de troubles auditifs, le taux de vitamine D et d'albumine. Les ordonnances avaient une médiane de 6 médicaments. La présence d'au moins une chute était notifiée pour 53,8\% des patients alors que 5,9\% n'avaient jamais chuté et 40,2\% n'avaient pas d'information sur la chute. Il n'y a pas eu de recherche d'HTO pour 51 patients chuteurs (81\%) et quand le test a été réalisé il a été positif dans $70,6 \%$ des cas. La population était homogène sur les niveaux d'ADL avec 35\% des patients classés indépendants ou en dépendance modérée, contre $30 \%$ en dépendance sévère. L'incontinence urinaire a été recherchée chez $48,7 \%$ des patients avec 23,9\% de déclarations positives. En moyenne l'albumine était de $29,8 \mathrm{~g} / \mathrm{L}$, associée à un déficit en vitamine $\mathrm{D}$ modéré dont la médiane était de $22,9 \mathrm{ng} / \mathrm{ml}$ (tableau 3).

\begin{tabular}{ccccc}
\hline \multicolumn{4}{l}{ Tableau 2: Antécédents de chirurgies abdominales } & \\
\hline Caractéristiques & Total & Groupe mésusage & $\begin{array}{c}\text { Groupe non- } \\
\text { mésusage }\end{array}$ & $\mathrm{p}$ \\
Chirurgies abdominales & $45(38.5 \%)$ & $33(38.3 \%)$ & $12(36.4 \%)$ & 0.682 \\
Cure d'éventration & $3(2.6 \%)$ & $3(3.6 \%)$ & 0 & 0.558 \\
Colectomie & $7(6.0 \%)$ & $4(4.8 \%)$ & $3(9.1 \%)$ & 0.401 \\
Hernie inguinale & $21(17.9 \%)$ & $18(21.4 \%)$ & $3(9.1 \%)$ & 0.118 \\
Cholécystectomie & $12(10.3 \%)$ & $10(11.9 \%)$ & $2(6.1 \%)$ & 0.505 \\
Appendicectomie & $18(15.4 \%)$ & $13(15.5 \%)$ & $5(15.2 \%)$ & 0.965 \\
\hline
\end{tabular}

\section{c. Données urologiques de la population}

Les patients ont eu au moins une consultation urologique dans $41,0 \%$ des cas et $49,6 \%$ avaient déjà présenté une RAU. L'HBP était précisée dans les antécédents de 57,3\% des patients et 29,9\% avaient un examen prouvant cette HBP. Dans 79,5\% des cas, il y avait la présence d'au moins un traitement courant pouvant favoriser les troubles urologiques (antalgiques de palier 2 ou 3, les neuroleptiques, les diurétiques, les inhibiteurs calciques, les benzodiazépines, les anticholinergiques).

L'indication initiale du traitement a pu être retrouvée dans $75,2 \%$ des cas, principalement sur HBP notifiée (35\%) suite à une rétention aigüe d'urine (30,8\%), des symptômes cliniques 
obstructifs $(36,8 \%)$, irrittatifs $(10,3 \%)$ ou mixtes $(9,4 \%)$. Le traitement a été initié chez 5 patients sondés pour une surveillance de diurèse sans avoir été stoppé par la suite malgré la reprise spontanée de la miction.

Le premier prescripteur à l'origine du traitement urologique a été dans $13,7 \%$ des cas un urologue. Le traitement le plus courant était l'alfuzosine à $58,1 \%$ puis le finastéride à $23,1 \%$ avec $18,8 \%$ des patients sous bi-thérapie. Une association de 2 alpha-bloquants était présente chez 2 patients; et 1 patient avait une incompatibilité médicamenteuse associant de la midodrine (alpha-adrénergique) avec de la tamsulosine (alphabloquant).

Le fait de consulter un urologue était associé à la réalisation d'examens complémentaires $(\mathrm{p}<0.007)$. Après introduction d'un traitement, une réévaluation en consultation n'a montré une amélioration de la qualité de vie que pour 6 patients sur les 14 interrogés. Quand la date d'introduction a été retrouvée, le traitement était pris en moyenne depuis 1.2 an et depuis au moins 4.5 ans quand la date d'introduction exacte n'était pas connue (tableau 4).

\begin{tabular}{|c|c|c|c|c|}
\hline Caractéristiques & Total & Groupe mésusage & $\begin{array}{l}\text { Groupe non- } \\
\text { mésusage }\end{array}$ & $\mathrm{p}$ \\
\hline Polymédication & $6 \pm 2.0$ & $6 \pm 2.0$ & $7 \pm 3.0$ & 0,061 \\
\hline Chuteurs & $63(53.8 \%)$ & $51(60.7 \%)$ & $12(36.4 \%)$ & 0.043 \\
\hline \multicolumn{5}{|l|}{$\mathrm{ADL}_{1}$} \\
\hline Indépendant & $41(35.0 \%)$ & $27(32.1 \%)$ & $14(42.4 \%)$ & 0.294 \\
\hline Dépendance modérée & $41(35.0 \%)$ & $30(35.7 \%)$ & $11(33.3 \%)$ & 0.808 \\
\hline Dépendance sévère & $35(30.0 \%)$ & $27(32.1 \%)$ & $8(24.2 \%)$ & 0.401 \\
\hline Constipation & $55(47.0 \%)$ & $39(46.4 \%)$ & $16(48.5 \%)$ & 0.511 \\
\hline \multicolumn{5}{|l|}{ Incontinence urinaire } \\
\hline Oui & $28(23.9 \%)$ & $23(27.4 \%)$ & $5(15.2 \%)$ & 0.248 \\
\hline Non & $29(24.8 \%)$ & $20(23.8 \%)$ & $9(27.3 \%)$ & 0.248 \\
\hline Non connue & $60(51.3 \%)$ & $41(48.8 \%)$ & $19(57.6 \%)$ & 0.393 \\
\hline \multicolumn{5}{|l|}{ Hypotension orthostatique } \\
\hline Recherche avec test positif & $12(10.3 \%)$ & $12(14.3 \%)$ & 0 & 0.007 \\
\hline Recherche avec test négatif & $5(4.3 \%)$ & $3(3.6 \%)$ & $2(6.0 \%)$ & 0.074 \\
\hline Non recherchée & $100(84.5 \%)$ & $69(82.1 \%)$ & $31(94.0 \%)$ & 0.103 \\
\hline Troubles visuels & $36(30.8 \%)$ & $26(31 \%)$ & $10(30.3 \%)$ & 0.556 \\
\hline Troubles auditifs & $19(16.2 \%)$ & $15(17.9 \%)$ & $4(12.1 \%)$ & 0.429 \\
\hline \multicolumn{5}{|l|}{ Paramètres nutritionnels } \\
\hline Albumine & $29.8 \pm 6.1$ & $30.2 \pm 6.4$ & $28.8 \pm 5.2$ & 0.308 \\
\hline Vitamine D & $22.9 \pm 11.6$ & $23.5 \pm 12.0$ & $20.9 \pm 10.4$ & 0.467 \\
\hline
\end{tabular}

Abréviations : ADL, Activity of Daily Living (échelle de Katz) ; AVC, accident vasculaire cérébrale 1, indépendant si ADL 6/6, dépendance modérée si ADL 3 à 5, dépendance sévère si ADL 0 à 2. 


\begin{tabular}{|c|c|c|c|c|}
\hline Caractéristiques & \multicolumn{2}{|c|}{ Groupe mésusage } & \multirow{2}{*}{$\begin{array}{l}\text { Groupe non- } \\
\text { mésusage } \\
8(24.2 \%)\end{array}$} & \multirow{2}{*}{$\begin{array}{c}\mathrm{p} \\
0.026\end{array}$} \\
\hline Consultation avec un urologue & $48(41.0 \%)$ & $40(47.6 \%)$ & & \\
\hline Antécédent de sondage vésical & $55(47.0 \%)$ & $42(50.0 \%)$ & $13(39.4 \%)$ & 0.301 \\
\hline Antécédent de rétention aigüe d'urine & $58(49.6 \%)$ & $41(48.8 \%)$ & $16(48.5 \%)$ & 0.883 \\
\hline HBP notifiée dans les courriers & $67(57.3 \%)$ & $56(66.7 \%)$ & $11(33.3 \%)$ & 0.983 \\
\hline HBP prouvée 1 & $35(29.9 \%)$ & $30(35.7 \%)$ & $5(15.2 \%)$ & 1.000 \\
\hline \multicolumn{5}{|l|}{ Taille de la prostate } \\
\hline$<30 \mathrm{~g}$ & $7(6.0 \%)$ & $7(8.3 \%)$ & 0 & 0.301 \\
\hline $30-50 g$ & $12(10.3 \%)$ & $10(11.9 \%)$ & $2(6.1 \%)$ & 1.000 \\
\hline$>50 \mathrm{~g}$ & $12(10.3 \%)$ & $10(11.9 \%)$ & $2(6.1 \%)$ & 1.000 \\
\hline Antécédent de prostatite & $26(22.2 \%)$ & $23(27.4 \%)$ & $3(9.1 \%)$ & 0.525 \\
\hline Traitements favorisant les troubles mictionnels & $93(79.5 \%)$ & $67(79.7 \%)$ & $26(78.8 \%)$ & 0.907 \\
\hline \multicolumn{5}{|l|}{ Traitement urologique } \\
\hline Connaissance du prescripteur & $66(56.4 \%)$ & $47(56.0 \%)$ & $19(57.6 \%)$ & 0.873 \\
\hline Médecin généraliste & $10(8.5 \%)$ & $9(10.7 \%)$ & $1(3.0 \%)$ & 0.278 \\
\hline Urologue & $16(13.7 \%)$ & $12(14.3 \%)$ & $4(12.1 \%)$ & 1.000 \\
\hline Autre & $40(34.2 \%)$ & $25(29.8 \%)$ & $15(45.5 \%)$ & 0.107 \\
\hline Alpha-bloquant & $101(86.3 \%)$ & $80(95.2 \%)$ & $21(63.6 \%)$ & $<0.001$ \\
\hline Alfuzosine & $68(58.1 \%)$ & $54(64.3 \%)$ & $14(42.4 \%)$ & 0.026 \\
\hline Tamsulosine & $25(21.4 \%)$ & $22(26.2 \%)$ & $3(9.1 \%)$ & 0.042 \\
\hline Silodosine & $8(6.8 \%)$ & $7(8.3 \%)$ & $1(3.0 \%)$ & 0.437 \\
\hline Inhibiteur de la 5-alpha réductase & $37(31.6 \%)$ & $21(25.0 \%)$ & $16(48.5 \%)$ & 0.014 \\
\hline Dutastéride & $10(8.5 \%)$ & $7(8.3 \%)$ & $3(9.1 \%)$ & 1.000 \\
\hline Finastéride & $27(23.1 \%)$ & $14(16.7 \%)$ & $13(39.4 \%)$ & 0.010 \\
\hline Association de traitement & $22(18.8 \%)$ & $22(26.2 \%)$ & $1(3.0 \%)$ & 0.004 \\
\hline Amélioration de la qualité de vie & $6(5.1 \%)$ & $4(4.8 \%)$ & $2(6.1 \%)$ & 0.165 \\
\hline \multicolumn{5}{|l|}{ Indication du traitement } \\
\hline Indication dans le courrier médical & $53(45.3 \%)$ & $43(51.2 \%)$ & $10(30.3 \%)$ & 0.041 \\
\hline Indication dans le dossier informatique & $88(75.2 \%)$ & $65(77.4 \%)$ & $23(69.7 \%)$ & 0.386 \\
\hline Symptômes obstructifs & $43(36.8 \%)$ & $31(36.9 \%)$ & $12(36.3 \%)$ & 0.147 \\
\hline Symptômes irritatifs & $12(10.3 \%)$ & $11(13.1 \%)$ & $1(3.0 \%)$ & 0.273 \\
\hline Symptômes mixtes & $11(9.4 \%)$ & $10(11.9 \%)$ & $1(3.0 \%)$ & 0.433 \\
\hline Hypertrophie bénigne de prostate & $41(35.0 \%)$ & $34(40.5 \%)$ & $7(21.2 \%)$ & 0.049 \\
\hline Résidu post mictionnel augmenté & $1(0.9 \%)$ & $1(1.2 \%)$ & 0 & 1.000 \\
\hline Sondage pour surveillance de diurèse & $5(4.3 \%)$ & $2(2.4 \%)$ & $3(9.1 \%)$ & 0.135 \\
\hline \multicolumn{5}{|l|}{ Exposition au traitement } \\
\hline Durée précise (années) & 1.2 & 1.8 & $0 \pm 0.2$ & $<0.001$ \\
\hline Durée minimale connue (en années) & $4.5 \pm 1.8$ & $4.4 \pm 3.7$ & $4.2 \pm 2.2$ & 0.837 \\
\hline Réévaluation du traitement & $43(36.8 \%)$ & $33(39.3 \%)$ & $10(30.3 \%)$ & 1.000 \\
\hline
\end{tabular}

Abréviations : HBP, hypertrophie bénigne de prostate 


\section{d. Le critère de jugement principal}

Le critère de jugement principal est un critère composite de 8 sous critères. Ils sont notés de $\mathrm{R} 1$ à $\mathrm{R} 8$ et sont résumés dans le tableau 5.

Il y avait $13,7 \%$ des patients qui répondaient au critère R1. Le fait d'avoir une SAD était significativement associé à la prescription d'alfuzosine $(\mathrm{p}<0.012)$, présent chez 14 patients parmi les 16 avec SAD. L'association était également significative sur le fait de connaître l'indication médicale initiale sur les courriers d'hospitalisation $(\mathrm{p}<0.010)$ ou sur les dossiers informatiques $(\mathrm{p}<0.013)$. Ils avaient été significativement plus nombreux à avoir déjà eu un sondage auparavant $(\mathrm{p}<0.016)$. Il n'y avait pas de différence sur la polymédication, mais ces patients étaient pourtant plus à risque d'avoir des interactions pharmacodynamiques sur les troubles du rythme $(\mathrm{p}<0.001)$ et de neutropénie $(\mathrm{p}<0.018)$ du fait de l'alfuzosine. Au niveau biologique, ces patients avaient une albumine significativement plus basse avec une moyenne à 25,3 g/L $(\mathrm{p}<0.003)$. Ils n'avaient pas plus de risque d'avoir une HBP, une chirurgie de prostate ou une chirurgie abdominale. Il y avait une tendance d'association avec un niveau de dépendance sévère $(\mathrm{p}=0.078)$ et avec la présence de traitements favorisants les troubles mictionnels $(\mathrm{p}=0.094)$.

Le critère R2 était présent pour 23,9\% des patients dont 1 avait eu une intervention pour un autre motif que l'HBP, à savoir un cancer vésical ayant bénéficié d'une prostatectomie totale et résection vésicale totale, et 1 patient avait eu une dilatation urétrale sur sténose plusieurs années après une résection transurétrale de prostate (RTUP), dont la récidive des troubles mictionnels a fait réaliser une cystoscopie mettant en évidence la sténose intrinsèque (tableau 8). Ce critère R2 était significativement associé aux antécédents de chirurgie d'hernie inguinale $(\mathrm{p}<0.001)$ et $\mathrm{d}$ 'appendicectomie $(\mathrm{p}<0.037)$.

Le critère R3 a classé 50,4\% des patients en mésusage et était associé au critère R4 ( $<<0.014)$. Les alphabloquants étaient significativement plus utilisés sur une RAU initiale $(\mathrm{p}<0.039)$ et étaient associés au fait d'avoir une HBP notifiée sur les courriers médicaux $(p<0.014)$. En dehors de la RAU, ils étaient plus prescrits chez les patients avec symptômes identifiés. Leurs prescriptions étaient initiées majoritairement par des médecins non urologues. Le fait d'avoir au long cours un aplhabloquant augmentait le risque d'interactions pharmacodynamiques liées aux alpha-bloquants. 
Le critère R4 était présent chez $12,8 \%$ des patients. Ces patients avaient une tendance à être plus incontinents $(\mathrm{p}=0.078)$, chuteurs $(\mathrm{p}=0.343)$ et plus carencés en vitamine $\mathrm{D}(\mathrm{p}<0.038)$.

Pour le critère R5, 2,6\% des patients avaient un I5AR sans que l'on ait de notion d'HBP dans les dossiers médicaux, représentant $8,1 \%$ des patients sous ces traitements. Ils étaient plus suceptibles d'avoir une association de traitement $(\mathrm{p}<0.007)$ et avaient moins de symptômes d'hyperactivité vésicale $(\mathrm{p}<0.030)$. Ces patients étaient également plus jeunes $(\mathrm{p}<0.047)$ et avec moins de comorbidités $(\mathrm{p}<0.041)$.

Pour le critère R6, 1 patient en soins palliatifs s'était vu prescrire un I5AR associé à un alphabloquant à la suite d'une RAU.

Pour le critère R7, 6,8\% des patients ont déclaré ne pas avoir eu d'amélioration de leur qualité de vie après mise sous traitement. Ils avaient plus de syndromes obstructifs à l'initiation du traitement $(\mathrm{p}=0.021)$ et une tendance à avoir moins d'I5AR $(\mathrm{p}=0.107)$ comme traitement de fond.

Pour le critère R8, 8,5\% des patients n'avaient aucune information permettant de comprendre la prescription d'alpha-bloquant et ce critère était associé au fait d'être sous bi-thérapie $(\mathrm{p}<0.001)$ notamment avec du finastéride $(\mathrm{p}<0.051)$.

\begin{tabular}{ccc}
\hline Tableau 5 : Détails du critère de jugement principal (composite) & \\
\hline Numéro du critère & Groupe mésusage & $\mathrm{p}$ \\
R1 & $16(13.7 \%)$ & 0.005 \\
R2 & $28(23.9 \%)$ & 0.001 \\
R3 & $59(50.4 \%)$ & 0.001 \\
R4 & $15(12.8 \%)$ & 0.006 \\
R5 & $3(2.6 \%)$ & 0.558 \\
R6 & $1(0.9 \%)$ & 1 \\
R7 & $8(6.8 \%)$ & 0.103 \\
R8 & $10(8.5 \%)$ & 0.060 \\
\hline
\end{tabular}

1, patient avec sonde à demeure sous alpha bloquant; 2, absence d'arrêt du traitement après chirurgie prostatique ou antécédent de chirurgie prostatique avec reprise d'un traitement sans réévaluation par examen complémentaire prouvant une composante prostatique ; 3 , Introduction au long cours d'un alpha-bloquant après rétention aigüe d'urine (RAU) définie comme la présence du traitement sur l'ordonnance de sortie ; ou utilisation d'un alpha bloquant plus d'un an pour prévenir le risque de survenue d'une rétention aigüe d'urine (RAU) ou utilisation à visée symptomatique avec HBP confirmée sans I5AR associée; 4, utilisation d'un alpha-bloquant dans les situations de contre-indication selon l'AMM; 5, utilisation d'un inhibiteur de la 5-alpha réductase sans hypertrophie bénigne de la prostate ; 6 , utilisation d'un inhibiteur de la 5-alpha réductase chez un patient avec espérance de vie limitée < 6 mois (soins palliatifs) ; 7, absence de bénéfice sur la qualité de vie ; 8, données insuffisantes. 


\section{e. Analyses univariées sur le critère de jugement principal}

Parmi les 117 patients de l'échantillon, 84 (71,8\%) ont le critère de jugement principal «mésusage ». Le groupe mésusage et le groupe non mésusage alors définis comprenaient respectivement 84 et 33 patients. Le groupe mésusage avait une tendance à avoir moins de médicaments $(\mathrm{p}=0.061)$, mais avait pourtant plus de patients chuteurs $(\mathrm{p}<0.043)$. Aucun test d'HTO n'a été positif dans le groupe non-mésusage contre 12 dans le groupe mésusage, soit $80 \%$ des tests effectués, sans différence sur la prise des anti-hypertenseurs (tableau 6). Sur les données urologiques, les patients du groupe mésusage avaient eu plus de consultations avec un médecin urologue $(\mathrm{p}<0.026)$, plus d'alpha-bloquants $(\mathrm{p}<0.001)$ notamment d'alfuzosine $(p<0.026)$ et plus d'associations de traitements $(p<0.004)$. Le groupe mésusage avait moins de traitements par I5AR $(\mathrm{p}<0.014)$. L'analyse d'ordonnance a permis de déceler plus de risques d'interactions pharmacocynamiques dans le groupe mésusage, pour l'HTO $(p<0.005)$ et les troubles du rythme $(\mathrm{p}<0.028)$, du fait de l'utilisation plus fréquente de l'alfuzosine (tableau 7). Les principaux médicaments responsables des intéractions pharmacodynamiques étaient les anti-hypertenseurs (70,9\%), les diurétiques $(33,3 \%)$ et les benzodiazépine/produit Z $(31,6 \%)$. Il y avait une tendance a davantage de chutes lorsque le nombre d'interactions pharmacodynamiques augmentait $(\mathrm{p}=0.228)$.

Les patients chuteurs étaient plus souvent sous alphabloquant $(\mathrm{p}<0.041)$ et notamment alfuzosine $(\mathrm{p}<0.001)$ ou sous I5AR $(\mathrm{p}<0.001)$ et particulièrement le dutastéride $(\mathrm{p}<0.010)$. La chute n'était en revanche pas significativement associée à l'utilisation de la tamsulosine $(\mathrm{p}=0.350)$, de la silodosine $(\mathrm{p}=0.490)$ ou du finastéride $(\mathrm{p}=0.610)$. Ces patients chuteurs étaient significativement plus dépendants sur les ADL $(\mathrm{p}=0.018)$ (figure 4). 

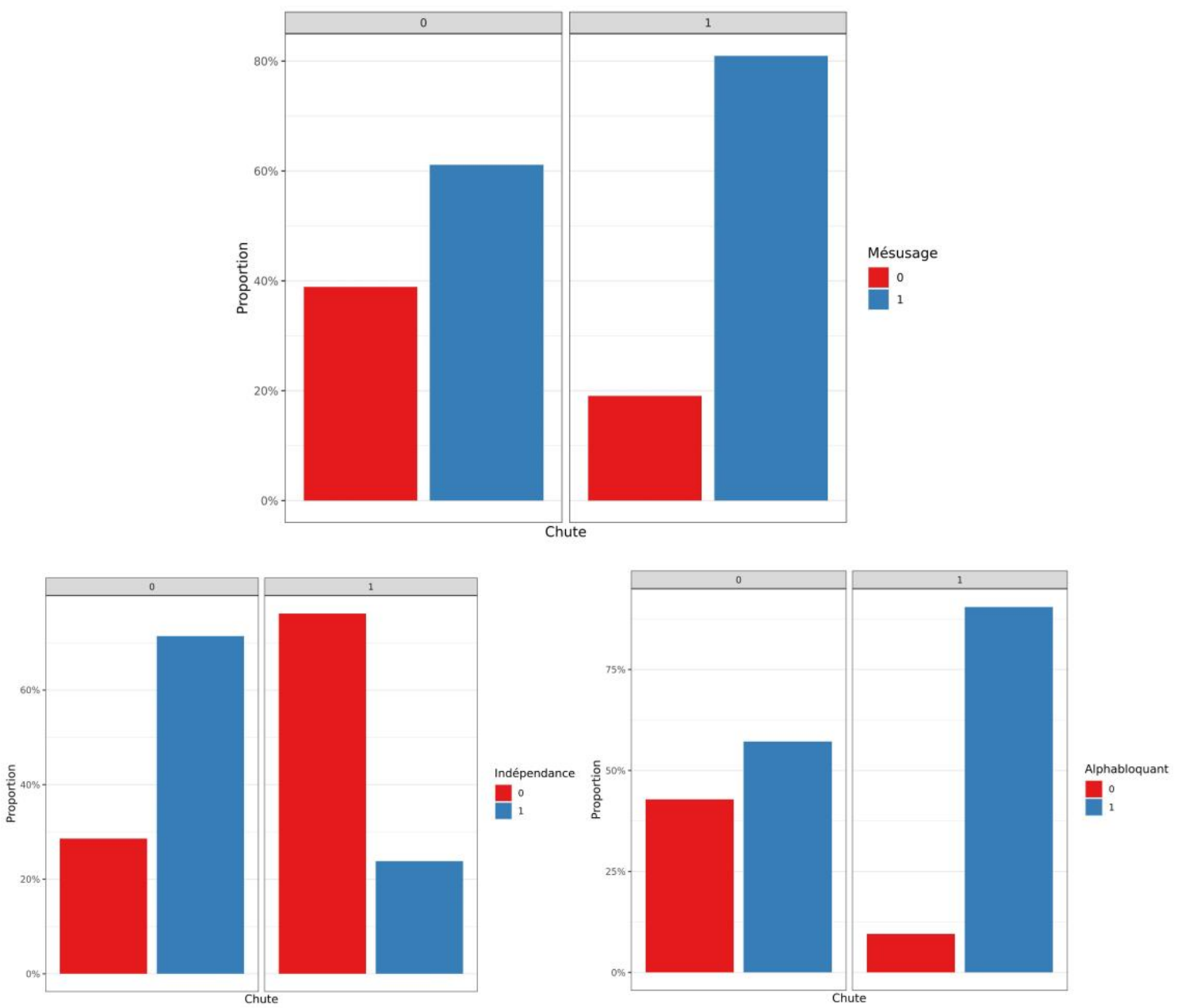

Figure 5 : histogrammes analysant la chute selon le mésusage, l'indépendance et la prise d'alpha bloquant. $0=$ non $/ 1=$ oui

\begin{tabular}{lcccc}
\hline \multicolumn{5}{l}{ Tableau 6 : Traitements antihypertenseurs } \\
\hline \multicolumn{1}{c}{ Caractéristiques } & Total & Groupe mésusage & Groupe non-mésusage & $\mathrm{p}$ \\
$\begin{array}{l}\text { Prise de traitements } \\
\text { antihypertenseurs }\end{array}$ & $83(70.9 \%)$ & $59(70.2 \%)$ & $24(72.7 \%)$ & 0.790 \\
Bétabloquant & $51(43.6 \%)$ & $36(42.9 \%)$ & $15(45.5 \%)$ & 0.799 \\
Inhibiteur calcique & $23(19.7 \%)$ & $15(17.9 \%)$ & $8(24.2 \%)$ & 0.434 \\
Diurétique thiazidique & $4(3.4 \%)$ & $2(2.4 \%)$ & $2(6.1 \%)$ & 0.316 \\
IEC/ARA2 & $49(41.9 \%)$ & $35(41.7 \%)$ & $14(42.4 \%)$ & 0.940 \\
Furosémide & $41(35 \%)$ & $25(29.8 \%)$ & $16(48.5 \%)$ & 0.056 \\
Inhibiteur centrale & $5(4.3 \%)$ & $2(2.4 \%)$ & $3(9.1 \%)$ & 0.135 \\
Spironolactone & $8(6.0 \%)$ & $3(3.6 \%)$ & $4(12.1 \%)$ & 0.097 \\
\hline
\end{tabular}

Abréviations : IEC, inhibiteur de l'enzyme de conversion; ARA2, antagoniste des récepteurs de l'angiotensine de type 2 


\begin{tabular}{|c|c|c|c|c|}
\hline Caractéristiques & Total & Groupe mésusage & $\begin{array}{l}\text { Groupe non- } \\
\text { mésusage }\end{array}$ & $\mathrm{p}$ \\
\hline $\begin{array}{l}\text { Nombre de traitements ayant une interaction } \\
\text { PD avec les médicaments urologiques }\end{array}$ & $3 \pm 2$ & $3 \pm 2$ & $4 \pm 3$ & 0,391 \\
\hline \multicolumn{5}{|l|}{ Interactions PD } \\
\hline Hypotension orthostatique & $107(91.5 \%)$ & $81(96.4 \%)$ & $26(78.8 \%)$ & 0.005 \\
\hline Troubles de rythme & $58(49.6 \%)$ & $47(56.0 \%)$ & $11(33.3 \%)$ & 0.028 \\
\hline Thrombopénie & $50(42.7 \%)$ & $39(46.4 \%)$ & $11(33.3 \%)$ & 0.198 \\
\hline Neutropénie & $2(1.7 \%)$ & $2(2.4 \%)$ & 0 & 1.000 \\
\hline \multicolumn{5}{|l|}{ Les traitements avec interactions PD } \\
\hline Allopurinol & $6(5.1 \%)$ & $5(6.0 \%)$ & $1(3.0 \%)$ & 1.000 \\
\hline Antalgiques de paliers 3 & $8(6.8 \%)$ & $6(7.1 \%)$ & $2(6.1 \%)$ & 1.000 \\
\hline Anti-arythmiques & $5(4.3 \%)$ & $5(6.0 \%)$ & 0 & 0.320 \\
\hline Anticholinestérasiques & $1(0.9 \%)$ & $1(1.2 \%)$ & 0 & 1.000 \\
\hline Antiépileptiques & $7(6.0 \%)$ & $4(4.8 \%)$ & $3(9.1 \%)$ & 0.401 \\
\hline Anti-hypertenseurs & $83(70.9 \%)$ & $59(70.2 \%)$ & $24(72.7 \%)$ & 0.790 \\
\hline Antiparkinsoniens & $2(1.7 \%)$ & $2(2.4 \%)$ & 0 & 1.000 \\
\hline AOD & $25(21.4 \%)$ & $19(22.6 \%)$ & $6(18.2 \%)$ & 0.598 \\
\hline Aspirine & $25(21.4 \%)$ & $20(23.8 \%)$ & $5(15.2 \%)$ & 0.304 \\
\hline AVK & $3(2.6 \%)$ & $2(2.4 \%)$ & $1(3.0 \%)$ & 1.000 \\
\hline Benzodiazépines/produits Z & $37(31.6 \%)$ & $26(31.0 \%)$ & $11(33.3 \%)$ & 0.803 \\
\hline Clopidogrel & $5(4.3 \%)$ & $5(6.0 \%)$ & 0 & 0.320 \\
\hline Diurétiques & $39(33.3 \%)$ & $25(29.8 \%)$ & $14(42.4 \%)$ & 0.081 \\
\hline Hydroxyzine & $3(2.6 \%)$ & $2(2.4 \%)$ & $1(3.0 \%)$ & 1.000 \\
\hline IPP & $25(21.4 \%)$ & $16(19.0 \%)$ & $9(27.3 \%)$ & 0.329 \\
\hline ISRS/IRSNA & $19(16.2 \%)$ & $11(13.1 \%)$ & $8(24.2 \%)$ & 0.141 \\
\hline Neuroleptiques & $7(6.0 \%)$ & $5(6.0 \%)$ & $2(6.1 \%)$ & 1.000 \\
\hline Statines & $13(11.1 \%)$ & $10(11.9 \%)$ & $3(9.1 \%)$ & 1.000 \\
\hline Sulfamides hypoglycémiants & $2(1.7 \%)$ & $1(1.2 \%)$ & $1(3.0 \%)$ & 0.486 \\
\hline Tramadol & $13(11.1 \%)$ & $10(11.9 \%)$ & $3(9.1 \%)$ & 1.000 \\
\hline
\end{tabular}

Abréviations: PD, pharmacodynamiques

Tableau $8:$ chirurgies des voies urinaires

\begin{tabular}{lcccc}
\hline \multicolumn{1}{c}{ Caractéristiques } & Total & Groupe mésusage & Groupe non-mésusage & $\mathrm{p}$ \\
Chirurgie de prostate & $28(24.0 \%)$ & $27(32.1 \%)$ & $1(3.0 \%)$ & $<0.001$ \\
Incision cervicoprostatique & $2(1.7 \%)$ & $2(2.4 \%)$ & 0 & 1.000 \\
RTUP & $15(12.8 \%)$ & $14(16.7 \%)$ & $1(3.0 \%)$ & 0.064 \\
Photo vaporisation laser & $4(3.4 \%)$ & $4(4.8 \%)$ & 0 & 0.576 \\
Prostatectomie sans précision & $4(3.4 \%)$ & $44.8 \%)$ & 0 & 0.576 \\
Prostatectomie totale & $2(1.7 \%)$ & $2(2.4 \%)$ & 0 & 1.000 \\
Prostatectomie partielle & $2(1.7 \%)$ & $2(2.4 \%)$ & $1(3.0 \%)$ & 1.000 \\
Dilatation urétrale & $1(0.9 \%)$ & 0 & 0 & 0.282 \\
Résection vésico-prostatique & $1(0.9 \%)$ & $1(0.8 \%)$ & 0.282 \\
\hline
\end{tabular}

Abréviations: RTUP, résection transurétrale de prostate 


\section{f. Analyses multivariées sur le critère de jugement principal}

Après régression logistique (tableau 9), le fait de prendre les traitements ATC G04C en mésusage a augmenté les chutes avec un OR de 3,22 (p<0.039; IC [1.1-10.2]). Les variables d'ajustements prises en compte étaient la prise d'alpha bloquants et la prise de traitements en association (alphabloquant avec I5AR) car ce sont les principaux traitements favorisant les chutes dans cette étude, ainsi que la présence de troubles neurocognitifs et d'insuffisance cardiaque car leur association avec les chutes était très significative.

Tableau 9 : analyse multivariée sur le risque de chutes

\begin{tabular}{cccc} 
& & Odds-Ratio & $\mathrm{p}$ \\
\hline Mésusage & 1 vs 0 & $3.22[1.08 ; 10.2]$ & 0.039 \\
Alphabloquant & 1 vs 0 & $2.22[0.551 ; 9.31]$ & 0.270 \\
Association de traitements & 1 vs 0 & $0.229[0.0725 ; 0.667]$ & $<0.010$ \\
Insuffisance cardiaque & 1 vs 0 & $2.91[1.12 ; 8.14]$ & 0.034 \\
Troubles neurocognitifs & 1 vs 0 & $5.66[2.35 ; 14.8]$ & $<0.001$
\end{tabular}

\section{g. Analyses des critères secondaires}

\section{Comptabiliser les patients traités chirurgicalement encore sous traitement médicamenteux}

Il y avait 28 patients $(23,9 \%)$ avec antécédent de chirurgie des voies urinaires et prostatique. Le groupe de patients avec intervention chirurgicale était plus âgé $(\mathrm{p}<0.044)$, avait fait plus d'AVC $(p<0.038)$ et avait eu plus d'opérations d'hernie inguinale $(p<0.001)$. Les patients avaient tendance à avoir un traitement depuis plus longtemps de 5.25 années contre 4,08 années $(\mathrm{p}=0.34)$ et n'avaient pas de différence sur la prise d'alpha bloquant ou d'I5AR comme traitement de fond. Parmi ces 28 patients avec antécédents de chirurgie des voies urinaires, 25 étaient sous alpha-bloquant, 8 sous I5AR et 8 avaient une association de traitements dont 1 avec 2 alpha-bloquants (alfuzosine et silodosine). Une SAD était présente chez 5 patients. 


\section{Montrer combien de patients ont eu des explorations étiologiques et une évaluation sur la qualité de vie}

Des examens étiologiques ont été réalisés chez 43 patients, principalement un ECBU et une échographie pour évaluation de la prostate, par voie sus-pubienne ou endorectale. Il y a eu significativement plus d'imageries du haut appareil urinaire dans le groupe de mésusage $(\mathrm{p}<0.035)$ (tableau 8). Une réévaluation du traitement a été consignée chez 43 patients (tableau 4). Chez les patients opérés, la réintroduction d'un traitement médical à la suite de la réapparition des symptômes n'a pas amélioré la QDV ( $\mathrm{p}=0.3)$.

En consultation, 2 patients ont eu une évaluation de la symptomatologie avec aide du score IPSS ou d'un score de qualité de vie.

\begin{tabular}{lcccc}
\hline \multicolumn{5}{l}{ Tableau 10 : Examens urologiques complémentaires } \\
\hline \multicolumn{1}{c}{ Caractéristiques } & Total & Groupe mésusage & Groupe non-mésusage & $\mathrm{p}$ \\
Examen(s) étiologique(s) & $43(36.8 \%)$ & $34(40.5 \%)$ & $9(27.3 \%)$ & 0.148 \\
ECBU & $37(31.6 \%)$ & $30(35.7 \%)$ & $7(21.2 \%)$ & 0.113 \\
Imagerie & $38(32.5 \%)$ & $31(36.9 \%)$ & $7(21.2 \%)$ & 0.035 \\
Débimétrie & $15(12.8 \%)$ & $13(15.5 \%)$ & $2(6.1 \%)$ & 0.288 \\
Bilan urodynamique & $3(2.6 \%)$ & $3(3.6 \%)$ & 0 & 0.557 \\
Cystographie & $23(19.7 \%)$ & $19(22.6 \%)$ & $4(12.1 \%)$ & 0.179 \\
\hline
\end{tabular}

Abréviations: ECBU, examen cytobactériologique des urines

\section{Rechercher les autres étiologies possibles aux troubles mictionnels}

Les étiologies aux troubles mictionnels ont été classées en 3 groupes. Le groupe cortico-souscorticale, le groupe sous vésicale et le groupe autre. Le premier groupe comprenait les troubles neurocognitifs, la maladie de parkinson idiopathique, les AVC (ischémique ou hémorragique), l'épilepsie, le SAS. Le second groupe comprenait l'HBP, la sténose urétrale et également la maladie de parkinson idiopathique. Le troisième regroupait l'insuffisance cardiaque toutes causes, la BPCO, l'obésité, l'insuffisance rénale chronique, la cirrhose (tableau 11)

Le groupe 1 avait plus de dépendance modérée ou sévère $(p<0.001)$ et était associé au fait $\mathrm{d}$ 'avoir une incontinence urinaire $(\mathrm{p}=0.060)$.

Le groupe 2 était aussi associé au fait d'être plus dépendant ( $\mathrm{p}<0.001$ ), à avoir plus d'alphabloquant $(p=0.075)$ et donc plus de chutes $(p=0.054)$, à avoir fait plus de RAU $(p=0.013) d u$ fait des causes obstructives inhérantes à ce groupe mais avait moins de $\mathrm{SAD}(\mathrm{p}<0.031)$. les patients du groupe 2 avaient tendance à plus consulter un urologue $(\mathrm{p}=0.067)$. 
Le groupe 3 n'était pas associé à des caractéristique particulières. La plupart des patients cumulaient les groupes avec 31 sur un seul groupe, 52 sur deux groupes et 26 sur les trois groupes.

Tableau 11 : Etiologies participantes aux troubles mictionnels

\begin{tabular}{|c|c|c|c|c|c|}
\hline \multicolumn{2}{|c|}{ Groupe 1 } & \multicolumn{2}{c|}{ Groupe 2 } & \multicolumn{2}{c|}{ Groupe 3 } \\
\hline $\begin{array}{c}\text { Troubles } \\
\text { neurocognitifs }\end{array}$ & $67(57.3 \%)$ & HBP & $67(57.3 \%)$ & IRC & $52(44.4 \%)$ \\
\hline AVC & $36(30.8 \%)$ & Constipation & $55(47.0 \%)$ & $\begin{array}{c}\text { Insuffisance } \\
\text { cardiaque }\end{array}$ & $34(29.1 \%)$ \\
\hline SAS & $11(9.4 \%)$ & Sténose urétrale & $1(0.8 \%)$ & BPCO & $17(14.5 \%)$ \\
\hline $\begin{array}{c}\text { Maladie de } \\
\text { Parkinson }\end{array}$ & $5(4.3 \%)$ & Maladie de Parkinson & $5(4.3 \%)$ & Obésité & $16(13.7 \%)$ \\
\hline Epilepsie & $5(4.3 \%)$ & & Cirrhose & $5(4.3 \%)$ \\
\hline
\end{tabular}

Abréviations : AVC, accident vasculaire cérébral ; SAS, syndrome d'apnée du sommeil ; HBP, hypertrophie bénigne de la prostate ; IRC insuffisance rénale chronique ; BPCO, bronchite chronique obstructive

\section{Estimer le coût médico économique dû au mésusage}

Dans notre échantillon de 117 patients, 84 avaient une utilisation en mésusage soit 71,8\% dont $68,4 \%$ des utilisateurs d'alpha bloquants et 17,9\% des utilisateurs d'I5AR. En prenant comme base les prix suivants affichés sur Thériaque ${ }^{8}$ pour 1 mois de traitement : alfuzosine LP à $11,44 €$, tamsulosine à $5,57 €$, silodosine à $4,71 €$, finastéride à $10,97 €$, et dutastéride à $8,81 €$, avec respectivement 54 patients, 22 patients , 7 patients, 14 patients et 7 patients, alors le mésusage a représenté un coût de 988,91€ par mois soit $11866,92 €$ par an. Le remboursement étant de 30\% (hors prise en charge à 100\%), le surcoût pour la sécurité sociale a été de $3560,08 €$ par an pour ces 84 patients.

La base de données sur le site ameli.fr d'Open médic (http://open-data-assurancemaladie.ameli.fr/medicaments/index.php\#Open_MEDIC), permet l'extraction du nombre de consommants pour les alpha-bloquants et des inhibiteurs de la 5-alpha réductase avec le remboursement effectué par la sécurité sociale de 2014 à 2018 (annexe 2).

Les patients de sexe masculin de plus de 60 ans en 2018 consommant des alpha-bloquants et des I5AR ont été respectivement de 1244091 et 344 773, représentant un remboursement total pour la sécurité sociale de $44070480 €$ pour les alpha-bloquants et de $16202107 €$ pour les I5AR (tableau 12). 


\begin{tabular}{lcc}
\hline \multicolumn{1}{c}{ Tableau 12: montants remboursés par la sécurité sociale en 2018} & \\
\hline \multicolumn{1}{c}{ Traitements } & Nombre de consommant & Remboursement $(€)$ \\
Âges et sexes confondus & & \\
Alpha-bloquants & 1518441 & 49936425 \\
I5AR & 369807 & 16828574 \\
Plus de 60 ans & 1244091 & 44070480 \\
Alphabloquants homme & 31956 & 808185 \\
Alphabloquants femme & 344773 & 16202107 \\
I5AR homme & 1975 & 15040 \\
\hline I5AR femme &
\end{tabular}

Abréviations: I5AR, inhibiteurs de la 5-alpha réductase

En extrapolant les résultats de notre étude aux chiffres de la sécurité sociale, alors le surcoût lié au mésusage en 2018 peut être estimé à $30144208 €$ pour les alpha-bloquants et à $2900177 €$ pour les IA5R soit un total de $33044385 €$.

$\mathrm{Au}$ coût des médicaments, il faut rajouter le coût des hospitalisations et consultations suites aux effets indésirables des médicaments.

Depuis 2016 il y a une chute du remboursement des I5AR (-36\%) en faveur d'une augmentation pour les alphabloquants $(+8 \%)$ sur la même population des plus de 60 ans (figure 5).

Figure 6 : Evolution du remboursement des alphabloquants et I5AR

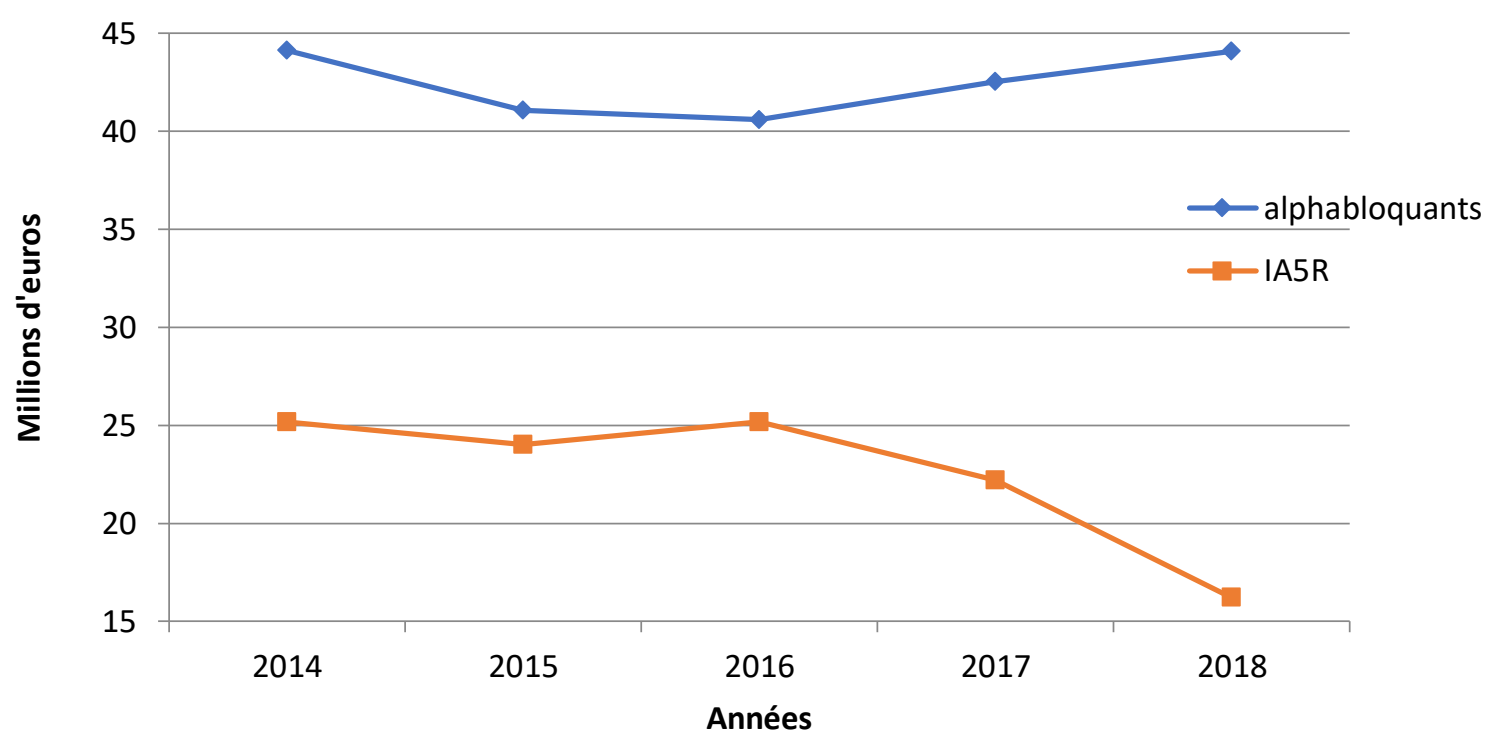




\section{PARTIE 3 : DISCUSSION}

\section{Principaux résultats :}

Dans cette étude, sur les 117 patients inclus, nous avons observé $70 \%$ de mésusage. Pour les I5AR aucune étude à notre connaissance n'a montré d'interaction médicamenteuse significative ni d'effets secondaires qui pourraient être particulièrement à risque en population gériatrique. Nos données suggéraient cependant une majoration du risque de chutes sous l'association I5AR et alphabloquants, ce qui n'est pas retrouvé dans la littérature. Une étude suggérait même un effet protecteur si l'I5AR était pris 6 mois avant l'initiation de l'alphabloquant et avancait comme hypothèse un mécanisme adaptatif [29]. Néanmoins, il n’y a pas de preuve sur leur utilisation en cas de prostate de faible volume sans obstruction clinicoradiologique ou chez des patients à faible espérance de vie puisque leur effet est d'autant plus important que la prostate est volumineuse et la durée de prise prolongée [30]. Les recommandations de l'EAU le précisent vaguement par les termes «si traitement au long cours ». C'est leur utilisation choisie dans la bonne indication qui permettra de modifier favorablement l'évolution de la maladie et des symptômes en agissant sur la composante obstructive, en diminuant les complications et en retardant la prise en charge chirurgicale [31;32].

Pour les alphabloquants, leur mésusage faisait principalement suite à une RAU en milieu hospitalier, sans essai d'arrêt de l'alpha-bloquant après réussite du désondage. Pourtant, cette complication fréquente est souvent contextuelle. La RAU était favorisée par l'alitement inhérent à l'hospitalisation, la consommation d'antalgiques de palier 2 ou 3, de médicaments anticholinergiques, d'une constipation, d'un contexte infectieux, ou avec une association de ces facteurs de risques pour $80 \%$ des cas, soit beaucoup plus que ce qui est retrouvé dans d'autres études, retrouvant $40 \%$ des RAU comme précipitées [33;34]. Nous expliquons cette différence par des patients plus médiqués, avec plus d'infections du bas appareil urinaire, plus dépendants et vulnérables au stress. Ces évènements précipitants devraient être considérés comme transitoires, donc sans nécessité de traitement de fond par un alpha-bloquant. D'ailleurs, les RAU précipitées étaient un critère d'exclusion dans les études, partant du principe que le facteur précipitant était corrigeable. Un traitement de 3 jours avec l'alfuzosine et de 7 jours avec la tamsulosine était généralement utilisé dans les ECR comme traitement adjuvant au désondage [35]. En pratique courante il sont en revanche continués. Au long cours, les alpha-bloquants ne permettent pourtant pas de prévenir la récidive de RAU, comme 
le confirment les données prospectives de l'étude CombAT menée sur 4 ans [36]. En 2006, Roehrborn avait déjà montré l'absence de modification de la taille de la prostate et de sa zone de transition sous alphabloquant [37] et les recommandations de 1'EAU réaffirment cette absence d'effet ; pourtant nous avons observé plus de 10\% d'utilisation d'alpha-bloquant chez des patients porteurs d'une SAD au long cours.

Nous avions moins de 5\% des patients qui estimaient leur qualité de vie améliorée par ces traitements. Ce résultat peut être expliqué par la surestimation des effets bénéfiques par le prescripteur comme montré dans l'étude Trophée [38] où le test de corrélation kappa entre le ressenti du médecin et celui du patient était très faible (0.144). Une autre explication peut être la difficulté à modifier un traitement instauré par un confrère, d'autant plus s'il est spécialiste, évocateur d'un manque de coopération entre les spécialités, alors que l'étude EVALURO [20] a déjà montré l'importance d'une réévaluation régulière en médecine générale. Ici, 40\% étaient suivis par un médecin urologue, contre environ 30\% dans d'autres études [39], probablement par notre sélection de données hospitalières.

Dans notre population, 1/3 avaient un trouble neurocognitif majeur, 1/4 étaient incontinents et 65\% étaient dépendants. Par conséquent, il peut être plus difficile d'apprécier les symptômes de l'HBP et leur retentissement sur la qualité de vie. L'efficacité des traitements en données urodynamiques sur la Qmax et le nombre de mictions est admise. Leur corrélation avec l'amélioration clinique des patients est en revanche débattue. L'utilisation des outils comme l'IPSS, ICIQ-MLUTS, N-QoL ou DAN-PSS (annexes 3 à 6) n'est pas adaptée aux patients gériatriques. Le PGI-I en post chirurgie est simple d'utilisation et peut être utilisé en gériatrie en complément d'autres informations (annexe 7). En 2015, Stenzelius [39] mentionnait déjà cette difficulté dans sa revue de littérature. En se basant sur ces scores, ce sont bien les patients les plus gênés qui bénéficient de la plus grande amélioration de leurs symptômes après introduction d'un alpha-bloquant [40]. Ainsi, devant des symptômes paraissant frustres ou difficilement évaluables, le bénéfice à attendre du traitement paraît moindre. Dans le cas où les symptômes sont invalidants, Barkin en 2003 a montré que l'association I5AR et alphabloquant peut être débutée puis l'alpha-bloquant arrété [41].

Si les effets bénéfiques sont discutables [42], les effets secondaires sont graves et concrets. Nos données convergent vers ceux de la littérature. Nous avions un peu plus de $10 \%$ des patients prenant un traitement en présence d'une contre indication par la présence d'un antécédent d'HTO ou d'une insuffisance rénale chronique sévère risquant une accumulation du médicament. L'accumulation plasmatique peut aussi être la conséquence d'une dénutrition, avec ici un taux moyen d'albuminémie juste sous le seuil de $30 \mathrm{~g} / \mathrm{dl}$, puisque l'alfuzosine s'y 
fixe à $90 \%$ [Vidal@]. Chez nos patients avec HTO, il y avait une tendance à être plus chuteurs et carencés en 250HD. Ils seraient donc plus à risque d'avoir des complications de la chute, mais notre étude ne permet pas de confirmer une telle causalité. La méta analyse de Nickel [19] a montré des effets indésirables vasculaires significatifs sous doxazosine, térazosine et alfuzosine. La tamsulosine n'atteignait pas le seuil de significativité, mais d'autres montraient une augmentation des symptômes généraux comme les malaises [35;43]. Plus récemment, les chutes et malaises sous alpha-bloquants dits sélectifs, alfuzosine, tamsulosine et silodosine (non significatif en sous-groupe), ont été démontrés dans l'étude de Blayne après seulement 3 mois de l'initiation du traitement [29]. La majoration du risque de chute par le traitement était la même chez les patients de plus de 75 ans ou de moins de 75 ans. Bien qu'appelés sélectifs, il faut rappeler qu'ils ne le sont pas totalement. La silodosine est la plus sélective avec un rapport $\alpha 1 \mathrm{~A} / \alpha 1 \mathrm{~B}$ de 162/1, mais ne semble pas pour autant apporter une différence clinique perceptible par rapport aux autres alphabloquants [43].

La classification des étiologies en groupes en fonction des atteintes sous vésicale, vésicale ou supra vésicale n'a pas permis d'apporter d'informations exploitables. Nous l'expliquons par la présence des étiologies intriquées.

Sur le plan économique, nos données recueillies sur OpenMedic allaient dans le sens de l'analyse de la base OBSERVAPUR publiées en 2018 [2]. La prise moyenne des traitements étaient de 6.5 ans ce qui rejoint nos données où nous avions une moyenne de prise estimée d'au moins 4.5 ans.

\section{Limitations de l'étude}

Notre étude était descriptive, transversale et monocentrique. Le lien de causalité entre la chute et la prise d'alphabloquant ne peut donc pas être affirmé même s'il y est associé. Des facteurs de confusions ont pu ne pas avoir été pris en compte. Les examens réalisés en ambulatoire nous étaient inconnus sous estimant peut-être la part d'HBP prouvée et nous manquions de puissance pour réaliser une régression logistique plus complète. Les médicaments dépendaient de notre livret thérapeutique expliquant la prédominance de l'alfuzosine dans nos données. La définition du mésusage que nous avons donnée contenait des critères « durs », comme la contre-indication de l'alfuzosine en cas d'HTO, et des critères innovants, comme le fait d'être sous alphabloquant au long cours ou d'avoir un I5AR en cas d'espérance de vie faible. Cela a pu donner un biais de classement différentiel. Cependant, cette définition de mésusage a été murement réfléchie. Nous avons voulu y ajouter des éléments de discussion 
gériatrique, pour rejoindre nos questionnements quotidiens sur le bénéfice recherché des médicaments.

A notre connaissance, il s'agit de la première étude en gériatrie donnant une définition de mésusage sur l'utilisation des I5AR et des alpha-bloquants dans l'indication de l'HBP. Une étude transversale était donc adaptée pour tester cette hypothèse et nous permettre de constituer la base d'un futur travail.

\section{Futures recherches}

\section{Proposition d'un nouvel algorithme de prise en charge}

Pour limiter le mésusage, nous proposons le nouvel organigramme décisionnel ci-dessous, basé sur les recommandations actuelles, l'évaluation gériatrique standardisée et nos observations. La prise en charge chirurgicale n'est pas abordée car elle reste du domaine spécialisé de l'urologue, même si nous incitons à une collaboration pluridisciplinaire.

Nous allons détailler les principales différences avec les recommandations actuelles vues dans les parties précédentes et les points essentiels. Le reste est dans l'organigramme ci-dessous.

Au début de la prise en charge, nous insistons sur une évaluation des traitements pour limiter l'iatrogénie médicamenteuse et sur l'adaptation du mode de vie [44;45]. La prescription d'une chaise garde-robe peut diminuer la distance à parcourir lors des envies mictionnelles, des bas de contention diminuer les symptômes évocateurs d'HTO et la diminution des apports le soir peut diminuer la nycturie. Dans cette population les examens paracliniques non invasifs devraient être plus fréquents pour mieux estimer le bénéfice à apporter par les médicaments. La mesure du RPM, pronostique d'une intervention chirurgicale pour les volumes $>300 \mathrm{ml}$ [46], le volume prostatique, pour évaluer la présence d'un lobe médian, d'une protrusion vésicale prostatique ou la mesure de l'épaisseur de la paroi vésicale et du détrusor $[47 ; 48]$ sont facilement réalisables.

Après cette étape, il conviendra au médecin prenant en charge le patient de déterminer son profil de fragilité. Nous avons choisi l'index de fragilité de Rockwood [49]. Cet index allant de 1 à 9 n'est pas un score chronophage. Après quelques utilisations, ses vignettes cliniques sont très intuitives et permettent en quelques secondes d'apprécier l'état global du malade. Il s'agit d'un index validé et adapté dans ce cadre de dépistage rapide en consultation. Il existe de nombreux autres échelles et scores pour le dépistage de la fragilité comme celle du gérontopôle de Toulouse conseillée par la haute autorité de santé (HAS), la SEGA ou encore 
les critères de Fried. Mais ils ne sont pas adaptés à ce contexte et ne seraient pas utilisés en pratique courante.

Pour les patients avec un index $\leq 4$, ils peuvent être pris en charge comme un sujet jeune. Pour un index à 5 ou 6, l'avis concomitant du gériatre devrait être demandé notamment en cas de doute sur un trouble neurocognitif ou de polypathologies/polymédication. L'évaluation de l'impact des troubles sur la vie quotidienne, éventuellement aidé par les questionnaires classiques guidera la prise en charge. Un traitement ne sera proposé qu'en cas d'impact modéré ou sévère. Seuls un impact sévère devra faire prescrire un traitement lors de la première consultation. Lors de l'entretien suivant, les traitements devront être réadaptés en fonction des résultats d'examens et des symptômes résiduels du patient. En cas d'impact modéré, les examens complémentaires doivent être faits avant la prescription de traitement. Puis, en cas de nycturie un alphabloquant, le plus sélectif possible, pourra être prescrit. En cas de symptômes de stockage, nous décourageons la prescription d'anti-muscarinique. Dans les autres cas, un I5AR en monothérapie sera privilégié si le patient a une bonne espérance de vie et une HBP $>40 \mathrm{ml}$. Dans le cas contraire, nous ne recommandons pas de traitement spécifique.

Chez les patients avec un indice $\geq 7$, un avis gériatrique pour évaluation globale spécialisée et aider à évaluer l'impact sur la qualité de vie devrait être nécessaire avant d'instaurer un traitement. Le risque semble supérieur au bénéfice attendu pour les alpha-bloquants chez un patient avec un impact léger à modéré. Dans les cas où l'HBP est $>40 \mathrm{ml}$ et l'espérance de vie $>1$ an, un I5AR sera plus approprié. En cas d'impact sévère, les examens complémentaires devront être faits avant toute prescription médicamenteuse.

Dans tous les cas de figure, la fragilité étant un continuum sensible, les traitements devront être réévalués tous les 6 à 12 mois. En cas de non-amélioration des symptômes ou d'effets indésirables, ils devront être suspendus. En cas de doute sur leur efficacité ou de nouvelle comorbidité, une fenêtre thérapeutique peut être proposée. S'ils sont bien tolérés et efficaces il faudra les continuer et poursuivre une réévaluation régulière.

\section{Prévenir la rétention aigue d'urine précipitée?}

En plus de cette prise en charge de fond au quotidien en service d'hospitalisation nous avons vu la problématique liée aux RAU précipitées rallongeant la durée moyenne de séjour, les complications et la dépendance iatrogène. Comment prévenir cette complication ? Nous savons que les héparines de bas poids moléculaire sont utilisées en prévention des évènements thromboemboliques veineux au quotidien chez presque tous nos patients en gériatrie aiguë qui 
présentent un facteur de risque (insuffisance cardiaque aigüe, alitement, infection...). Sur ce même modèle, un traitement préventif par alphabloquant dès le premier jour d'hospitalisation et de façon temporaire pourrait-il diminuer ce risque chez les patients entrant pour prostatite, douleurs avec utilisation d'antalgiques opioïdes ou alitement? Aucune étude à notre connaissance n'a évalué leur utilisation contrôlée et temporaire sous cet angle. 


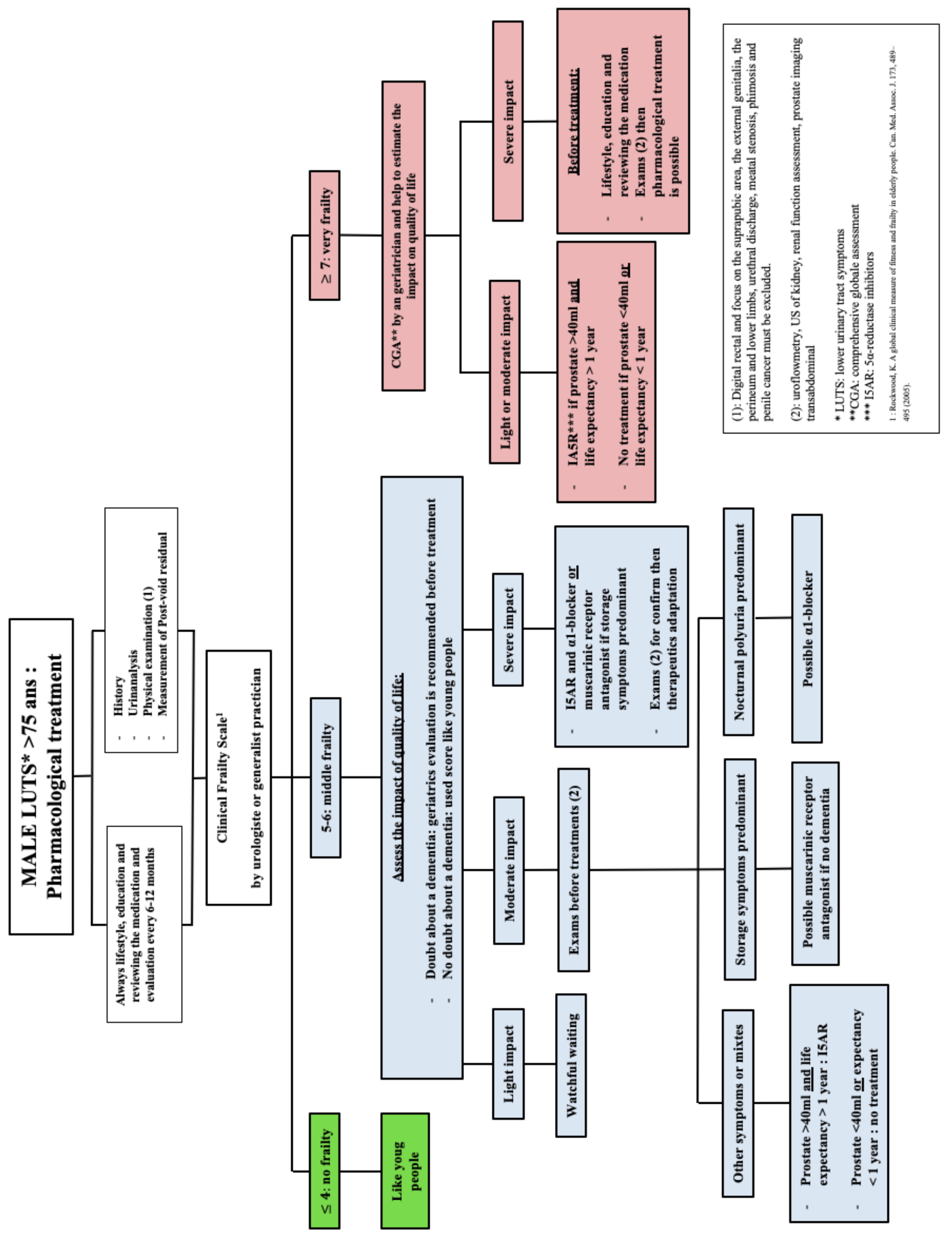




\section{CONCLUSION}

La prévalence des troubles mictionnels liés à l'HBP augmente avec l'âge. La prescription des traitements par alpha-bloquants et I5AR est ainsi devenue un enjeu majeur de santé public. Alors que le rapport bénéfices-risques a été prouvé en population adulte jeune, il reste à évaluer en population gériatrique. Afin d'adapter au mieux les prescriptions, nous avons donné une définition de mésusage de ces traitements en population gériatrique. Dans cette étude, le mésusage des thérapeutiques de l'HBP concernait $70 \%$ des patients. Les patients du groupe mésusage avaient un suivi urologique plus fréquent, plus d'examens diagnostiques complémentaires, plus de traitements alpha-bloqueurs, plus d'HTO et ils avaient un risque majoré de risque de chutes en analyse multivariée (OR de 3.22 (p=0.039; IC [1.1-10.2]).

La première difficulté dans la prise en charge est d'établir le lien de causalité entre l'HBP et les symptômes. Les explorations paracliniques non invasives sont donc plus fréquentes et informatives et doivent guider la prise en charge. La seconde difficulté est d'évaluer l'impact des symptômes sur la qualité de de vie, puis d'estimer le rapport bénéfices-risques d'un traitement. Nous avons alors proposé un nouvel algorithme de prise en charge adapté au profil gériatrique du patient, et basé sur une meilleure pluridisciplinarité. Ce premier travail ouvre donc la voie à de futures recherches pour valider la définition de mésusage des traitements de l'HBP en gériatrie et le nouvel algorithme de prise en charge. 


\section{RÉFÉRENCES BIBLIOGRAPHIQUES}

1. Berry SJ, Coffey DS, Walsh PC, Ewing LL. The development of human benign prostatic hyperplasia with age. J Urol. 1984;132(3):474-479

2. Robert G, De La Taille A, Descazeaud A. Epidemiology of benign prostatic hyperplasia. Prog Urol. 2018;28(15):803-812

3. De Ridder D, Roumeguère T, Kaufman L. Urgency and other lower urinary tract symptoms in men aged $\geq 40$ years: a Belgian epidemiological survey using the ICIQ-MLUTS questionnaire. Int J Clin Pract. 2015;69(3):358-365

4. Gurwitz JH, Field TS, Harrold LR, et al. Incidence and preventability of adverse drug events among older persons in the ambulatory setting. JAMA. 2003;289(9):1107-1116

5. Ministère des solidarités et de la santé [en ligne]. Paris [consulté le 13/08/2020]. Mis à jour le 13/06/2016. Disponible sur https://solidarites-sante.gouv.fr/soins-etmaladies/medicaments/glossaire/article/mesusage

6. CNEG. Polycopié National de Gériatrie. Gériatrie-réussir les ECNI 2018, 4è édition. Issy-les moulineaux : Elsevier Masson ; 2018. p.27-37

7. Bouchon JP : 1+2+3 ou comment tenter d'être efficace en gériatrie ? Rev Prat 1984 ; $34: 888-92$

8. Opsomer Reinier-Jacques, Jean de Leval. Les incontinences urinaires de l'homme. Liège (Belgique) : Springer Verlag France ; 2011. p.149-250

9. Dalle Marie-charlotte. L'assentiment, une alternative au consentement libre et éclairé ? Boulogne-billancourt: Rev Geriatr 2017; 42(10):619-626.

10. EAU Guidelines. Edn. presented at the EAU Annual Congress Amsterdam 2020. ISBN 978-94-92671-07-3

https://uroweb.org/guideline/sexual-and-reproductive-health/.

11. Saga S, Vinsnes AG, Mørkved S, Norton C, Seim A. What characteristics predispose to continence in nursing home residents?: a population-based cross-sectional study. Neurourol Urodyn. 2015;34(4):362-367

12. Chapple CR, Wein AJ, Abrams P, et al. Lower urinary tract symptoms revisited: a broader clinical perspective. Eur Urol. 2008;54(3):563-569

13. de la Taille A, Robert G, Descazeaud A. Consequences of prostatic obstruction on bladder function, impact of removal, and management of recurrence after surgery. Prog Urol. 2018;28(15):813-820

14. Kerdraon, J. \& Karsenty, G. Nouveaux concepts physiopathologiques du syndrome 
clinique d'hyperactivité vésicale. Pelvi-Périnéologie 4, 115-120 (2009).

15. Gibson, W. \& Wagg, A. New horizons: urinary incontinence in older people. Age Ageing 43, 157-163 (2014).

16. de la Rosette JJ, Witjes WP, Schäfer W, et al. Relationships between lower urinary tract symptoms and bladder outlet obstruction: results from the ICS-"BPH" study. Neurourol Urodyn. 1998;17(2):99-108

17. Roehrborn CG, Sech S, Montoya J, Rhodes T, Girman CJ. Interexaminer reliability and validity of a three-dimensional model to assess prostate volume by digital rectal examination. Urology. $2001 ; 57(6): 1087-1092$

18. Barendrecht MM, Koopmans RP, de la Rosette JJ, Michel MC. Treatment of lower urinary tract symptoms suggestive of benign prostatic hyperplasia: the cardiovascular system. BJU Int. 2005;95 Suppl 4:19-28

19. Nickel JC, Sander S, Moon TD. A meta-analysis of the vascular-related safety profile and efficacy of alpha-adrenergic blockers for symptoms related to benign prostatic hyperplasia. Int J Clin Pract. 2008;62(10):1547-1559

20. Descazeaud A, Coloby P, De La Taille A, et al. Interest of a systematic assessment of the treatment of the lower urinary tract symptoms in the management of benign prostatic hypertrophy in general practice (1380 patients)-Study EVALURO. Prog Urol. 2019;29(2):116-126

21. Sakalis VI, Karavitakis M, Bedretdinova D, et al. Medical Treatment of Nocturia in Men with Lower Urinary Tract Symptoms: Systematic Review by the European Association of Urology Guidelines Panel for Male Lower Urinary Tract Symptoms. Eur Urol. 2017 ;72(5):757-769

22. Fisher E, Subramonian K, Omar M. The role of alpha blockers prior to removal of urethral catheter for acute urinary retention in men. Cochrane Database of Systematic Reviews 2014, Issue 6. Art. No. CD006744

23. Blanchard Y, Robaire B, Le mode d'action des androgènes et la 5 $\alpha$-réductase, Med Sci (Paris), 1997, Vol. 13, º 4; p.467-473

24. Nickel JC, Gilling P, Tammela TL, Morrill B, Wilson TH, Rittmaster RS. Comparison of dutasteride and finasteride for treating benign prostatic hyperplasia: The Enlarged Prostate International Comparator Study (EPICS). BJU Int. 2011 ;108(3):388-394

25. McConnell JD, Roehrborn CG, Bautista OM, et al. The long-term effect of doxazosin, finasteride, and combination therapy on the clinical progression of benign prostatic hyperplasia. N Engl J Med. 2003;349(25):2387-2398 
26. Gacci M, Corona G, Salvi M, et al. A systematic review and meta-analysis on the use of phosphodiesterase 5 inhibitors alone or in combination with $\alpha$-blockers for lower urinary tract symptoms due to benign prostatic hyperplasia. Eur Urol. 2012;61(5):994-1003

27. Toren P, Margel D, Kulkarni G, Finelli A, Zlotta A, Fleshner N. Effect of dutasteride on clinical progression of benign prostatic hyperplasia in asymptomatic men with enlarged prostate: a post hoc analysis of the REDUCE study. BMJ. 2013;346:f2109. Published 2013 Apr 15

28. Fwu CW, Eggers PW, Kirkali Z, et al. Change in Sexual Function in Men with Lower Urinary Tract Symptoms/Benign Prostatic Hyperplasia Associated with Long-Term Treatment with Doxazosin, Finasteride, and Combined Therapy. Journal of Urology 2014;191(16):1828-34

29. Welk B, McArthur E, Fraser LA, et al. The risk of fall and fracture with the initiation of a prostate-selective $\alpha$ antagonist: a population based cohort study. BMJ. 2015;351:h5398. Published 2015 Oct 26

30. Roehrborn CG, Lukkarinen O, Mark S, Siami P, Ramsdell J, Zinner N. Long-term sustained improvement in symptoms of benign prostatic hyperplasia with the dual 5alphareductase inhibitor dutasteride: results of 4-year studies. BJU Int. 2005;96(4):572-577

31. Naslund MJ, Miner M. A review of the clinical efficacy and safety of 5alpha-reductase inhibitors for the enlarged prostate. Clin Ther. 2007;29(1):17-25

32. McConnell JD, Bruskewitz R, Walsh P, et al. The effect of finasteride on the risk of acute urinary retention and the need for surgical treatment among men with benign prostatic hyperplasia. Finasteride Long-Term Efficacy and Safety Study Group. N Engl J Med. 1998;338(9):557-563

33. Verhamme KM, Dieleman JP, van Wijk MA, Bosch JL, Stricker BH, Sturkenboom MC. Low incidence of acute urinary retention in the general male population: the triumph project. Eur Urol. 2005;47(4):494-498. doi:10.1016/j.eururo.2004.11.011

34. Kaplan SA, Dmochowski R, Cash BD, Kopp ZS, Berriman SJ, Khullar V. Systematic review of the relationship between bladder and bowel function: implications for patient management. Int J Clin Pract. 2013;67(3):205-216

35. Karavitakis M, Kyriazis I, Omar MI, et al. Management of Urinary Retention in Patients with Benign Prostatic Obstruction: A Systematic Review and Meta-analysis. Eur Urol. 2019;75(5):788-798

36. Roehrborn CG, Siami P, Barkin J, et al. The effects of combination therapy with dutasteride and tamsulosin on clinical outcomes in men with symptomatic benign prostatic 
hyperplasia: 4-year results from the CombAT study [published correction appears in Eur Urol. 2010 Nov;58(5):801]. Eur Urol. 2010;57(1):123-131

37. Roehrborn CG. Three months' treatment with the alpha1-blocker alfuzosin does not affect total or transition zone volume of the prostate. Prostate Cancer Prostatic Dis. 2006;9(2):121-125

38. Lacoin F, Fourcade RO, Rouprêt M, et al. Perceptions of benign prostatic hyperplasia according to the perspective of patients and general practitioners - the Trophee study. Prog Urol. 2013;23(1):50-57

39. Stenzelius K, Molander U, Odeberg J, et al. The effect of conservative treatment of urinary incontinence among older and frail older people: a systematic review. Age Ageing. 2015;44(5):736-744

40. Michel MC, Mehlburger L, Bressel HU, Goepel M. Comparison of tamsulosin efficacy in subgroups of patients with lower urinary tract symptoms. Prostate Cancer Prostatic Dis. 1998;1(6):332-335

41. Barkin J, Guimarães M, Jacobi G, Pushkar D, Taylor S, van Vierssen Trip OB. Alphablocker therapy can be withdrawn in the majority of men following initial combination therapy with the dual 5alpha-reductase inhibitor dutasteride. Eur Urol. 2003;44(4):461-466

42. Lepor H. Phase III multicenter placebo-controlled study of tamsulosin in benign prostatic hyperplasia. Tamsulosin Investigator Group. Urology. 1998;51(6):892-900.

43. Jung JH, Kim J, MacDonald R, Reddy B, Kim MH, Dahm P. Silodosin for the treatment of lower urinary tract symptoms in men with benign prostatic hyperplasia. Cochrane Database Syst Rev. 2017;11(11):CD012615. Published 2017 Nov 22

44. Bryant CM, Dowell CJ, Fairbrother G. Caffeine reduction education to improve urinary symptoms. Br J Nurs. 2002;11(8):560-565

45. Hashim H, Abrams P. How should patients with an overactive bladder manipulate their fluid intake?. BJU Int. 2008;102(1):62-66

46. Mochtar CA, Kiemeney LA, van Riemsdijk MM, Laguna MP, Debruyne FM, de la Rosette JJ. Post-void residual urine volume is not a good predictor of the need for invasive therapy among patients with benign prostatic hyperplasia. J Urol. 2006;175(1):213-216

47. Mariappan P, Brown DJ, McNeill AS. Intravesical prostatic protrusion is better than prostate volume in predicting the outcome of trial without catheter in white men presenting with acute urinary retention: a prospective clinical study. J Urol. 2007;178(2):573-577

48. Arnolds M, Oelke M. Positioning invasive versus noninvasive urodynamics in the assessment of bladder outlet obstruction. Curr Opin Urol. 2009;19(1):55-62 
49. Rockwood K, Song X, MacKnight C, et al. A global clinical measure of fitness and frailty in elderly people. CMAJ. 2005;173(5):489-495 


\section{ANNEXES}

\section{ANNEXE 1 : Formulaire de non-opposition du patient}

\section{Mésusage des traitements de l'hypertrophie bénigne de la prostate chez le sujet âgé au CHU d'Amiens}

\section{NOTE D'INFORMATION POUR LA PARTICIPATION A UNE ETUDE N'IMPLIQUANT PAS LA PERSONNE HUMAINE}

Madame, Monsieur,

Le Professeur BLOCH Frédéric souhaite réaliser une recherche n'impliquant pas la personne humaine dont le CHU Amiens-Picardie est le gestionnaire et responsable de traitement.

Il est important que vous lisiez attentivement ces pages qui vous apporteront les informations nécessaires concernant les différents aspects de cette recherche. N'hésitez pas à poser toutes les questions que vous jugerez utiles au professionnel de santé qui dirige cette recherche $\mathrm{Mr}$ RENONCOURT Thomas).

Votre décision de participer à l'étude est entièrement volontaire. Vous pouvez faire valoir votre droit d'opposition au traitement de vos données à n'importe quel moment sans avoir à vous justifier et sans que cela ait la moindre conséquence.

\section{Pourquoi cette recherche?}

L'hypertrophie bénigne de la prostate est une pathologie de plus en plus fréquente à mesure que l'on avance en âge. Les symptômes urinaires sont également fréquents mais également peu spécifiques. L'utilisation des traitements à visée prostatique augmentent donc avec l'âge. Ces derniers peuvent être responsables d'effets indésirables importants et leur bénéfice n'est pas toujours clair. Ainsi, ces traitements au long cours doivent être réévalués en reprenant l'histoire des symptômes du patient, des complications, du retentissement sur la qualité de vie et de la certitude diagnostique avec les examens pratiqués, des comorbidités associées ainsi que des traitements concomitants. Actuellement il y a des recommandations consensuelles sur l'introduction de ces médicaments mais aucune sur la réévaluation à distance en fonction du profil global du patient dans la population gériatrique. 
2. Quel est l'objectif de cette recherche?

L'objectif principal est de relever le nombre de patients avec un mésusage de ces traitements.

Les objectifs secondaires sont le nombre de patients traités chirurgicalement encore sous traitement médicamenteux, le nombre de patients avec explorations étiologiques, le nombre de patient ayant eu une évaluation sur la qualité de vie et l'estimation de la durée de prise des traitements de l'hypertrophie bégnine de la prostate (hors phytothérapie).

\section{Comment va se dérouler cette recherche?}

Les données sont recueillies de façon rétrospective de novembre 2019 à février 2020 puis les résultats seront analysés de février à avril 2020.

\section{Qui peut participer?}

Tous les patients de plus de 75 ans ayant eu une prescription d'un traitement pour l'hypertrophie bénigne de la prostate au CHU d'AMIENS entre le 25/02/2019 et le 03/03/2019 puis entre le 25/03/2019 et le 31/03/2019 ont été inclus.

\section{Quels sont les bénéfices attendus?}

Cette étude permettra de recueillir des données de vraie vie dans une population gériatrique sur l'utilisation des traitements de l'hypertrophie bénigne de la prostate et de les confronter aux recommandations actuelles afin de discuter leur réévaluation dans cette population.

\section{Quels sont les inconvénients possibles?}

Il n'existe pas d'inconvénients. Votre décision de participer ou non à cette étude - qui ne fait que réutiliser les données listées au point $n^{\circ} 7-$ n'aura pas de conséquences sur votre prise en charge ni sur vos relations avec l'équipe soignante.

\section{Concernant vos données}

Il s'agit d'une recherche réalisée à partir des données qui ont été collectées lors de votre prise en charge au CHU Amiens-Picardie. Les catégories de données qui seront utilisées pour les besoins de la recherche sont les suivantes :

les données d'identification (âge, date de naissance, sexe, ...) à l'exclusion des nom, prénom et numéro de Sécurité sociale. 
- Les données de santé strictement nécessaires à la réalisation de la recherche (ex : poids, taille, résultats d'examens, antécédents personnels, maladies ou évènements associés, traitements médicamenteux ...)

- $\quad$ Les habitudes de vie et comportements (par ex : la dépendance, l'assistance)

- Le statut vital (lorsque cette information figure dans les dossiers ou qu'elle est connue du professionnel intervenant dans la recherche)

- $\quad$ La qualité de vie (échelle de qualité de vie ou autres informations à ce sujet)

Dans le cadre de cette recherche, un traitement informatique de vos données personnelles (traitées de manière confidentielle et codées par un identifiant alphanumérique) sera mis en œuvre pour permettre d'analyser les résultats de la recherche sous la responsabilité du CHU Amiens Picardie. A cette fin, les catégories de personnes décrites ci-après auront accès aux données traitées dans les limites de leurs habilitations au regard de leurs fonctions et dans des conditions conformes à la règlementation :

- $\quad$ Le responsable de traitement (le CHU Amiens-Picardie)

- $\quad$ Le responsable scientifique de la recherche (le professionnel de santé responsable de la recherche)

- Les personnes chargées des affaires règlementaires et de l'enregistrement de la recherche auprès des autorités compétentes

- Le Délégué à la Protection des Données du responsable de traitement, uniquement dans le cas où la personne concernée par les données entrerait volontairement en contact avec lui

Les professionnels intervenant dans la recherche et les personnels agissant sous leur responsabilité ou leur autorité (les collaborateurs du professionnel de santé qui dirige la recherche)

- Les personnes chargées de la collecte, du contrôle qualité, du traitement et de l'analyse des données (les Attachés de Recherche Clinique, les Techniciens d'Étude Clinique, le datamanager, le biostatisticien...)

Ces catégories de personnes sont soumises au secret professionnel dans les conditions définies par les articles 226-13 et 226-14 du code pénal. 


\section{Quels sont vos droits?}

Cette recherche, menée à des fins d'intérêt public, est encadrée par des textes de loi qui précisent que seule votre non-opposition est recherchée. Sans réponse négative de votre part dans un délai d'un mois, les données vous concernant seront codées et traitées de manière confidentielle pour les besoins de la recherche.

Vos données seront conservées pendant un délai de 3 ans à compter de la date de début de la recherche. Elles seront ensuite archivées, avec un accès très restreint, pour un maximum de 20 ans.

Vous disposez d'un droit d'accès, d'opposition, de rectification, de limitation et d'effacement des données vous concernant, selon les modalités et conditions prévues par la loi.

Vous disposez également d'un droit d'opposition à la transmission de ces données couvertes par le secret professionnel, susceptibles d'être utilisées dans le cadre de cette recherche et d'être traitées.

Ces droits s'exercent auprès du Pr BLOCH Frédéric (tél : 03.22.45.57.10) ou du Délégué à la Protection des Données, désigné par le responsable de ce traitement au sens du Règlement Européen 2016/679 le CHU d'Amiens-Picardie, joignable à l'adresse mail suivante : dpo@chu-amiens.fr.

Si vous estimez, après nous avoir contacté, que vos droits sur vos données ne sont pas respectés, vous pouvez adresser une réclamation à la CNIL.

Ce document vous appartient. Après avoir lu cette note d'information, n'hésitez pas à poser toutes les questions que vous désirez par téléphone : 03.22.45.57.10 ou voie postale : $\mathrm{CHU}$ Amiens-Picardie, Site Nord, Place Victor Pauchet, 80080 AMIENS au Pr BLOCH Frédéric.

Lettre d'information envoyée : le 03/02/2020 à AMIENS

Par RENONCOURT Thomas (interne) 
Utilisation des traitements de l'hypertrophie bénigne de la prostate chez le sujet âgé au CHU d'Amiens

\section{LETTRE DE REFUS DE PARTICIPATION}

Si vous ne voulez pas participer à l'étude sur l'utilisation de l'hypertrophie bénigne de la prostate chez le sujet âgé au CHU d'Amiens actuellement en cours, veuillez remplir cette fiche et la transmettre à l'adresse : CHU Amiens-Picardie, Site Nord, Place Victor Pauchet, 80080 AMIENS au Pr BLOCH Frédéric.

Je soussigné(e) Mr/Mme

Ne veut pas participer à cette étude. Aucune donnée concernant mon dossier médical ne sera prise en compte pour l'étude.

Fais-le , à

Signature : 


\section{ANNEXE 2 : Tableau de remboursement sur Open Medic}

\begin{tabular}{|c|c|c|c|c|c|}
\hline $\mathrm{ATC}$ & NOM & Age & Sexe & $\mathrm{NBC}$ & REM (€) \\
\hline G04CA & ALPHA-BLOQUANTS & 0 & 1 & 1098 & 19754 \\
\hline G04CA & ALPHA-BLOQUANTS & 0 & 2 & 902 & 10943 \\
\hline G04CA & ALPHA-BLOQUANTS & 0 & 9 & 117 & 605 \\
\hline G04CA & ALPHA-BLOQUANTS & 20 & 1 & 216611 & 4511105 \\
\hline G04CA & ALPHA-BLOQUANTS & 20 & 2 & 22185 & 472077 \\
\hline G04CA & ALPHA-BLOQUANTS & 60 & 1 & 1244091 & 44070480 \\
\hline G04CA & ALPHA-BLOQUANTS & 60 & 2 & 31956 & 808185 \\
\hline G04CA & ALPHA-BLOQUANTS & 99 & 1 & 1457 & 43014 \\
\hline G04CA & ALPHA-BLOQUANTS & 99 & 9 & 24 & 262 \\
\hline G04CB & $\begin{array}{l}\text { INHIBITEURS DE L'ALPHA-5- } \\
\text { TESTOSTERONE REDUCTASE }\end{array}$ & 0 & 1 & 27 & 371 \\
\hline G04CB & $\begin{array}{l}\text { INHIBITEURS DE L'ALPHA-5- } \\
\text { TESTOSTERONE REDUCTASE }\end{array}$ & 0 & 2 & 11 & 118 \\
\hline G04CB & $\begin{array}{l}\text { INHIBITEURS DE L'ALPHA-5- } \\
\text { TESTOSTERONE REDUCTASE }\end{array}$ & 0 & 9 & 26 & 177 \\
\hline G04CB & $\begin{array}{l}\text { INHIBITEURS DE L'ALPHA-5- } \\
\text { TESTOSTERONE REDUCTASE }\end{array}$ & 20 & 1 & 22245 & 592615 \\
\hline G04CB & $\begin{array}{l}\text { INHIBITEURS DE L'ALPHA-5- } \\
\text { TESTOSTERONE REDUCTASE }\end{array}$ & 20 & 2 & 452 & 7653 \\
\hline G04CB & $\begin{array}{l}\text { INHIBITEURS DE L'ALPHA-5- } \\
\text { TESTOSTERONE REDUCTASE }\end{array}$ & 60 & 1 & 344773 & 16202107 \\
\hline G04CB & $\begin{array}{l}\text { INHIBITEURS DE L'ALPHA-5- } \\
\text { TESTOSTERONE REDUCTASE }\end{array}$ & 60 & 2 & 1975 & 15040 \\
\hline G04CB & $\begin{array}{l}\text { INHIBITEURS DE L'ALPHA-5- } \\
\text { TESTOSTERONE REDUCTASE }\end{array}$ & 99 & 1 & 287 & 10267 \\
\hline G04CB & $\begin{array}{l}\text { INHIBITEURS DE L'ALPHA-5- } \\
\text { TESTOSTERONE REDUCTASE }\end{array}$ & 99 & 9 & 11 & 226 \\
\hline
\end{tabular}

Abréviations: ATC, Anatomical Therapeutic Chemical ; NBC, nombre de consommant ; REM, remboursement par la sécurité sociale ; 1 , sexe masculin ; 2 , sexe féminin ; 9 , sexe non connu ; 0 , âge de 0 à 20 ans ; 20, âge de 20 à 60ans ; 60, âge de 60 ans et plus ; 99, âge inconnu. 


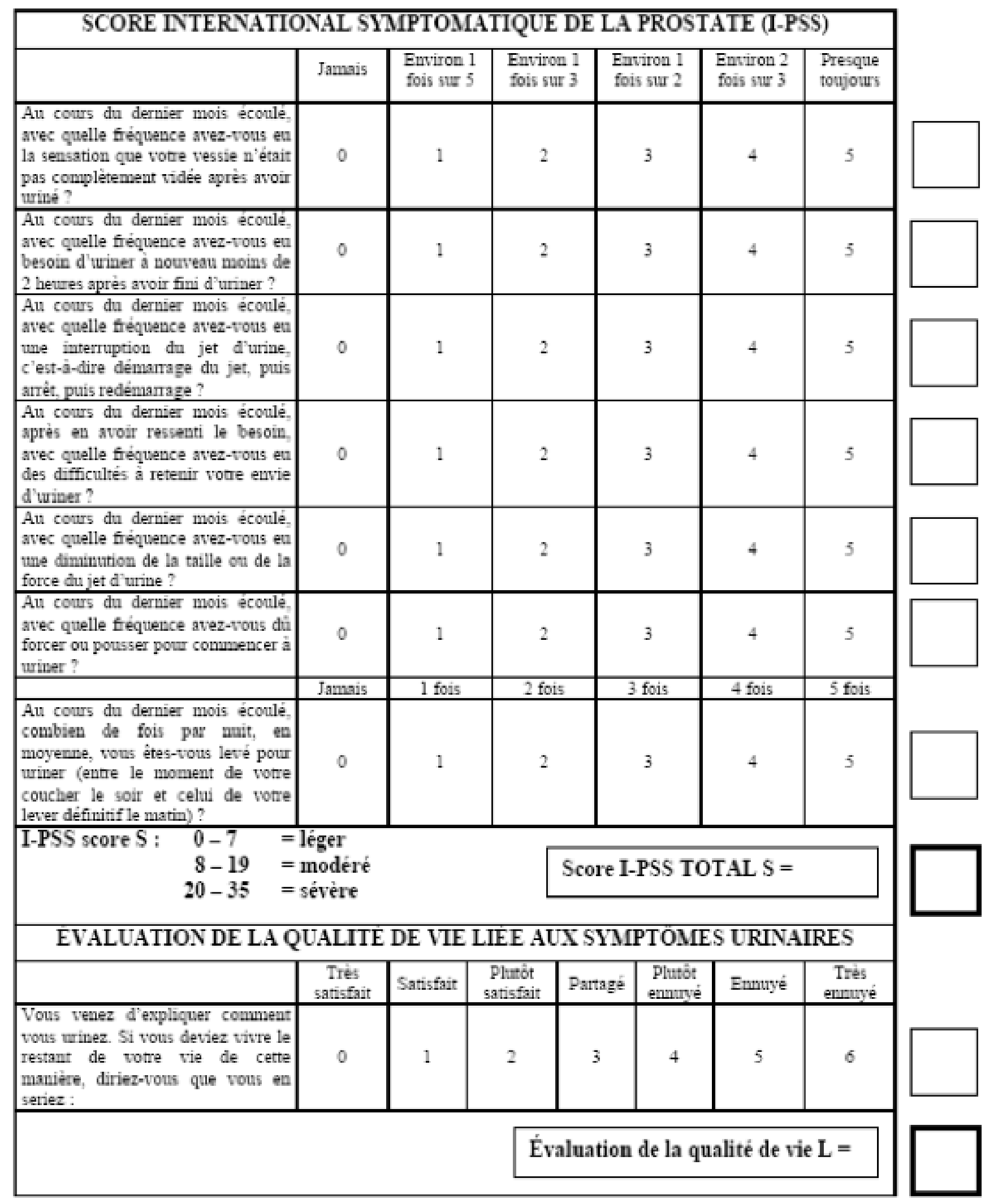




\section{ANNEXE 4 : Score ICIQ-MLUTS (International Consultation on Incontinence}

Questionnaire Male Lower Urinary Tract Symptoms Long Form Module)

1. Please write in your date of birth:

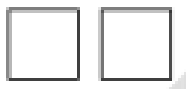

DAY

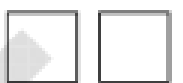

MONTH

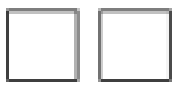

YEAR

2a. Is there a delay before you can start to urinate?

2b. How much does this bother you?

Please ring a number between 0 (not at all) and 10 (a great deal)

$\begin{array}{rrrrrrrrrrr}0 & 1 & 2 & 3 & 4 & 5 & 6 & 7 & 8 & 9 & \begin{array}{l}10 \\ \text { not at all }\end{array} \\ & & & & & & & & & \text { areat deal }\end{array}$

3a. Do you have to strain to continue urinating?

3b. How much does this bother you?

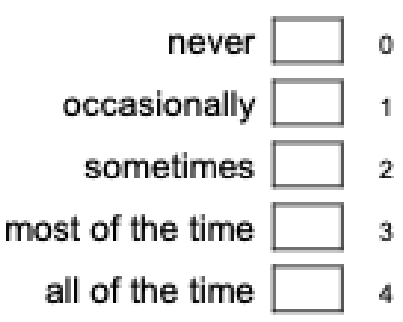

Please ring a number between 0 (not at all) and 10 (a great deal)

$\begin{array}{rrrrrrrrrrr}0 & 1 & 2 & 3 & 4 & 5 & 6 & 7 & 8 & 9 & \begin{array}{l}10 \\ \text { not at all }\end{array} \\ & & & & & & & & & \text { a great deal }\end{array}$

4a. Would you say that the strength of your urinary stream is...

4b. How much does this bother you?

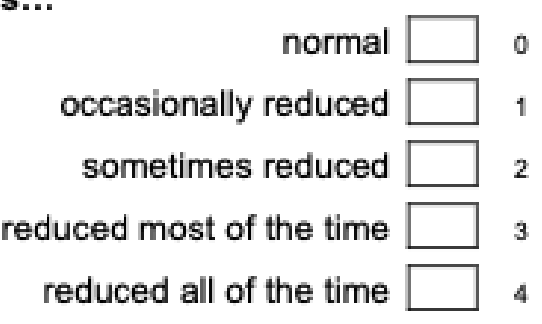

Please ring a number between 0 (not at all) and 10 (a great deal)

$\begin{array}{rrrrrrrrrrr}0 & 1 & 2 & 3 & 4 & 5 & 6 & 7 & 8 & 9 & \begin{array}{l}10 \\ \text { a great deal }\end{array} \\ \text { not at all } & & & & & & & & & \end{array}$


5a. Do you stop and start more than once while you urinate?

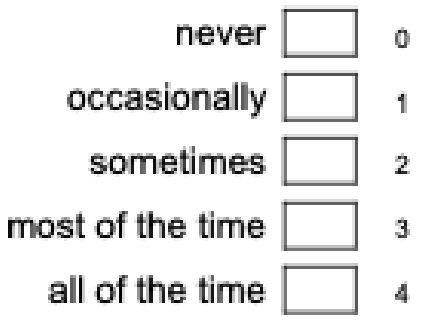

5b. How much does this bother you?

Please ring a number between 0 (not at all) and 10 (a great deal)

$\begin{array}{ccccccccccc}\mathbf{0} & 1 & 2 & 3 & 4 & 5 & 6 & 7 & 8 & 9 & \begin{array}{c}10 \\ \text { not at all }\end{array} \\ & & & & & & & & & \text { great deal }\end{array}$

6a. How often do you feel that your bladder has not emptied properly after you have urinated?

6b. How much does this bother you?

Please ring a number between 0 (not at all) and 10 (a great deal)

$\begin{array}{rrrrrrrrrrr}0 & 1 & 2 & 3 & 4 & 5 & 6 & 7 & 8 & 9 & \begin{array}{l}10 \\ \text { not at all }\end{array} \\ & & & & & & & \end{array}$

VS: sum scores 2-6

7a. Do you have a sudden need to rush to the toilet to urinate?

7b. How much does this bother you?

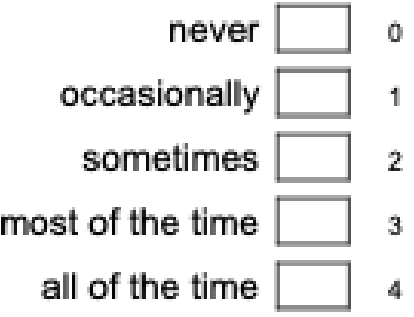

Please ring a number between 0 (not at all) and 10 (a great deal)

$\begin{array}{ccccccccccc}\mathbf{0} & 1 & 2 & 3 & 4 & 5 & 6 & 7 & 8 & 9 & \begin{array}{c}10 \\ \text { not at all }\end{array} \\ & & & & & & & & & \text { great deal }\end{array}$


8a. Does urine leak before you can get to the toilet?

8b. How much does this bother you?

Please ring a number between 0 (not at all) and 10 (a great deal)

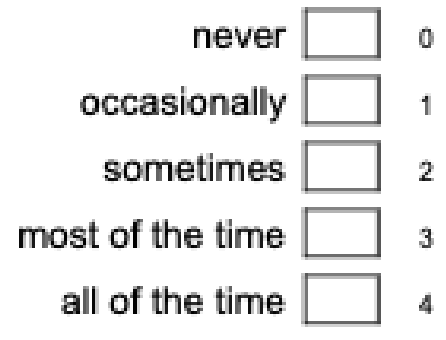

$\begin{array}{lllllllllll}0 & 1 & 2 & 3 & 4 & 5 & 6 & 7 & 8 & 9 & 10\end{array}$

not at all a great deal

9a. Does urine leak when you cough or sneeze?

9b. How much does this bother you?

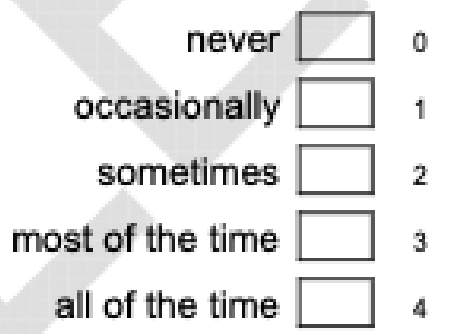

Please ring a number between 0 (not at all) and 10 (a great deal)

$\begin{array}{ccccccccccc}0 & 1 & 2 & 3 & 4 & 5 & 6 & 7 & 8 & 9 & \begin{array}{c}10 \\ \text { not at all }\end{array} \\ & & & & & & & & & \end{array}$

10a. Do you ever leak for no obvious reason and without feeling that you want to go?

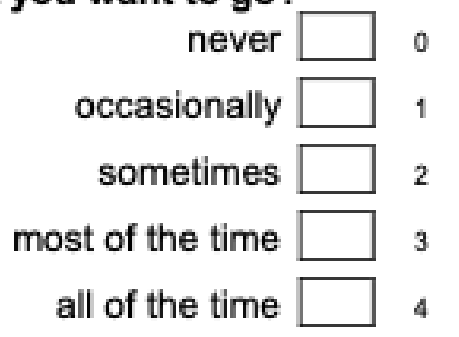

10b. How much does this bother you?

Please ring a number between 0 (not at all) and 10 (a great deal)

$\begin{array}{ccccccccccc}0 & 1 & 2 & 3 & 4 & 5 & 6 & 7 & 8 & 9 & \begin{array}{c}10 \\ \text { not at all }\end{array}\end{array}$


11a. Do you leak urine when you are asleep?

11b. How much does this bother you?

Please ring a number between 0 (not at all) and 10 (a great deal)

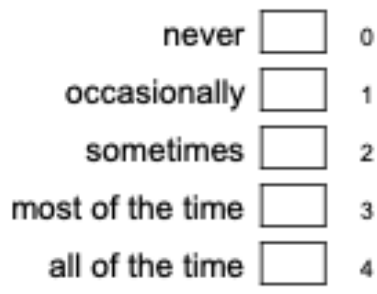

$$
\begin{array}{rrrrrrrrrrr}
0 & 1 & 2 & 3 & 4 & 5 & 6 & 7 & 8 & 9 & \begin{array}{c}
10 \\
\text { not at all }
\end{array}
\end{array}
$$

12a. How often have you had a slight wetting of your pants a few minutes after you had finished urinating and had dressed yourself?

12b. How much does this bother you?

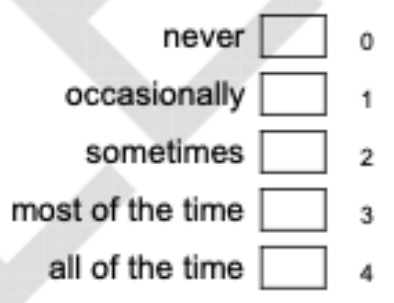

Please ring a number between 0 (not at all) and 10 (a great deal)

$\begin{array}{rrrrrrrrrrr}0 & 1 & 2 & 3 & 4 & 5 & 6 & 7 & 8 & 9 & \begin{array}{c}10 \\ \text { not at all }\end{array}\end{array}$

IS: sum scores 7-12

13a. How often do you pass urine during the day?

13b. How much does this bother you?

Please ring a number between 0 (not at all) and 10 (a great deal)

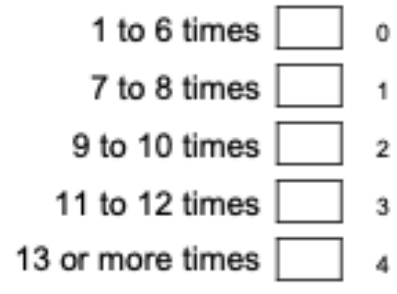

$\begin{array}{rrrrrrrrrrr}\mathbf{0} & 1 & 2 & 3 & 4 & 5 & 6 & 7 & 8 & 9 & \begin{array}{c}10 \\ \text { not at all }\end{array} \\ & & & & & & & & & \text { great deal }\end{array}$

14a. During the night, how many times do you have to get up to urinate, on average?

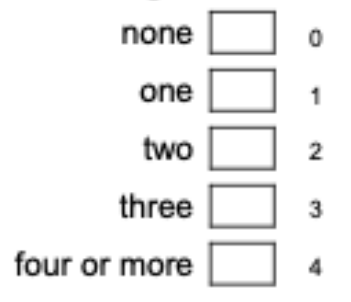

14b. How much does this bother you?

Please ring a number between 0 (not at all) and 10 (a great deal)

$\begin{array}{rllllllllll}0 & 1 & 2 & 3 & 4 & 5 & 6 & 7 & 8 & 9 & \begin{array}{c}10 \\ \text { not at all }\end{array} \\ & & & & & & & & & \text { great deal }\end{array}$




\section{ANNEXE 5 : Score ICIQ-NQoL (International Consultation on Incontinence Questionnaire Nocturia Quality of Life Module)}

OVER THE PAST FOUR WEEKS, HAVING TO GET UP AT NIGHT TO URINATE ...

3. Has made it difficult for me to concentrate the next day

$\begin{aligned} \text { every day } \square & 4 \\ \text { most days } \square & 3 \\ \text { some days } \square & 2 \\ \text { rarely } \square & 1 \\ \text { never } \square & 0\end{aligned}$

4. Has made me feel generally low in energy the next day

$\begin{aligned} \text { every day } \square & 4 \\ \text { most days } \square & 3 \\ \text { some days } \square & 2 \\ \text { rarely } \square & 1 \\ \text { never } \square & 0\end{aligned}$

5. Has required me to nap during the day

$\begin{aligned} \text { every day } & 4 \\ \text { most days } \square & 3 \\ \text { some days } \square & 2 \\ \text { rarely } \square & 1 \\ \text { never } \square & 0\end{aligned}$

6. Has made me less productive the next day

$\begin{aligned} \text { every day } \square & 4 \\ \text { most days } \square & 3 \\ \text { some days } \square & 2 \\ \text { rarely } \square & 1 \\ \text { never } \square & 0\end{aligned}$

7. Has caused me to participate less in activities I enjoy

$\begin{aligned} \text { extremely } \square & 4 \\ \text { quite a bit } \square & 3 \\ \text { moderately } \square & 2 \\ \text { a little bit } \square & 1 \\ \text { not at all } \square & 0\end{aligned}$

8. Has caused me to be careful about when or how much I drink

all the time most of the time some of the time

rarely

never

9. Has made it difficult for me to get enough sleep at night

$\begin{aligned} \text { every night } \square & 4 \\ \text { most nights } \square & 3 \\ \text { some nights } \square & 2 \\ \text { rarely } \square & 1 \\ \text { never } \square & 0\end{aligned}$


10. Concerned that I am disturbing others in the house because of having to get up at night to urinate

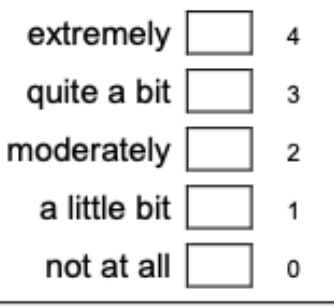

11. Preoccupied about having to get up at night to urinate

$\begin{array}{r}\text { all the time } \square \\ \text { most of the time } \square \\ \text { some of the time } \square \\ \text { rarely } \begin{array}{r}1 \\ \text { never } \square\end{array} \\ \hline \square\end{array}$

12. Worried that this condition will get worse in the future

$\begin{aligned} \text { extremely } \square & 4 \\ \text { quite a bit } \square & 3 \\ \text { moderately } \square & 2 \\ \text { a little bit } \square & 1 \\ \text { not at all } \square & \end{aligned}$

13. Worried that there is no effective treatment for this condition (having to get up at night to urinate)

$\begin{array}{rr}\text { extremely } \square & 4 \\ \text { quite a bit } \square & 3 \\ \text { moderately } \square & 2 \\ \text { a little bit } \square & 1 \\ \text { not at all } \square & 0\end{array}$

14. Overall, how bothersome has having to get up at night to urinate been during the past four weeks?

\begin{tabular}{|c|c|}
\hline extremely & 4 \\
\hline quite a bit & 3 \\
\hline moderately & 2 \\
\hline a little bit & 1 \\
\hline not at all & 0 \\
\hline
\end{tabular}

15. Overall, how much does having to get up at night to urinate interfere with your everyday life?

Please ring a number between 0 (not at all) and 10 (a great deal)

$\begin{array}{rrrrrrrrrrr}0 & 1 & 2 & 3 & 4 & 5 & 6 & 7 & 8 & 9 & 10 \\ \text { not at all } & & & & & & & & & & \text { a great deal }\end{array}$




\section{ANNEXE 6 : Score DAN-PSS (Danish Prostate Symptom Scoring)}

\begin{tabular}{|c|c|}
\hline Nej & $0 \square$ \\
\hline Sjældent & $1 \square$ \\
\hline Dagligt & $2 \square$ \\
\hline Hver gang & $3 \square$ \\
\hline \multicolumn{2}{|c|}{ 2A. Synes du urinstrålen er: } \\
\hline Normal? & $0 \square$ \\
\hline Lidt slap? & $1 \square$ \\
\hline Meget slap? & $2 \square$ \\
\hline Dryppende? & $3 \square$ \\
\hline
\end{tabular}

3A. Føler du, at du får tomt blæren helt ved vandladning

Ja, altid 0

Oftest 1 ㅁ

Sjældent $\quad 2 \square$

Tømmes aldrig helt 3

4A. Skal du presse for at starte vandladningen og/eller for at holde vandladningen i gang?

Nej

Sjældent 1 민

Dagligt 2 ㅁ

Hver gang 3

5A. Hvor lang tid går der højst mellem hver vandladning, fra du vâgner, til du går i seng?

Mere end 3 timer $\quad 0 \square$

2-3 timer $\quad 1$

1-2 timer 2 -

Mindre end 1 time 3

6A. Hvor mange gange skal du lade vandet om natten?

0 gange $\quad 0$

1-2 gange $\quad 1 \square$

3-4 gange 2 -

5 gange eller mere 3

7A. Oplever du en bydende (stærk) vandladningstrang?

Aldrig $\quad 0$

Sjæildent $\quad 1$ 口

Dagligt $2 \square$

Hver gang

3 ㅁ

8A. Er vandladningstrangen så kraftig, at du ikke kan holde på vandet, inden du når toilettet?

$\mathrm{Ne}$

Sjældent

Dagligt

$0 \square$

$1 \square$

Hver gang

3

9A. Gor det ondt eller svier det, når du lader vandet?

$\begin{array}{ll}\text { Nej } & 0 \square \\ \text { Sjældent } & 1 \square \\ \text { Dagligt } & 2 \square \\ \text { Hver gang } & 3 \square\end{array}$

Hver gang $\quad 3 \square$

10A. Drypper der urin, nâr du tror, at vandladningen er færdig (efterdryp)?

I toilettet

$0 \square$

Lidt i bukserne

Meget i bukserne $3 \square$

11A. Har du ufrivillig vandladning ved fysisk anstrengelse ( $f x$ hoste, nys eller loft)?

$\mathrm{Nej}$

$1 \square$

Dagligt 2

Hver gang

$3 \square$

12A. Har du ufrivillig vandladning uden fysisk anstrengelse og uden trang (siven)?

$0 \square$

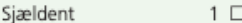

Dagligt $2 \square$

Hver gang

3 ㄷ
1B. Hvis du skal vente, hvor stor en gene er det så for dig?

Ikke generende $\quad 0$ प

Lidt generende $\quad 1$ 맘

Moderat generende $\quad 2 \square$

Meget generende $3 \square$

2B. Hvis urinstrålen er slap, hvor stor en gene er dette så for dig?

Ikke generende $\quad 0 \square$

Lidt generende $\quad 1$ 마

Moderat generende $\quad 2 \square$

Meget generende 3 व

3B. Hvis du feler, at blæren ikke tommes helt ved vandladning, hvor stor en gene er dette sả for dig?

lkke generende 0 口

Lidt generende $\quad 1$ व

Moderat generende $\quad 2 \square$

Meget generende $3 \square$

4B. Hvis du skal presse, hvor stor en gene er dette så for dig?

Ikke generende $\quad 0$

Lidt generende $\quad 1$ (

Moderat generende $\quad 2$ ㅁ

Meget generende $\quad 3 \square$

5B. Hvis du ofte skal lade vandet, hvor stor en gene er dette sã for dig?

Ikke generende $\quad 0$ 口

Lidt generende $\quad 1$ 口

Moderat generende $\quad 2 \square$

Meget generende $\quad 3 \square$

6B. Hvis du skal lade vandet om natten, hvor stor en gene er dette så for dig?

lkke generende $\quad 0$

Lidt generende $\quad 1$ ㅁ

Moderat generende 2

Meget generende $\quad 3 \square$

7B. Hvis du oplever en bydende (stærk) vandladnings trang, hvor stor en gene er dette så for dig?

Ikke generende $\quad 0 \square$

Lidt generende $\quad 1$ प

Moderat generende $\quad 2 \square$

Meget generende $\quad 3 \square$

8B. Hvis urinen løber fra dig, inden du når toilettet, hvor stor en gene er dette så for dig?

Ikke generende $\quad 0 \square$

Lidt generende $\quad 1 \square$

Moderat generende $2 \square$

Meget generende$$
3 \square
$$

9B. Hvis det ger ondt eller svier, når du lader vandet, hvor stor en gene er dette så for dig?

Ikke generende $\quad 0 \square$

Lidt generende $\quad 1 \square$

Moderat generende $\quad 2 \square$

Meget generende $\quad 3 \square$

10B. Hvis der drypper urin, når du tror, at vandladnin gen er færdig, hvor stor en gene er dette så for dig? lkke generende $\quad 0 \square$

Lidt generende $\quad 1$ प

Moderat generende $\quad 2 \square$

Meget generende $\quad 3 \square$

11B. Hvis du har ufrivillig vandladning ved fysisk anstrengelse, hvor stor en gene er dette så for dig?

lkke generende $\quad 0 \square$

Lidt generende $\quad 1 \square$

Moderat generende $\quad 2$ 口

Meget generende $\quad 3 \square$

12B. Hvis urinen siver fra dig uden fysisk anstrengels og uden trang, hvor stor en gene er dette sá for dig? Ikke generende $\quad 0 \square$

Lidt generende $\quad 1 \square$

Moderat generende $\quad 2$ 口

Meget generende $\quad 3 \square$ 
ANNEXE 7 : Score PGI-I (Patient Global Impression of Improvement)

\begin{tabular}{|l|r|}
\hline $\begin{array}{l}\text { Check the number that best describes how your post-operative condition is now, } \\
\text { compared with how it was before you had the surgery: }\end{array}$ \\
\hline Very much better & $\mathbf{1}$ \\
\hline Much better & $\mathbf{2}$ \\
\hline A little better & $\mathbf{3}$ \\
\hline No change & $\mathbf{5}$ \\
\hline A little worse & 6 \\
\hline Much worse & 7 \\
\hline Very much worse & $\mathbf{7}$ \\
\hline
\end{tabular}




\section{ANNEXE 8 : Clinical frailty score (indice de Rockwood)}

\section{Clinical Frailty Scale}

1 Very Fit - People who are robust, active, energetic and motivated. These people commonly exercise regularly. They are among the fittest for their age.

2 Well - People who have no active disease symptoms but are less fit than category 1 . Often, they exercise or are very active occasionally, e.g. seasonally.

3 Managing Well - People whose medical problems are well controlled, but are not regularly active beyond routine walking.

4 Vulnerable - While not dependent on others for daily help, often symptoms limit activities. A common complaint is being "slowed up", and/or being tired during the day.

5 Mildly Frail - These people often have more evident slowing, and need help in high order IADLs (finances, transportation, heavy housework, medications). Typically, mild frailty progressively impairs shopping and walking outside alone, meal preparation and housework.

6 Moderately Frail - People need help with all outside activities and with keeping house. Inside, they often have problems with stairs and need help with bathing and might need minimal assistance (cuing, standby) with dressing.

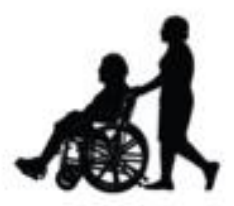

7 Severely Frail - Completely dependent for personal care, from whatever cause (physical or cognitive). Even so, they seem stable and not at high risk of dying (within $\sim 6$ months).

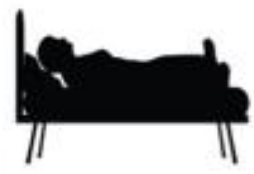

8 Very Severely Frail - Completely dependent, approaching the end of life. Typically, they could not recover even from a minor illness.

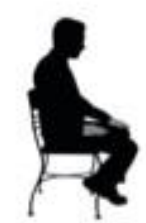

9 Terminally III - Approaching the end of life. This category applies to people with a life expectancy $<6$ months, who are not otherwise evidently frail.

\section{Scoring frailty in people with dementia}

The degree of frailty corresponds to the degree of dementia. Common symptoms in mild dementia include forgetting the details of a recent event, though still remembering the event itself, repeating the same question/story and social withdrawal.

In moderate dementia, recent memory is very impaired, even though they seemingly can remember their past life events well. They can do personal care with prompting.

In severe dementia, they cannot do personal care without help. 


\section{Titre : Mésusage des traitements de l’hypertrophie bénigne de la prostate chez le sujet âgé}

Introduction : L'hypertrophie bénigne de la prostate (HBP) est une des pathologies les plus fréquentes du sujet âgé. La prévalence chez les hommes atteint $80 \%$ après 80 ans. Les objectifs de ce travail étaient d'évaluer la fréquence du mésusage des traitements médicamenteux de l'HBP chez le sujet âgé $>75$ ans, de regarder les effets secondaires potentiellement imputables et de proposer une prise en charge adaptée aux patients fragiles.

Matériel et méthode : Cette étude était transversale (25/02/2019 au 03/03/2019 et du 25/03/2019 au 31/03/2019). Toutes les prescriptions ciblant l'HBP (ATC G04CA ; ATC G04CB) effectuées au sein de notre groupe hospitalier pendant cette période ont été extraites. Parmi ces données, 117 patients de sexe masculin ont été étudiés. Le mésusage était évalué en utilisant une échelle composite (données de l'autorisation de mise sur le marché (AMM), résumés des caractéristiques du produit (RCP), recommandations de l'Association Européenne d'Urologie (EAU) et données gériatriques). Une analyse des interactions médicamenteuses a été réalisée avec le logiciel GPR Diane ${ }^{\circledR}$ puis comparée rétrospectivement aux données de l'évaluation gériatrique (chutes, hypotension orthostatique, dépendance, troubles neurocognitifs).

Résultats : Le mésusage des thérapeutiques de l'HBP concernait $70 \%$ des patients $(\mathrm{n}=84)$. Les patients avec mésusage avaient un suivi urologique plus fréquent, plus d'examens diagnostiques urologiques complémentaires, plus de traitements alpha-bloqueurs et plus d'hypotension orthostatique $(p<0.02$; $\mathrm{p}<0.02 ; \mathrm{p}<0.001 ; \mathrm{p}<0.005)$ comparativement aux patients sans mésusage. Il majorait aussi le risque de chutes en analyse multivariée (OR de 3.22 ( $\mathrm{p}=0.039$; IC [1.1-10.2]).

Conclusion: Le mésusage des traitements de l'HBP du sujet âgé est de plus de $70 \%$. Il concerne particulièrement les alphabloquants avec un risque d'hypotension orthostatique et de chutes majorées. Nous proposons un nouvel algorithme de prise en charge adapté aux patients âgés fragiles avec HBP symptomatique.

Mots-clés : Gériatrie - Prescription Inappropriées - Hypertrophie Bénigne de la Prostate

Title: Misuse of treatments for benign prostatic hyperplasia in the elderly population

Introduction: Benign prostatic hyperplasia (BPH) is one of the most common pathologies in the elderly. The prevalence in men is $80 \%$ after 80 years. The objectives of this work were to assess the frequency of the misuse of pharmacological treatments for BPH in the elderly> 75 years old, to observe at the attributable side effects and to done appropriate management for frailty patients.

Methods: This study was transversal (02/25/2019 to 03/03/2019 and from 03/25/2019 to 03/31/2019). All prescriptions targeting BPH (ATC G04CA; ATC G04CB) made within our hospital during this time were retrieved. Of these data, 117 men patients were studied. Misuse was assessed using a composite scale (indications, product characteristics, European Association of Urology (EAU) recommendations and geriatric data). An analysis of drug interactions was performed with GPR Diane ${ }^{\circledR}$ software and then compared retrospectively with data from the geriatric assessment (falls, orthostatic hypotension, dependence, neurocognitive disorders).

Results: The misuse of BPH therapies concerned $70 \%$ of patients $(n=84)$. The patients with misuse had more frequent urological follow-up, more additional urological exams, more alpha-blocker drugs and more orthostatic hypotension ( $\mathrm{p}<0.02 ; \mathrm{p}<0.02 ; \mathrm{p}<0.001 ; \mathrm{p}<0.005$ ) compared to patients without misuse. It also increased the risk of falls in multivariate analysis (OR of 3.22 ( $p=0.039$; IC [1.1-10.2]).

Conclusion: The misuse of BPH treatments in the elderly is $70 \%$. It particularly concerns alpha-blockers with a risk of orthostatic hypotension and increased falls. We propose a new care algorithm for male frailty patients with LUTS.

Keywords: Elderly - Inappropriate Prescribing - Benign Prostatic Hyperplasia 